San Jose State University

SJSU ScholarWorks

Master's Theses

Master's Theses and Graduate Research

Fall 2016

\title{
Evaluation of a Silica Hydride-Based Undecynoic Acid Stationary Phase For High Performance Liquid Chromatography
}

Veena Menon Kozhikote

San Jose State University

Follow this and additional works at: https://scholarworks.sjsu.edu/etd_theses

\section{Recommended Citation}

Kozhikote, Veena Menon, "Evaluation of a Silica Hydride-Based Undecynoic Acid Stationary Phase For High Performance Liquid Chromatography" (2016). Master's Theses. 4761.

DOI: https://doi.org/10.31979/etd.ujh3-2f9e

https://scholarworks.sjsu.edu/etd_theses/4761

This Thesis is brought to you for free and open access by the Master's Theses and Graduate Research at SJSU ScholarWorks. It has been accepted for inclusion in Master's Theses by an authorized administrator of SJSU ScholarWorks. For more information, please contact scholarworks@sjsu.edu. 


\title{
EVALUATION OF A SILICA HYDRIDE-BASED UNDECYNOIC ACID STATIONARY PHASE FOR HIGH PERFORMANCE LIQUID CHROMATOGRAPHY
}

\author{
A Thesis \\ Presented to \\ The Faculty of the Department of Chemistry \\ San José State University
}

\author{
In Partial Fulfillment \\ of the Requirements for the Degree \\ Master of Science
}

by

Veena Menon Kozhikote

December 2016 
(C) 2016

Veena Menon Kozhikote

ALL RIGHTS RESERVED 
The Designated Thesis Committee Approves the Thesis Titled

EVALUATION OF A SILICA HYDRIDE-BASED UNDECYNOIC ACID STATIONARY PHASE FOR HIGH PERFORMANCE LIQUID CHROMATOGRAPHY

by

Veena Menon Kozhikote

APPROVED FOR THE DEPARTMENT OF CHEMISTRY

SAN JOSÉ STATE UNIVERSITY

December 2016

Joseph J. Pesek, Ph.D. Department of Chemistry

Roger Terrill, Ph.D. Department of Chemistry

Annalise Van Wyngarden, Ph.D Department of Chemistry 


\title{
ABSTRACT \\ EVALUATION OF A SILICA HYDRIDE-BASED UNDECYNOIC ACID STATIONARY PHASE FOR HIGH PERFORMANCE LIQUID CHROMATOGRAPHY
}

\author{
by Veena Menon Kozhikote
}

Undecynoic acid (UDA) attached to a silica hydride surface has been found to exhibit weak cationic exchange properties and an aqueous normal phase (ANP) type of retention. ANP is a mechanism similar to normal phase chromatographic retention, except for the use of a polar solvent such as water in the mobile phase. In ANP, the retention of a polar molecule is increased with a higher concentration of the non-polar mobile phase solvent (usually acetonitrile). Non-polar molecules exhibit retention behavior as in reverse phase (RP) chromatography. The goal of this research was to characterize the chromatographic retention pattern of an undecynoic based silica hydride column by studying various polar and nonpolar analytes. Also investigated were the effects of varying the buffer concentrations -formic acid and ammonium acetate and the effect of temperature on the retention of selected compounds. It has been established from the current work that a silica hydride based UDA column can be used for separation and analysis of nucleotides and nucleosides as well as phenolic acid components in pomegranate peel samples. A phenyl hydride column was additionally used to complete the study on the peel samples since the UDA column was not effective in separating isobaric compounds found in the peels. In conclusion, silica hydride based UDA column has been found to exhibit dual retention capabilities for polar and non-polar molecules. 


\section{ACKNOWLEDGMENTS}

I would like to express my sincere thanks to Dr. Joseph Pesek for accepting me into this group and allowing me to work on this project. I am grateful for his patience and valuable feedback at every point of the research work. I truly appreciate his guidance in writing the thesis and providing his suggestions. I would also like to thank Dr. Maria Matyska Pesek for training me patiently on the instrumentation during the period of my research. I am equally grateful to Dr. Roger Terrill and Dr. Annalise Van Wyngarden for serving on my thesis committee and providing their comments during the thesis evaluation. I cannot thank enough Mr. Michael Stephens, the lead technician and Mr. Aklilu for providing me with their valuable help on the laboratory instruments from time to time.

I am equally thankful to all my fellow lab mates for providing me with all their help and support. My heartfelt thanks to my husband, Arun M.Kesavan for his understanding and providing me with all the moral support needed during the course of this project; my in-laws and my parents for extending all their help in the best possible way to speed up my work. I am equally indebted to my kids, Nandita and Madhav for sacrificing their mommy 'n me playtime to finish my research work and thesis. Without all this support, this task would certainly have been possible. 


\section{TABLE OF CONTENTS}

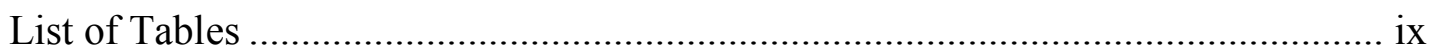

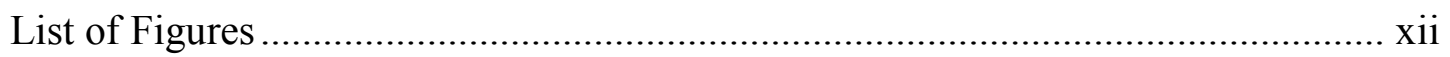

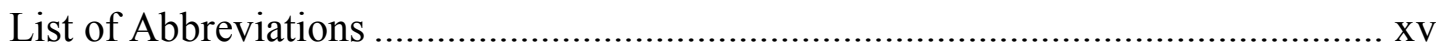

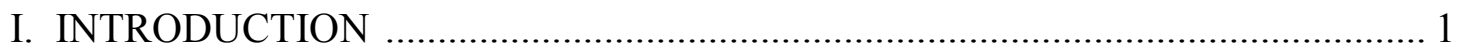

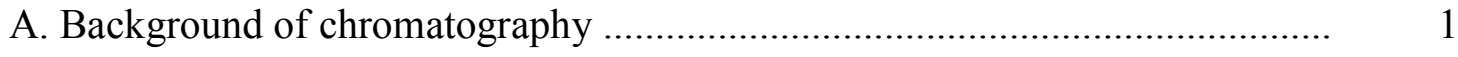

B. High performance liquid chromatography (HPLC) ……………………....... . 3

1.1. Solvent delivery system …………………………………………..... . 5

1.2. Degassing unit ................................................................................. . 6

1.3. Sample injector unit ..................................................................... . 6

1.4. Column oven .............................................................................. . 7

1.5. Pumps ................................................................................... 7

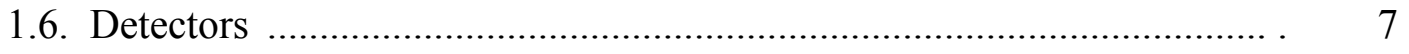

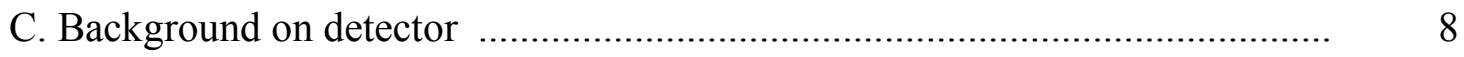

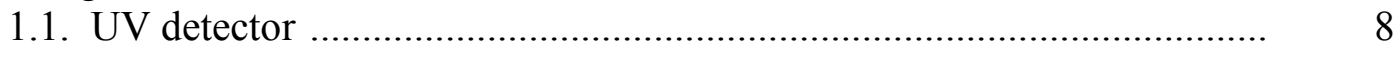

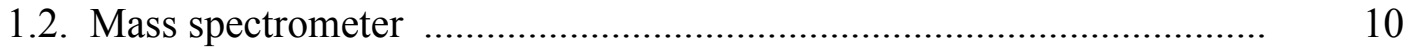

D. Chromatographic parameters ………………………................................. 12

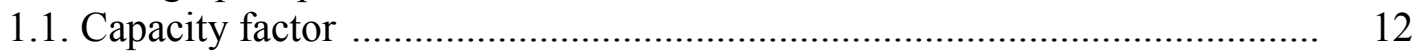

1.2. Selectivity ...................................................................................... 13

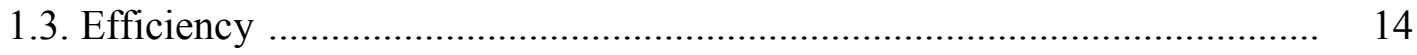

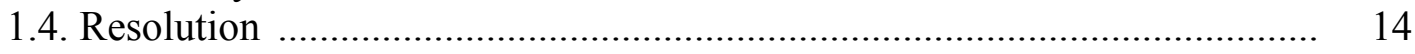

E. Silica surface-surface modification ................................................................ 15

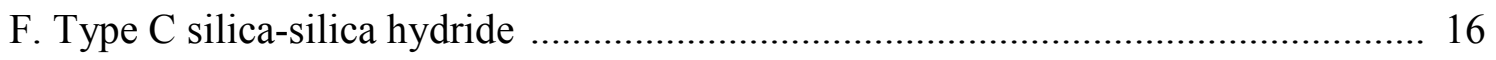

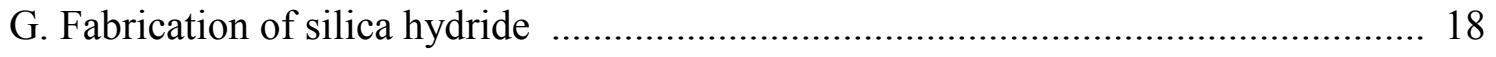

H. Aqueous normal phase chromatography ............................................................ 21

I. Types of samples used in the evaluation of HPLC column .................................... 24 


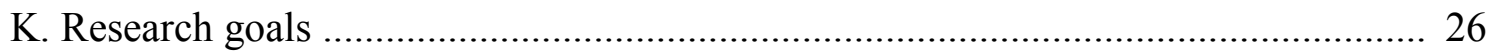

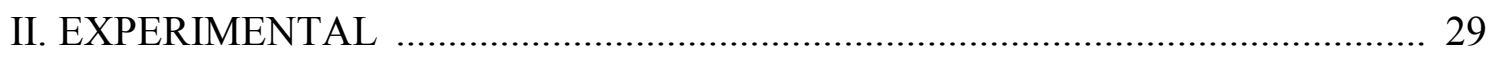

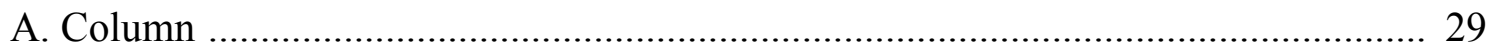

B. Compounds and mobile phase used for characterization studies ........................... 30

C. Chemical structures of the chemical compounds analyzed ..................................... 34

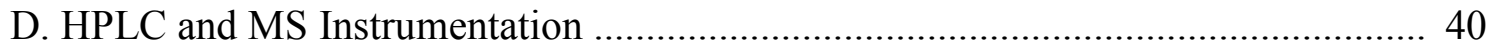

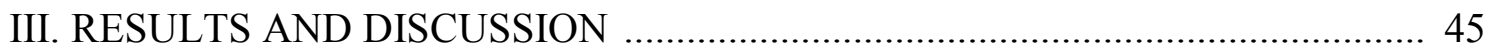

Column characterization studies

A. Chromatographic evaluation of HPLC column using UV detection ...................... 44

1.1. Evaluation of nitrogenous bases ................................................................. 45

1.2. Nucleosides and nucleotides .............................................. 47

1.3. Underivatized and PTH derivatized amino acids .......................... 49

1.4. Xanthine-related derivatives ........................................ 52

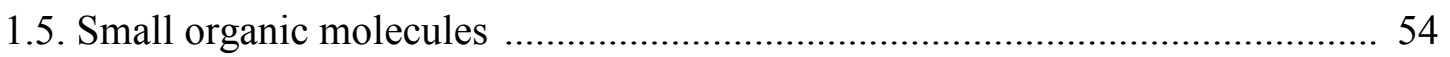

1.6. Polycyclic aromatic hydrocarbons (PAHs) ………………………………....... 56

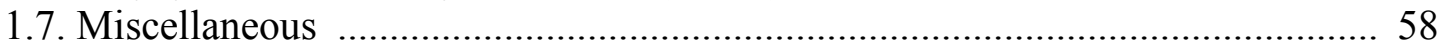

B. Retention study with a change in the additive concentration .................................. 60

C. Repeat study with various formic acid concentrations ........................................... 64

D. Compatibility of ammonium acetate as an additive .............................................. 66

E. Retention study with varying concentrations of

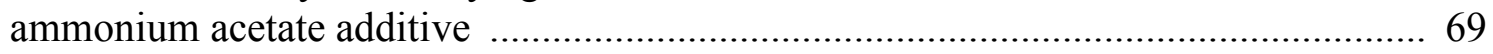

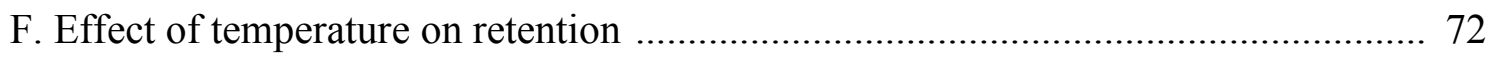

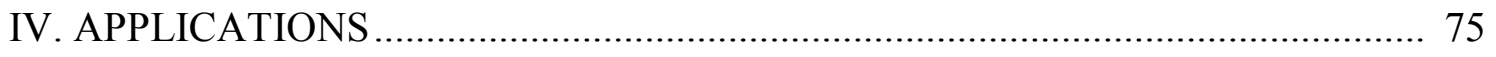

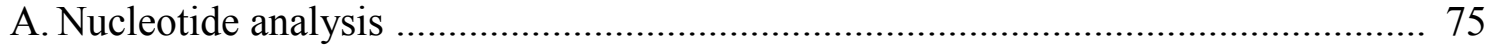

1.1. Nucleotide characterization ...................................................................... 75

1.2. Retention of ATP and NADP at varying
formic acid concentration ……................................................................ 77 


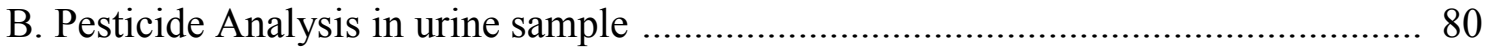

C. Quantification of phenolic acids in pomegranate peel

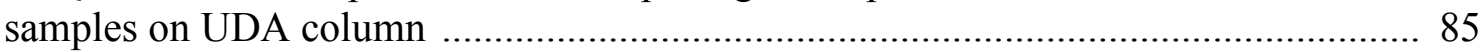

D. Quantification of phenolic acids in pomegranate peel samples on phenyl hydride column

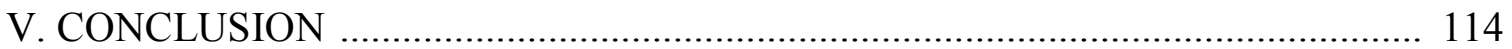

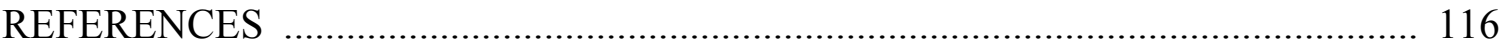




\section{LIST OF TABLES}

Table 1. Examples of silica hydride stationary phases and their application in analyzing various compounds

Table 2. Column specifications of Cogent UDA column .....................................30

Table 3. Chemicals used as mobile phase .......................................................... 30

Table 4.1. Nitrogenous bases, nucleosides, nucleotides,

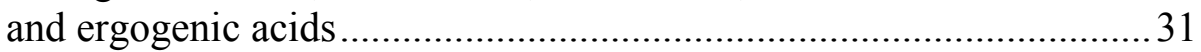

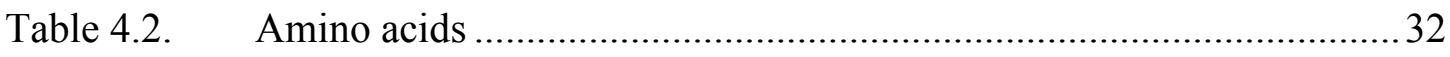

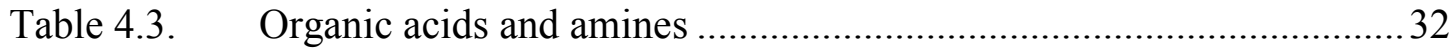

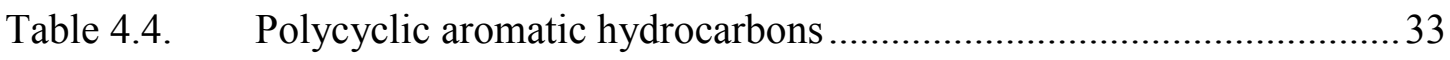

Table 4.5. Xanthine-related and other miscellaneous

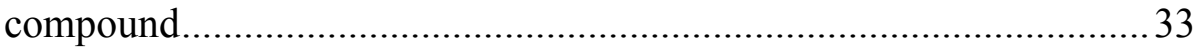

Table 5. Retention time data for nitrogenous bases ........................................4 46

Table 6. Retention time data for nucleosides.................................................4

Table 7. Retention time data for amino acids ................................................51

Table 8. Retention time data for xanthine-related compounds ...........................53

Table 9. Retention time data for small organic molecules..................................55

Table 10. Retention time data for polycyclic aromatic

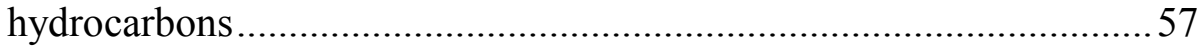

Table 11. Retention time data for miscellaneous compounds ..............................59

Table 12. Retention time data for polar compounds at varying formic acid concentrations 62

Table 13. Retention time data for non-polar compounds at varying formic acid concentrations 
Table 14. Retention time data for selected polar compounds

at varying formic acid concentrations - repeat study

Table 15. Retention time data for compounds at

$10 \mathrm{mM}$ ammonium acetate concentration

Table 16. Retention time data for compounds at

varying ammonium acetate concentration

Table 17. Retention time data for compounds at

different oven temperature

Table 18. Retention time data for nucleotides and coenzymes .........................76

Table 19. Retention time data for ATP and NADP ….................................... 79

Table 20. $\quad(\mathrm{m} / \mathrm{z})$ and $[\mathrm{M}-\mathrm{H}]^{-}$of deuterated and non-deuterated components analyzed

Table 21. Accession id's, names, and place of origin of the various pomegranate peel samples 85

Table 22. Weights and solvents used for the phenolic acid standards

Table 23. Chemical formulae, $(\mathrm{m} / \mathrm{z})$ 's in positive, and negative ionization modes, and UV absorbance of the phenolic acid standards 88

Table 24a. Retention time and peak areas of standards, unspiked, and spiked Molla Nepes (MN) sample on the

UDA column .99

Table 24b. Retention time and peak areas of standards, unspiked, and spiked Wonderful sample on the UDA column

Table 24c. Retention time and peak areas of standards, unspiked, and spiked Purple heart (PH) sample on the UDA column

Table 24d. Retention time and peak areas of standards, unspiked, and spiked Parfionka sample on the UDA column 100

Table 24e. Retention time and peak areas of standards, unspiked, and spiked Vkunsyi sample on the UDA column 
Table 25a. Retention time and peak areas of standards, unspiked, and spiked Molla Nepes (MN) sample on the phenyl hydride column 102

Table 25b. Retention time and peak areas of standards, unspiked, and spiked Wonderful sample on the phenyl hydride column.

Table 25c. Retention time and peak areas of standards, unspiked, and spiked Purple heart (PH) sample on the phenyl hydride column 103

Table 25d. Retention time and peak areas of standards, unspiked, and spiked Parfionka sample on the phenyl hydride column.

Table 25e. Retention time and peak areas of standards, unspiked, and spiked Vkunsyi sample on the phenyl hydride column....

Table 26. Amount of each of the phenolic acid component in the pomegranate peel samples in $\mu \mathrm{g} / \mathrm{g}$. 


\section{LIST OF FIGURES}

Figure 1. Flow channel diagram of HPLC …....................................... 4

Figure 2. Representative diagram of HPLC instrument ................................. 5

Figure 3. Arrangement of a variable wavelength detector ............................... 10

Figure 4. Instrumental setup of a diode array detector ................................. 10

Figure 5. Layout of mass spectrometer ...................................................... 11

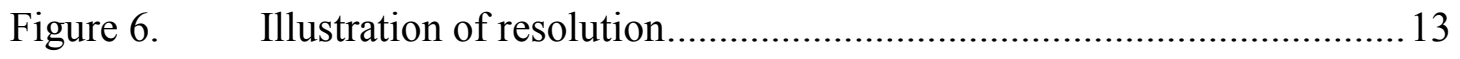

Figure 7a. Type B silica with silanol group on Si surface ............................... 17

Figure 7b. Type C silica with silica hydride on Si surface................................ 17

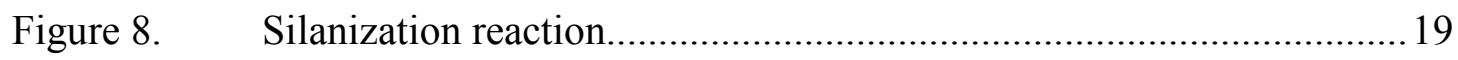

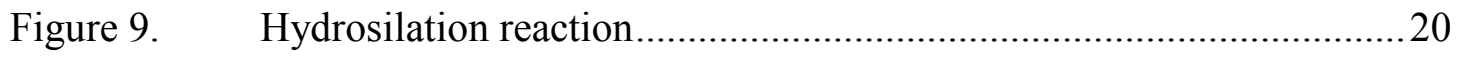

Figures

$10 \mathrm{a}, 10 \mathrm{~b}$, and 10c. Three kinds of retention observed in ANP ....................................23

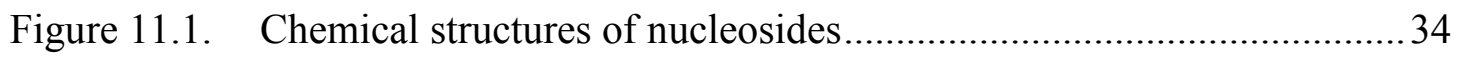

Figure 11.2. Chemical structures of nitrogenous bases..................................... 35

Figure 11.3. Chemical structures of nucleotides and coenzymes............................. 36

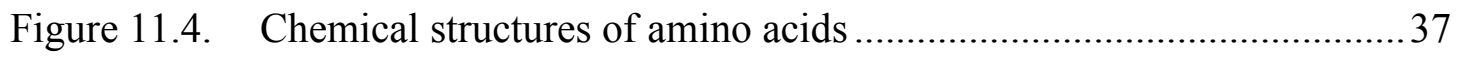

Figure 11.5. Chemical structures of xanthine-related cmpounds .......................... 38

Figure 11.6. Chemical structures of small organic molecules ............................. 38

Figure 11.7. Chemical structures of polycyclic aromatic

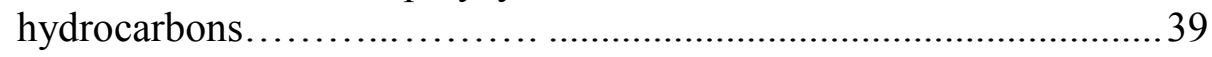

Figure 11.8. Chemical structures of miscellaneous compounds ...........................39 
Figure 12. A view of the HP 1090 series HPLC-UV Instrument........................ 41

Figure 13. 1100 series LC system -6220 series TOF detector........................... 42

Figure 14. 1200 series LC system -6520 series QTOF detector ........................ 43

Figure 15. Retention time plot for nitrogenous bases ...................................47

Figure 16. Retention time plot of nucleosides............................................ 49

Figure 17. Retention time plots for amino acids ..........................................52

Figure 18. Retention time plots of xanthine related compounds.........................54

Figure 19. Retention time plot of small organic molecules .............................56

Figure 20. Retention time plot for polycyclic aromatic hydrocarbons ....................................................................... 58

Figure 21. Retention time plots for miscellaneous compounds .........................60

Figure 22. Retention time plots for polar compounds at various concentrations of formic acid.

Figure 23. Retention time plots for non-polar compounds at various concentrations of formic acid.

Figure 24. Retention time plots for selected polar compounds at various concentrations of formic acid - repeat study

Figure 25. Retention time plots for compounds at $10 \mathrm{mM}$ ammonium acetate concentration

Figure 26. Retention time plots for compounds at varying concentrations of ammonium acetate..... 72

Figure 27. Retention time plots for varying temperature ….............................. 74

Figure 28. Retention time plot of nucleotides and coenzymes.......................... 77

Figure 29. Retention time plot of ATP and NADP ...................................... 80

Figure 30. Chemical structures of non-deuterated forms of the compounds analyzed in the pesticide sample 82 
Figure 31. Extracted ion chromatograms of standards spiked in urine sample

Figure 32. Chemical structures of the phenolic acids being identified and quantified 89

Figure 33. Comparison of caffeic acid standard with Vkunsyi sample

Figure 34. Comparison of Vkunsyi and Parfionka sample with rutin standard 95

Figure 35. Comparison of Vkunsyi and Parfionka sample with chlorogenic acid standard 96

Figure 36. Comparison of retention times of catechin, epicatechin, and spiked Molla Nepes sample 98

Figure 37. Separation of catechin and epicatechin in the standard mix on phenyl hydride column. 107

Figure 38. Separation of catechin and epicatechin on phenyl hydride columnin Molla Nepes and Parfianka sample 108

Figure 39. $(\mathrm{m} / \mathrm{z})$ of chlorogenic acid absent in the original sample and clearly seen in the spiked Molla Nepes sample

Figure 40. $(\mathrm{m} / \mathrm{z})$ of rutin in the unspiked and spiked Molla Nepes sample

Figure 41. $(\mathrm{m} / \mathrm{z})^{\prime}$ 's for punicalagin in each of the five unspiked pomegranate peel samples

Figure 42. Bar graph showing the amount of each of the phenolic acid component in the pomegranate peel samples 


\section{LIST OF ABBREVIATIONS}

$\mathrm{ACN}$ - acetonitrile

AMP-adenosine mono phosphate

ATP - adenosine triphosphate

$\mathrm{A}^{\circ}$ - Angstrom

ANP - aqueous normal-phase

CI - chemical ionization

DI - deionized

DNA - deoxyribonucleic acid

DEDTP - diethyl dithiophosphate

DEP - diethyl phosphate

DETP - diethyl thiophosphate

DMDTP - dimethyl dithiophosphate

DMP - dimethyl phosphate

DMTP - dimethyl thiophosphate

DAD - diode array detectors

ECD - electrochemical detectors

EI - electron impact

ESI - electron spray ionization

ELSD - evaporative light scattering detectors

FAB - fast atom bombardment

9- fluorenyl methoxy carbonyl chloridefluorophenylmethoxy chloroformate - FMOC

GC - gas chromatography

HETP - height equivalent to theoretical plate

HPLC - high performance liquid chromatography

HPTLC - high performance thin layer chromatography

HILIC- hydrophilic interaction liquid chromatography 
id - internal diameter

IEX - Ion exchange chromatography

MS - mass spectrometer

MALDI - matrix assisted laser desorption

$\mathrm{MeOH}$ - Methanol

$\mu \mathrm{m}$ - micrometers

MN - Molla Nepes

NAD - nicotinamide dinucleotide

NADP -nicotinamide dinucleotide phosphate

NP - normal phase

ONP - organic normal-phase

OPA - ortho pthalaldehyde

PA - peak area

PTH - phenyl thiohydantoin

PAH - polycyclic aromatic hydrocarbons

PH - Purple heart

Q-TOF - Quadrupole-time of flight

$\mathrm{RI}$ - refractive index

$\mathrm{RT}$ - retention time

$\mathrm{RP}$ - reverse phase

RNA - ribonucleic acid

TCC - thermostatted column compartment

TLC - Thin layer chromatography

TOF - time-of-flight

UV - Ultraviolet

UDA - undecynoic acid column

USDA - United States Department of Agriculture

VWD - Variable wavelength detectors 
v/v - volume/volume 


\section{INTRODUCTION}

\section{A. Background of chromatography}

This method of separation was first observed by Mikhail S Tswett while trying to separate the different components present in chlorophyll. ${ }^{1}$ It was initially believed that the green plant pigment chlorophyll was comprised of two pigments. However, the experiments conducted by Tswett that consisted of preparing homogenized plant extracts, passing the mixture into a column of calcium carbonate/chalk, and further addition of a mobile phase such as petroleum ether demonstrated that chlorophyll actually consisted of eight pigments. With the passing of the ether through the column, many colored bands were obtained with intermittent regions free of any color.

A book was published in 1910 describing the above technique of "chromatography," as coined by Tswett ("chroma" meaning color and "graphy" meaning writing in Greek). Later in 1931, the German chemist Richard Kuhn and his student, Edgar Lederer, reported the use of this technique to separate many biologically active molecules.

There exist many types of chromatography and the classification depends on many factors such as the physical state of the stationary and mobile phase, principle of separation, chemical nature of the mobile and stationary phase, and format of the stationary phase. Based on the physical state of the stationary phase and mobile phase, chromatography is classified as homogenous and heterogeneous chromatography. In the former type the physical states of the stationary and mobile phase are the same while in

the latter the physical states are different. An example of homogenous chromatography is liquid-liquid chromatography while liquid-solid, gas-liquid, and gas-solid 
chromatography belong to the class of heterogeneous chromatography. ${ }^{2}$ According to the principle of separation there exists adsorption and partition chromatography. The underlying principle for adsorption chromatography is the adsorption of the analyte molecule on the stationary phase. Compounds that are strongly adsorbed on the stationary phase elute slowly while those weakly adsorbed elute faster. Partition chromatography is based on the difference in the dissolution of the analytes in the stationary/mobile phase. For example in the case of liquid-solid chromatography, the partition arises between the liquid mobile phase and the quasi liquid layer on the stationary phase. $^{2}$

Normal phase (NP) and reverse phase (RP) chromatography are other types of chromatography and this classification is based on the chemical nature of the mobile and stationary phase. While NP employs a polar stationary phase and a non-polar mobile phase, in RP a non-polar stationary phase and a polar mobile phase are used. Polar analyte/hydrophilic compounds are retained longer on the column, while non-polar/ hydrophobic compounds elute at or near the void/dead volume in NP as opposed to RP chromatography wherein hydrophilic/polar compounds elute near the dead volume. Some examples of polar stationary phases used in NP are bare silica, or compounds bonded to the surface containing either cyano or amino groups. The non-polar mobile phase usually comprises solvents such as hexane, heptane, or ethyl acetate. Some examples of non-polar stationary phases and polar mobile phases used in RP are columns containing a $\mathrm{C} 8 / \mathrm{C} 18$ group and water, respectively. Yet another classification of chromatography based on the format of the stationary phases are column and planar 
chromatography. While in column chromatography the stationary phase is columnar shaped, it is planar or flat in planar chromatography. High performance liquid chromatography (HPLC) and gas chromatography (GC) are examples of the former type while thin layer chromatography (TLC), paper chromatography, and high performance thin layer chromatography (HPTLC) belong to the latter type of chromatography. ${ }^{2}$

Some additional types of chromatography include size exclusion and ionexchange chromatography (IEX). In size exclusion chromatography, the stationary phase has pores and the analytes are separated based on their molecular size. While larger molecules are unable to pass through, the small or medium sized molecules pass through the pores and thus takes a longer time to elute. In IEX, the stationary phase is charged and this enables the stationary phase to have an electrostatic attraction with oppositely charged species present in the sample. IEX is classified into cation exchange and anion exchange based on the charge of the stationary phase. Thus in cation exchange chromatography, the stationary phase is negatively charged and in anion exchange chromatography the stationary phase is positively charged.

\section{B. High performance liquid chromatography (HPLC)}

Chromatography paved the way for better separation of compounds with a reduction in the analysis time. ${ }^{3}$ The technique of HPLC was initially termed "high pressure liquid chromatography" but eventually it was replaced by the term "high performance liquid chromatography." In HPLC, the eluent is delivered by a pump that can withstand high pressures on the order of 6000 psi. The particle size used in HPLC 
(around 3-10 $\mu \mathrm{m}$ ) is far smaller than what was used for earlier chromatographic techniques.

Some of the advantages of this technique are a) higher separation capacity with batch analysis of multiple components, b) superior quantitative capability, c) reproducibility, d) easy preparative separation, e) higher sensitivity, and f) lower sample consumption. Figures 1 and 2 below depict a flow diagram of an HPLC and a typical HPLC instrument, respectively.

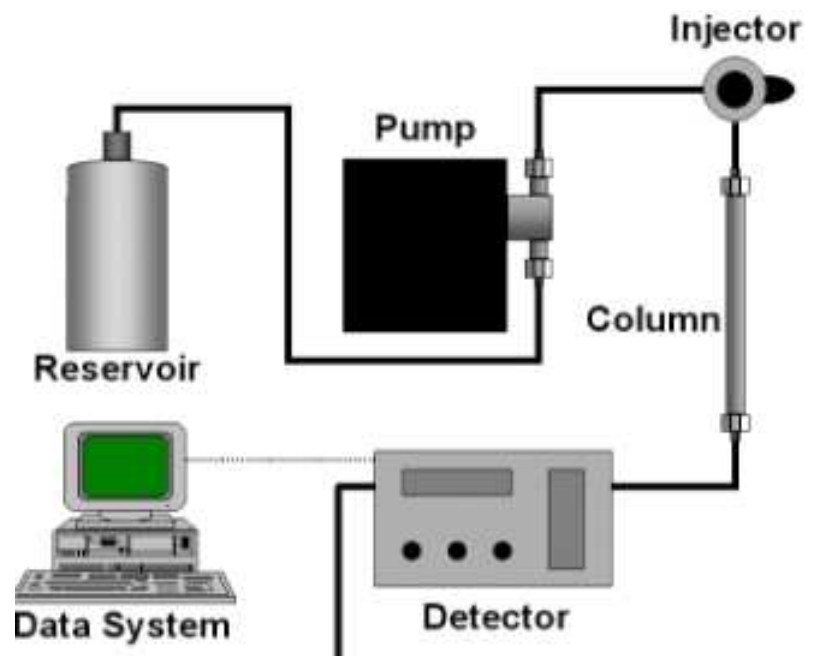

Figure 1. Flow diagram of $\mathrm{HPLC}^{7}$ (Reprinted with permission from LCResources.com) 


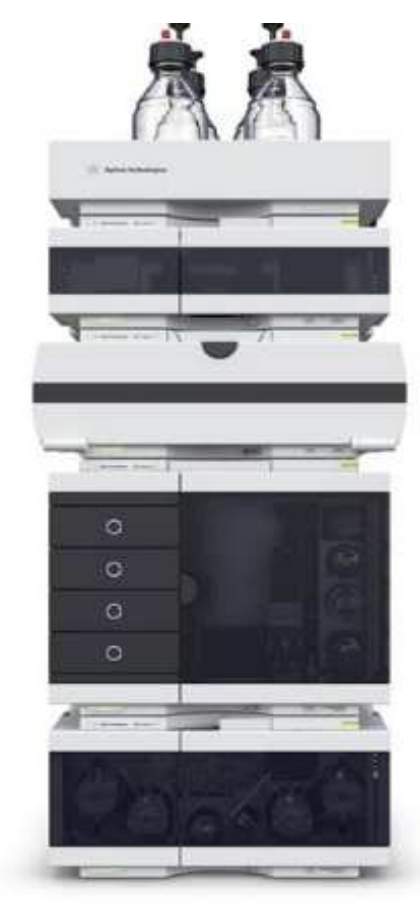

Figure 2. Representative photograph of HPLC instrument (C) Agilent Technologies, Inc. 2014. Reproduced with permission, Courtesy of Agilent Technologies, Inc.)

Some of the applications of HPLC include analysis of medical products (drugs and antibiotics), quality control studies in food products (vitamins, food additives, sugars, and organic acids), environmental sample analysis, and other organic industrial products. ${ }^{3}$ 1. A typical HPLC instrument consists of the following elements:

1.1. An ideal solvent delivery system should possess qualities like withstanding high pressure, have small pulsations accompanying pressure fluctuation, and an ability to accommodate a wide flow rate setting with accuracy in flow rate. ${ }^{3}$ Typical solvents used are deionized (DI) water and HPLC/special grade organic solvents such as acetonitrile, methanol, acetone, and isopropanol. 
The desirable properties of an HPLC grade solvent are inertness, low viscosity, high purity, and low toxicity. ${ }^{4}$ A highly viscous solvent tends to increase the back pressure in the column and capillaries, leading to heat generation and subsequent peak broadening. ${ }^{4}$ Additionally, an ideal solvent should also be transparent/invisible in the detector. For UV detectors, this means that the solvent should not absorb light at the wavelength selected. Further, an ideal solvent should be miscible with the other solvents, as immiscible solvents lead to unstable baselines and fluctuating/high pressures. ${ }^{4}$ Solvents are also to be filtered prior to their use in the HPLC instrument to prevent valve and column blocks. ${ }^{4}$ Acetonitrile (ACN) is the generally the preferred solvent over methanol (MeOH) or isopropanol.

1.2. Degassing unit: Dissolved air and bubbles in the solvent lead to large baseline shifts in the detector cell and the retention times and peak areas may not be stable. ${ }^{4}$ It is thus required to get rid of air bubbles and other dissolved gases before starting a chromatographic run. ${ }^{3}$ Some of the techniques used to degas are freeze thaw cycles under vacuum, ultra-sonication, or helium sparging. ${ }^{4}$ Some HPLC instruments also have an inbuilt degassing unit in the flow path between the solvent reservoir and pump. The basic principle of degassing includes applying vacuum to the solvent that is separated from an empty chamber by a semi permeable membrane for removing gas bubbles and other dissolved gases. ${ }^{4}$ The membrane permits the passage of small air molecules, while the larger solvent molecules remain in the liquid phase itself.

1.3. Sample injector unit: This component introduces the sample into the flow path. ${ }^{4}$ Some desirable properties of an injector are to permit free adjustment of injection 
volume with minimal sample loss, minimal sample band broadening, superior durability, and pressure resistance. ${ }^{3,4}$ A minimum delay volume high accuracy/precision of the injected sample, and fast injection cycle are some other useful features. ${ }^{4}$ Manual injectors and auto samplers are two types of commonly used injectors. While the manual injector enables a basic and affordable solution to introduce the desired volume of the sample to the flow path, standard auto samplers automatically inject the samples stored in vials. $^{4}$

1.4. Column oven /thermostatted column compartment (TCC): An ideal column oven /TCC should maintain a constant temperature for reproducible operation of the instrument.

1.5. Pumps: Pumps are an essential component of the HPLC instrument as a stable flow of the solvent and pressure are essential for reproducible chromatography. Pumps should also be able to withstand a range of pressures and flow rates, and various compositions of the mobile phases. ${ }^{4}$

1.6. Detectors: An ideal detector is required to be extremely sensitive to detect even small concentrations of the sample, be extremely selective, and have a low baseline noise. ${ }^{4}$ Detectors are broadly categorized into a) those that measure bulk property and b) those that detect specific properties. Some examples of the former class are refractive index detectors (RI), evaporative light scattering detectors (ELSD), and conductivity detectors. While these detectors are almost universal and measure bulk property, they have low sensitivity. The second class of detectors measure specific properties of the 
analytes and some examples are ultraviolet absorption (UV) detector, mass spectrometer (MS) detector, and fluorescence and electrochemical detector (ECD).

The most commonly used detectors are UV. Though UV detectors are simple and robust they require analyte molecules to bear a chromophore group in order to be

detected. ${ }^{4,5}$ Hence compounds that lack such a chromophore group either go undetected or need to be chemically converted to a chromophore bearing form before they can be detected. MS detectors on the other hand are highly specific and sensitive. However these detectors are very expensive and also require the sample to be ionizable in order to be detected. The two kinds of detectors that have been used in this project are UV and MS and a detailed explanation of their principle of operation is given in the following section.

\section{Background on detectors}

1.1.The UV detector works on the principle of the Beer-Lambert law that states the absorbance of electromagnetic radiation is proportional to the concentration of a compound in the cell and the cell length. ${ }^{6}$ Electromagnetic radiation either excites electrons from a lower energy level (ground) to a higher energy level (excited) or results in an increased rotation/vibration of the molecule. Either of these alterations results in a decrease in the intensity of the transmitted light and thus a measure of the absorbance helps estimate the concentration of the sample.

UV and visible radiation results in excitation of pi/non-paired electrons of some functional groups. Some types of UV detectors are fixed wavelength detectors, variable wavelength detectors (VWD), and diode array detectors (DAD). ${ }^{6}$ VWD's use a 
monochromatic slit and grating to select one wavelength to pass through a sample cell. ${ }^{7}$ DAD's enable a sample to be subjected to light of all wavelengths generated by a lamp and are the most versatile of all the UV detectors and hence most frequently used in method development. ${ }^{6,7}$ A typical UV detector permits a user to use wavelengths between 190 and 380 nanometers (nm) with $254 \mathrm{~nm}$ being most commonly used. ${ }^{8}$

In $\mathrm{DAD}$, light from a broad emission source is collimated by an achromatic lens to concentrate the light exiting through a detector cell, onto a holographic grating. The light spread from the grating falls onto a diode array that contains hundreds of diodes. The output from any of the diode can be selected and a chromatogram be developed using the UV wavelength that falls on that particular diode, thus producing a real time chromatogram. ${ }^{6}$ In spite of the ease and low cost of UV detectors, these detectors require the molecule to be tested to have a chromophore (color bearing) group in order to be detected. Figures 3 and 4 below show a schematic diagram of a VWD and DAD respectively. 


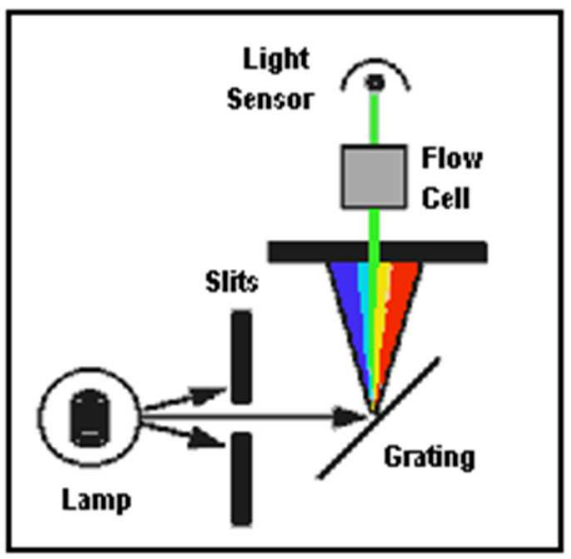

Figure 3. Arrangement of a variable wavelength detector ${ }^{7}$ (Reprinted with permission from LCResources.com)

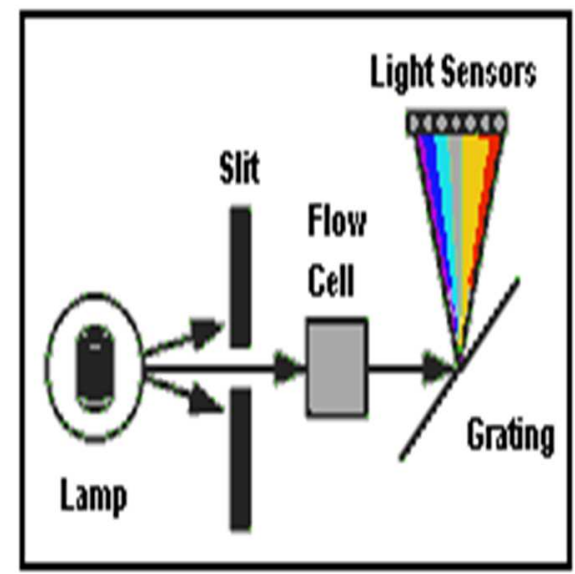

Figure 4. Instrumental setup of a diode array detector ${ }^{7}$ (Reprinted with permission from LCResources.com)

1.2. Mass spectrometers are the ultimate choice for any detector as they are highly selective and sensitive. The only downside of these detectors are their cost and need for a sample to be ionizable for detection. ${ }^{9}$ The three essential components of any mass spectrometer are an ion source, a mass analyzer, and a detector. An ion source, usually a 
high energy beam of electrons ionizes the sample to produce ions. ${ }^{9}$ Some of the diverse methods employed to achieve ionization include electron impact (EI), chemical ionization $(\mathrm{CI})$, electron spray ionization (ESI), fast atom bombardment (FAB), and matrix assisted laser desorption (MALDI). ${ }^{11}$ The mass analyzer separates the ions according to the mass /charge ratio, by focusing the accelerated ions in a beam that is bent by an external magnetic field. ${ }^{9,11}$ Some of the different kinds of mass analyzers are quadruple mass filters, quadruple ion traps and time-of-flight (TOF). Lastly, a detector records the charge-induced current that is created when an ion hits the surface. ${ }^{11}$ Figure 5 shows the layout of a mass spectrometer. ${ }^{10}$

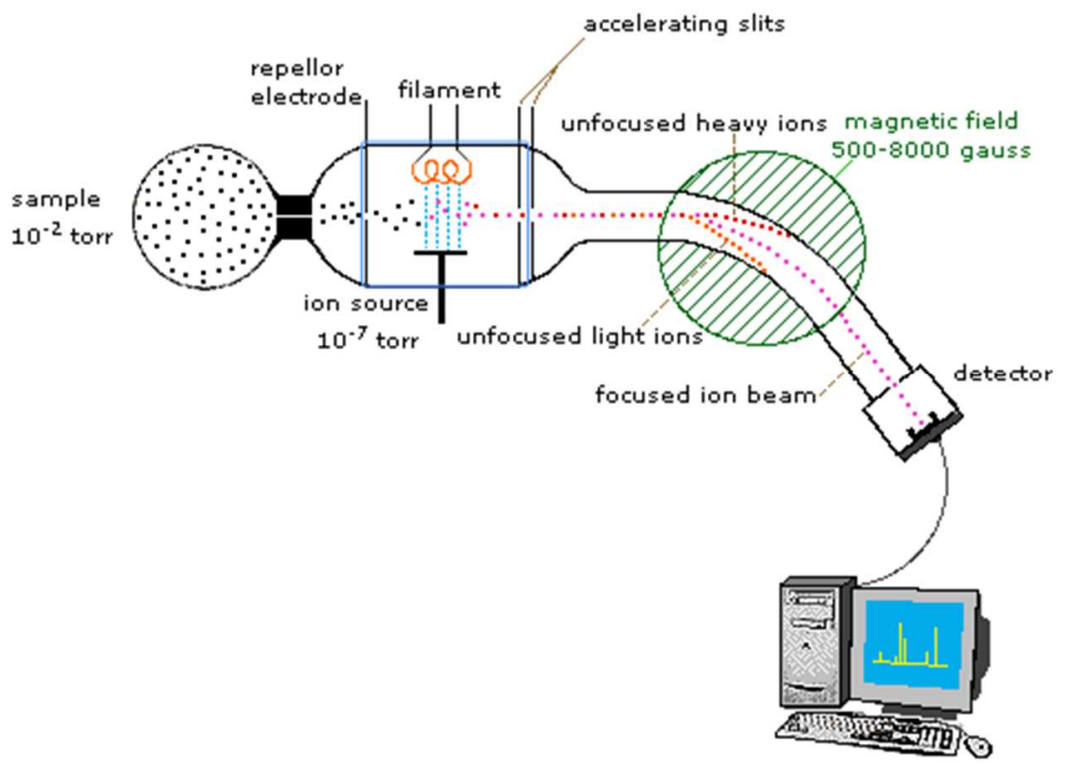

Figure 5. Layout of mass spectrometer ${ }^{10}$ (Reprinted with permission from William Reusch) 
Quadruple mass filters are utilized for a large number of studies in organic chemistry due to their high reproducibility, ease to operate, and robustness. The quadruple mass filters can also be interfaced with a variety of inlet systems. However, they lack high resolution. The instrumentation consists of four parallel rods of hyperbolic cross section set up symmetrically. By applying an appropriate ratio of radio frequency and DC voltage to the rods, desired ions are focused to pass through the vacuumed quadruples towards an electron multiplier detector and a plot of ion counts vs ion mass is recorded. $^{12}$

\section{Chromatographic parameters}

Some of the parameters needed to be considered during chromatographic studies are capacity factor (“"k”), selectivity (“' $\alpha$ "), resolution (“Rs"), and plate height (“"H”).

1.1.Capacity factor/retention factor ("k") measures the retention time of compounds relative to an unretained compound. " $\mathrm{k}$ " is calculated using Equation (1) below:

$\mathrm{k}=\left(\mathrm{t}_{\mathrm{R}}-\mathrm{t}_{0}\right) / \mathrm{t}_{0} \quad$ Equation 1

While $t_{R}$ denotes the retention time for the sample compound, to represents the elution time of an unretained compound. For an unretained compound that elutes with the solvent front, $\mathrm{k}$ equals 0 .

A higher retention factor indicates a strong retention of the compound on to the column. The capacity factor (" $\mathrm{k}$ ") is a dimensionless quantity and is also independent of column dimensions. The most common way to alter retention factor is to adjust the solvent strength of the mobile phase. A " $\mathrm{k}$ " value less than 1 is unreliable as the analytes 
may be co eluting with other sample components, while a higher "k" may also be undesirable as it may require a long time for the sample to elute, thus involving more time and solvent expenditure. It is also observed that as the retention factor increases, the peak height decreases and peak width increases. An ideal value for " $\mathrm{k}$ " is between 2 and 10.

1.2. Selectivity (" $\alpha$ ") is a measure of the system to chemically distinguish between sample components and is given by Equation (2). It is measured as a ratio of the retention factors of two peaks and is visualized as the distance between apices of two peaks as is illustrated in Figure $6 .{ }^{13}$

$$
\alpha=(k 2 / k 1)=\left(\mathrm{t}_{\mathrm{R} 2}-\mathrm{t}_{0}\right) /\left(\mathrm{t}_{\mathrm{R} 1}-\mathrm{t}_{0}\right) \quad \text { Equation } 2
$$

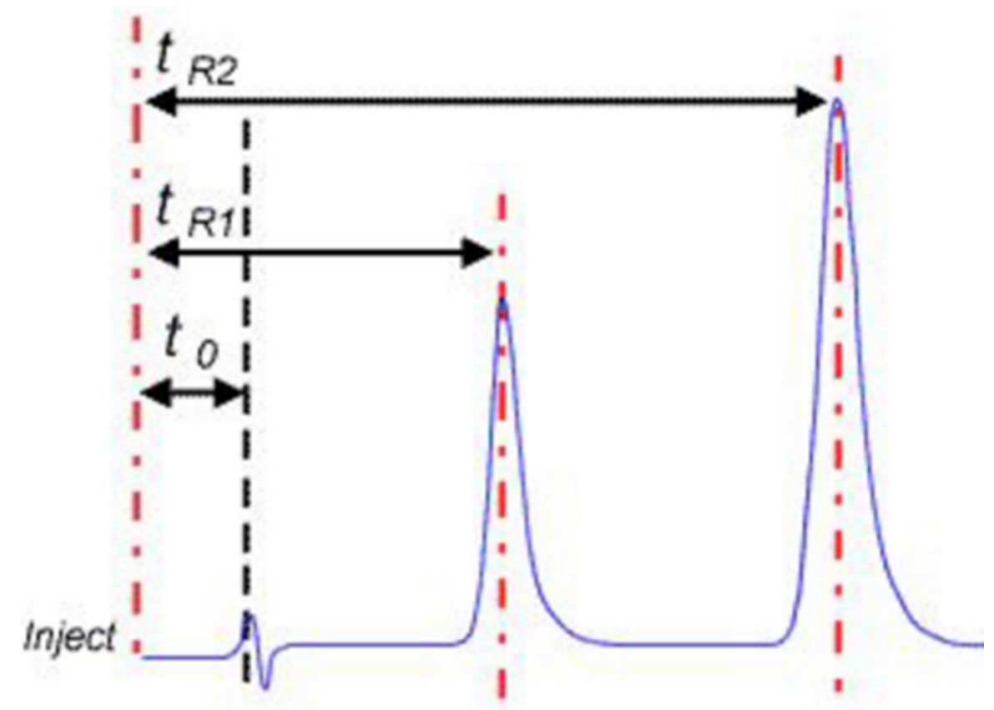

Figure 6. Illustration of resolution [Reprinted with permission from Chromacademy.com]

As can be clearly seen from Figure 6, the second compound has a longer retention time ("tR2") and thus "k2" is larger than "k1". A good separating power (high " $\alpha$ ") is indicated by an adequate separation between the apices of adjacent peaks. However, this 
is not directly indicative of good resolution and " $\alpha$ " also depends on the properties of the analyte, stationary phase, and the mobile phase. Any of these three factors may be altered to optimize the selectivity of an HPLC separation. Additionally the solvent strength, additives, and temperature also affect the selectivity factor. The $\mathrm{pH}$ of the mobile phase is another key factor especially when analyzing molecules having an ionizable group.

1.3. Efficiency ("N") /plate height ("H") measures the dispersion of the analyte band as it travels through the HPLC system/column and is mathematically given in Equations (3) and (4). Column performance is reflected by the value of "N." A large "N" indicates a highly efficient column. ${ }^{13}$ The column is divided into theoretical plates and the plate height denotes the distance over which the sample components achieve an equilibration between stationary and mobile phases in the column. The plate height is also referred to as "height equivalent to theoretical plate/HETP" and is given by Equation (5) below. For a highly efficient column, the distance between two successive plates (H) is small and the number of theoretical plate $(\mathrm{N})$ is large.

$$
\begin{array}{ll}
\mathrm{N}=16\left(\mathrm{t}_{\mathrm{R}} / \mathrm{t}_{\mathrm{W}}\right)^{2} & \text { Equation 3 } \\
\mathrm{N}=5.54\left(\mathrm{t}_{\mathrm{R}} / \mathrm{t}_{\mathrm{W} 0.5}\right)^{2} & \text { Equation 4 } \\
\mathrm{H}=\mathrm{L} / \mathrm{N} & \text { Equation } 5
\end{array}
$$

1.4. Resolution ("Rs") is a quantitative measure of how well two peaks can be differentiated in a chromatographic separation and is defined as the difference in retention times between two peaks divided by the combined width of the elution peaks and is given in Equation (5). In Equation (6), B has a longer retention time than A and 
"WA" and "WB" denote the peak widths of peaks A and B respectively. The fundamental formula for resolution involving all the parameters is given in Equation (7).

$$
\begin{array}{ll}
\mathrm{R}_{\mathrm{S}}=2\left[\left(\mathrm{t}_{\mathrm{R}}\right)_{\mathrm{B}}-\left(\mathrm{t}_{\mathrm{R}}\right)_{\mathrm{A}}\right] / \mathrm{W}_{\mathrm{B}}+\mathrm{W}_{\mathrm{A}} & \text { Equation } 6 \\
\mathrm{R}_{\mathrm{S}}=1 / 4 \sqrt{N} \mathrm{X}[(\alpha-1) / \alpha] \mathrm{X}[\mathrm{k} /(\mathrm{k}+1)] & \text { Equation } 7
\end{array}
$$

\section{E. Silica surface-surface modification}

Silica has been traditionally used as a solid support for chromatography due to its high mechanical strength and the ability to accurately fabricate particles of desirable pore size or diameter. ${ }^{14}$ However, irregularly shaped silica used initially restricted the flexibility of chromatographers to the usage of organic solvents for organic normal phase chromatography leading to poor efficiency and irreproducible results. Reverse-phase chromatography employed silica bonded to low polarity organosilanes using siloxane bonding technology (Si-O-Si-C). ${ }^{14}$ The hydrolytic susceptibility of this bond also became problematic while working at high or low $\mathrm{pH}$, strong buffers, and ion pairing reagents. Subsequently, spherical shaped silica particles that were more stable, uniformly shaped, sized, and those that gave better precision began to be used. However even with these type of silica frequent tailing problems were observed while separating basic compounds at an acceptable $\mathrm{pH}$ and this led to the development of Type B silica materials. $^{14}$

Type B silica of high purity demonstrated increased $\mathrm{pH}$ stability, improved packed-bed stability, and improved peak shape for chromatographic separations. ${ }^{14}$ The minimal trace metal content in the lattice also aided in reducing the effect of free silanol interactions when the solute was ionized. 
End-capping the silica surface by reacting the silica surface with a small reagent such as trimethylchlorosilane deactivates the silanol groups on the surface and also helps improve peak shapes for some compounds. It also serves the purpose of preventing the rapid dissolution of the silica at a higher $\mathrm{pH} .{ }^{14}$ However, even after end-capping many undesirable effects were observed during chromatographic separations like the loss of retention at a higher $\mathrm{pH}$ from the disintegration of the underlying silica bed and resulted in the loss of bonded material and instability of the packed columns. The hygroscopic nature of type A and B silica also led to retention time variability in normal phase separations and necessitated the careful control of the water content in the mobile phase while using these types of silica-based stationary phases. ${ }^{14}$ To overcome the disadvantages that result from using Type A and B silica, a novel grade of materials Type C silica was synthesized and characterized by Dr. Joseph Pesek of San Jose State University.

\section{F. Type C silica-silica hydride}

Silica hydride opened newer avenues for chromatographic /electro chromatographic analysis and separation by overcoming many challenges that were previously observed while using Type A and Type B silica. ${ }^{15}$ The novelty of Type C silica resulted from the replacement of polar silanol (-OH) groups by a non-polar hydride species $(-\mathrm{H})$ that imparted many useful chromatographic properties. ${ }^{14,16,17}$ The silica hydride surface possess nearly 10 times less silanol activity as compared to an endcapped Type B silica. ${ }^{14,15,17,18}$ Figures $7 \mathrm{a}$ and $7 \mathrm{~b}$ below depict the structural differences between Type B and C silica. ${ }^{15}$ 


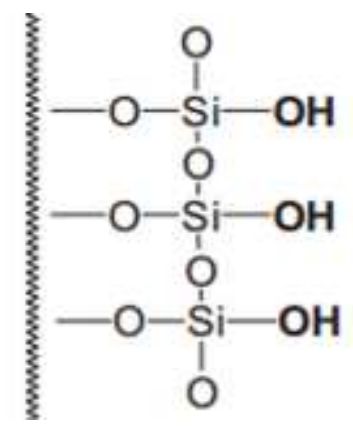

Figure 7a. Type B silica with silanol group on Si surface ${ }^{15}$ (Reprinted from from TrAC Trends in Analytical Chemistry,42, Pesek, J. J., Matyska, M. T.,Boysen, R. I., Yang, Y., $\&$ Hearn, M. T,Aqueous normal-phase chromatography using silica-hydride-based stationary phases, 64-73,2012, with permission from Elsevier)

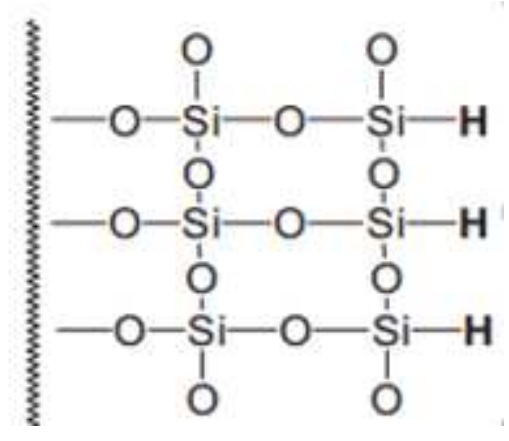

Figure 7b. Type C silica with silica hydride on Si surface ${ }^{15}$ (Reprinted from from TrAC Trends in Analytical Chemistry,42, Pesek, J. J., Matyska, M. T.,Boysen, R. I., Yang, Y., \& Hearn, M. T,Aqueous normal-phase chromatography using silica-hydride-based stationary phases, 64-73,2012, with permission from Elsevier)

The lack of a polar group on the silica surface in Type $\mathrm{C}$ silica also resulted in little or no water adsorption, thus making it a good choice for organic normal phase chromatography with a variety of solvents and improved speed. ${ }^{14,19}$ The Type C silica surface also provided stable chromatographic results when used between $\mathrm{pH}$ of 2 to $8 .{ }^{14}$ It was also possible to conduct chromatography over a wide range of mobile phase compositions ranging from $100 \%$ aqueous to pure organic solvents when utilizing a silica 
hydride-based column. ${ }^{14,19,20}$ Further, no phase dewetting/phase collapse was observed while using a pure aqueous mobile phase on a silica hydride based column as opposed to what is observed on an RP column. ${ }^{15,19}$ This new class of stationary phase could also be used in any of the three modes of chromatography, organic normal-phase (ONP), aqueous normal-phase (ANP), and reverse-phase chromatography (RP) and it exhibited minimum hysteresis while changing from one mode to another. ${ }^{14,17,19,20,21}$ This unique property also helped silica hydride stationary phases to retain both polar and nonpolar compounds, thus providing an experimental flexibility not available with other stationary phases based on organosilane chemistry. ${ }^{15,17,19}$ The equilibration time when changing from RP to NP or vice versa was also minimal and in some cases, both the NP and RP mechanisms operated simultaneously in a single isocratic run. ${ }^{17}$ The reproducibility between successive chromatographic runs and runs on different batches of the same Type $\mathrm{C}$ based stationary phase was also found to be excellent. ${ }^{17,19}$

\section{G. Fabrication of silica hydride}

There are two synthetic approaches to the fabrication of silica hydride materials:

1) Conversion of silicon hydroxide to a silicon chloride intermediate using thionyl chloride $\left(\mathrm{SOCl}_{2}\right)$ and subsequent reduction with lithium aluminum hydride $\left(\mathrm{LiAlH}_{4}\right)$. The reaction is conducted in a moisture free environment as the silicon-chlorine bond is hydrolytically unstable and reverts to silicon hydroxide in the presence of water. ${ }^{17,21}$

2) The second approach is a single step process involving a condensation reaction between silanols and triethoxysilane in the presence of an aqueous acid catalyst. The relative number of silica hydride groups to residual silanols depends on a number of 
reaction parameters. However, ${ }^{29} \mathrm{Si}-\mathrm{CP}-\mathrm{MAS}-\mathrm{NMR}$ studies reveal hydride coverage greater than $95 \%{ }^{21}$

The second approach has been used to synthesize the column used in the current research. A silanization reaction converts the silanol group on the silica surface to a hydride group and a subsequent hydrosilation reaction between the silica hydride intermediate and an unsaturated group, such as olefin in the presence of a catalyst (hexachloroplatinic acid /Spiers catalyst) or a free radical initiator (tertiary-butyl peroxide), gives a surface with the desired organic moiety attached. ${ }^{15,20}$ Figures 8 and 9 presents the scheme of silanization and hydrosilation reactions respectively.

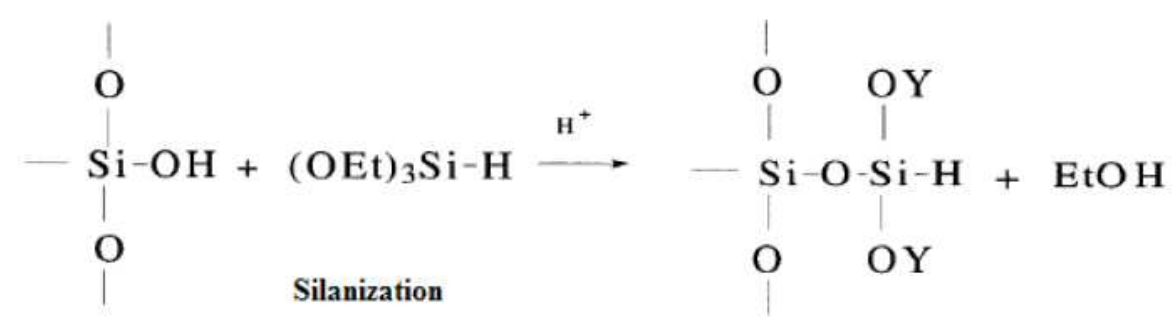

$$
\begin{aligned}
& \mathrm{Y}=\mathrm{Si} \text { or } \mathrm{H} \text { depending } \\
& \text { on extent of crosslinking }
\end{aligned}
$$

Figure 8. Silanization reaction ( Reprinted from Journal of Chromatography A, Pesek, J. J., Matyska, M. T., Oliva ,Michelle., \& Evanchic, Marc., Synthesis and characterization of bonded phases made via hydrosilation of alkynes on silica hydride surfaces, 145 154,1998, with permission from Elsevier) 


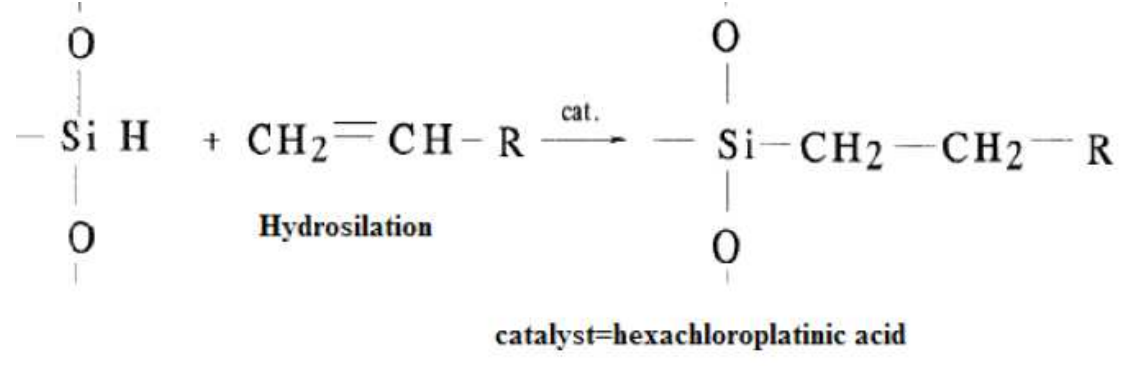

Figure 9. Hydrosilation reaction ${ }^{15}$ (Reprinted from from TrAC Trends in Analytical Chemistry,42, Pesek, J. J., Matyska, M. T.,Boysen, R. I., Yang, Y., \& Hearn, M. T,Aqueous normal-phase chromatography using silica-hydride-based stationary phases, 64-73,2012, with permission from Elsevier)

The specific property of the separation medium that has a stable $\mathrm{Si}-\mathrm{C}$ bond (hydrophobic, hydrophilic, or ion exchange property) is reflected by the nature of the organic moiety attached to silica hydride surface in the hydrosilation reaction. ${ }^{15,19,20,21}$ Though terminal olefins are usually employed in the hydrosilation step, it is also possible to bond olefins with a non-terminal double bond, alkynes or cyano groups to the silica hydride surface and in the case of alkynes, a bidentate attachment to the surface is observed. ${ }^{21}$ Table 1 below provides examples of silica hydride stationary phases and their applications to analysis of various compounds. ${ }^{15}$ 
Table 1. Examples of silica hydride stationary phases and their application in analyzing various compounds ${ }^{\mathbf{1 5}}$ (Reprinted from from TrAC Trends in Analytical Chemistry,42, Pesek, J. J., Matyska, M. T.,Boysen, R. I., Yang, Y., \& Hearn, M. T,Aqueous normal-phase chromatography using silica-hydride-based stationary phases, 64-73,2012, with permission from Elsevier)

\begin{tabular}{|c|c|}
\hline Functional group at the surface & Compounds \\
\hline Small alkyl (Diamond Hydride) & $\begin{array}{l}\text { Amino acids, carbohydrates, small organic acids and other metabolites, peptides, } \\
\text { propantheline bromide, fluoxetine, nucleotides }\end{array}$ \\
\hline Phenyl & Propantheline bromide, fluoxetine \\
\hline Cholesterol & $\begin{array}{l}\text { Nucleotides, quinolinedione, tetramic acid, benzopyran, choline, tobramycin, } \\
\text { peptides, ribose nucleosides, cytidine derivatives }\end{array}$ \\
\hline Octadecyl & $\begin{array}{l}\text { Metformin, glyburide, amphotericin, peptides, glucosamine, tobramycin, triacetyl } \\
\text { derivatives, carvone, loratadine }\end{array}$ \\
\hline Alkyl carboxylic acid & $\begin{array}{l}\text { Amino acid, nucleic acids, theophylline-related compounds, anilines, benzoic } \\
\text { acids, choline and tobramycin }\end{array}$ \\
\hline
\end{tabular}

\section{H. Aqueous normal phase chromatography}

ANP chromatography is a novel separation mechanism displayed by silica hydride based stationary phases using an acidic / neutral $\mathrm{pH}$ of mobile phase showing a retention pattern similar to that of normal phase chromatography. ${ }^{16,18}$ However, in ANP the mobile phase also contains a small amount of polar solvent such as water in addition to the organic solvent. ${ }^{17,18}$ This type of chromatography exhibits "dual retention" behavior by retaining polar and non-polar compounds on the same column. The retention of a polar compound increases with an increase in the concentration ( $60 \%$ or more) of the organic solvent, usually ACN and the retention of the hydrophobic/non-polar compound increases with an increase in the concentration of the polar component in the mobile phase. ${ }^{17,18}$ In ANP chromatography, a mobile phase with a high $\mathrm{pH}$ is not necessary in order to separate polar and non-polar compounds as opposed to RP. Additives such as formic acid, acetic acid, ammonium acetate, ammonium formate are also present in the mobile phase to serve the purpose of a buffering reagent and to improve peak shapes. ${ }^{18}$ 
In the RP retention mechanism, the hydrophobic interaction between the organic moiety on the stationary phase and the analyte tends to dominate the mechanism with silica hydride materials. ${ }^{17}$

ANP can be coupled with mass spectrometer detectors for analysis of metabolites (amino acids, small organic acids, and carbohydrates) in physiological samples. ${ }^{16}$ Some of the other advantages observed in the ANP retention mechanism are excellent reproducibility and minimum column equilibration time. ${ }^{16}$

The partition mechanism between the mobile phase and a hydration shell on the silica surface is observed for typical hydrophilic interaction liquid chromatography (HILIC) chromatography. Partitioning occurs between the mobile phase and a thin layer of water (hydration shell) on the silica surface. The hydration shell formed as a result of the interaction between the polar silanol groups and the water molecules in the eluent has a greater affinity for polar analyte molecules than the non polar analytes and is thus responsible for the NP retention displayed by HILIC materials. ${ }^{17}$ Type C silica that has half of a monolayer of water cannot function by such a partition mechanism and an adsorption mechanism, wherein an adsorbed water molecule or a component derived from the mobile phase is displaced by solute molecules is more likely. ${ }^{17}$ However, the exact mechanism of ANP retention has not been fully established.

HILIC materials separate only polar compounds and no separation can be achieved while using mixtures containing polar and non-polar compounds on such a material, while a type $\mathrm{C}$ based stationary phase material exhibits dual retention or retention of both polar and non-polar compounds. ${ }^{15}$ Figures 10a,10b, and 10c shown 
below illustrate the three kinds of retention observed in the ANP chromatography separation mechanism. ${ }^{15}$

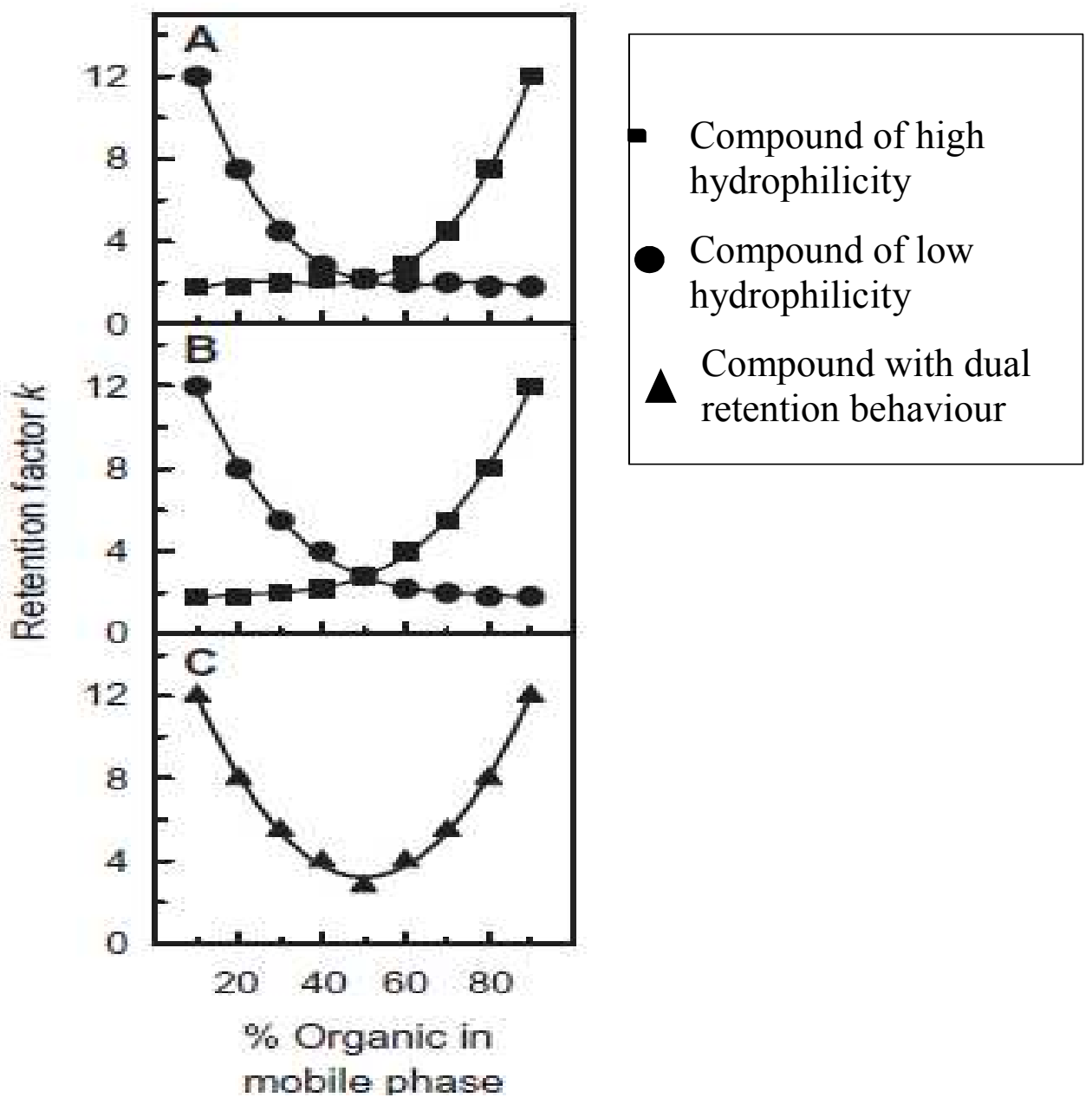

Figures 10a, 10b, and 10c. The three kinds of retention mechanism observed in ANP ${ }^{15}$ (Reprinted from from TrAC Trends in Analytical Chemistry,42, Pesek, J. J., Matyska, M. T.,Boysen, R. I., Yang, Y., \& Hearn, M. T,Aqueous normal-phase chromatography using silica-hydride-based stationary phases, 64-73,2012, with permission from Elsevier)

In Figure 10a, clear NP and RP mechanisms with no overlap over any mobile phase composition range is observed. At a higher water content, the non-polar /hydrophobic molecules are retained while the polar molecules/hydrophilic species elute at void volume. A reverse trend is observed at higher concentration of the nonpolar 
component. Figure 10b shows both RP and NP operating with a small range of mobile phase concentrations (around $45-65 \%$ organic content) thus exhibiting an overlap of the two retention mechanisms and enabling the separation of mixtures of polar and non-polar

compounds under isocratic conditions. ${ }^{15}$ Gradient elution can also be used to improve the efficiency and decrease retention times. ${ }^{15}$ The retention as illustrated in Figure 10c is observed for solute molecules having polar and non-polar groups hence permitting either the RP or ANP mode to operate by varying the mobile phase composition. ${ }^{15,17,19}$ The "U" shaped retention profile is typical of ANP retention and can be explained as a switch in the retention mechanism from RP to NP. ${ }^{19}$

\section{Types of samples used in the evaluation of HPLC column}

In this research, small molecules such as amino acids, nucleotides, nitrogenous bases (purine and pyrimidine), organic acids, ergogenic acids, organic amines, and polycyclic aromatic hydrocarbons $(\mathrm{PAH})$ have been used. The first class consists of amino acid molecules such as L- phenylalanine, L- tryptophan and phenyl thiohydantoin (PTH) derived amino acids such as PTH asparagine, PTH aspartic acid, and PTH Isoleucine. Amino acids are important biological molecules that exist as zwitterions at normal physiological $\mathrm{pH}(\mathrm{pH}$ between 6 and 8 ) and they constitute the monomeric units of peptides. ${ }^{21}$ Amino acids are composed of an amino group (-NH2) at one end and a carboxylic acid group $(-\mathrm{COOH})$ at the other end and this multiple polarity makes it difficult to separate them on RP based columns. ${ }^{22}$ The dual retention capacity observed in ANP makes these small molecules a suitable candidate for study. 
Of the 22 amino acids only tyrosine, tryptophan and phenylalanine can be detected by a UV detector. The remaining amino acids need to be derivatized before they can be detected in the UV-visible range. Some of the compounds used for derivatizing amino acids are dansyl chloride, ortho-pthalaldehyde (OPA), 9- fluorenylmethoxy carbonyl (FMOC), and phenyl thiohydantoin (PTH). In this project, three PTH derived amino acids have been used besides L-phenylalanine and L-tryptophan.

The second class of compounds tested includes nitrogenous bases and nucleosides that make up the backbone of deoxyribonucleic acid (DNA) and ribonucleic acid (RNA). The retention of nucleotides such as adenosine triphosphate (ATP), adenosine mono phosphate (AMP), nicotinamide dinucleotide phosphate (NADP), and nicotinamide dinucleotide (NAD) that are found in cell extracts and used as biomarkers for various diseases have also been studied in this project. ${ }^{23}$ The determination of nucleotide concentration is significant in order to realize the degree of cellular metabolic stress and inherited diseases of purine and pyrimidine nucleotide metabolism ${ }^{23}$. The NAD/NADP ratio is thus an indication of the metabolic activity and health of the cells. ${ }^{23}$ The highly charged and polar nature of these molecules makes retention difficult on RP columns. Further, the incompatibility of other chromatographic techniques with MS detectors also makes it challenging to analyze these molecules. Thus, they become suitable solutes for ANP retention study.

PAH's such as naphthalene, fluorene, and acenapthene are expected to exhibit reverse phase retention. An ergogenic acid such as creatinine that is obtained as a breakdown product of creatine and vitamin B12 (thiamine hydrochloride) have also been 
found to be relevant candidates for this study. Lastly, the retention behavior of theophylline, caffeine, 7-(2,3-dihydroxypropyl) theophylline and other some small organic compounds such as benzoic acid, p-amino benzoic acid, p-nitro aniline, and p-amino ethyl benzoate have also been investigated in this project.

\section{J. Silica hydride based undecynoic acid (UDA) column}

The silica hydride based UDA had been previously synthesized in our lab and packed into columns of the following dimensions: $75 \mathrm{~cm} \times 4.6 \mathrm{~mm}$ id and $50 \mathrm{~cm} \times 2.1$ mm id. The former column was used while conducting studies on a UV detector while the latter was used for MS studies.

UDA is an 11 carbon chain molecule terminating in a carboxylic acid (-COOH) group. It has a bidentate attachment to the silica hydride surface and the column displays weak cation exchange properties in addition to the ANP behavior. The weak cationic exchange property of the silica hydride based UDA column is attributed to the presence of a carboxylic acid group on the organic moiety. The (-COOH) group is either neutral or negatively charged based on the $\mathrm{pH}$ of the mobile phase. While under acidic conditions the carboxylic acid group is fully protonated and neutral, at a $\mathrm{pH}$ above the pKa the acidic group is deprotonated and capable of exhibiting the ion exchange property. The ion exchange property of the UDA provides additional selectivity in cases where ANP retention fails to provide full resolution. ${ }^{24}$

\section{K. Research goals}

The primary goal of this research was to study the normal and reverse phase retention ability of the silica hydride based UDA column using HPLC. In order to 
establish the dual retention property, a number of small molecules like amino acids, nucleosides, nucleotides, ergogenic acids, nitrogenous bases, and other small organic molecules were tested and their retention times documented. UV detectors were used for the isocratic runs of these molecules and the ANP retention behavior of the UDA column was established. The solvents used for the retention study were DI water and ACN both containing formic acid at a $0.1 \%$ volume/volume $(\mathrm{v} / \mathrm{v})$ concentration.

The second goal was to evaluate the change in retention behavior of some of the polar and non-polar compounds with a change in the buffer concentration, using $0.05 \%$, $0.075 \%, 0.2 \%$, and $0.3 \%$ (all concentrations expressed as $\mathrm{v} / \mathrm{v}$ ) formic acid. Yet another goal of the current research was aimed at testing the compatibility of a new buffer such as ammonium acetate and to study the retention time of few polar compounds with a change in the concentration of ammonium acetate.

A further objective was to examine the retention behavior of some selected nucleotides on the UDA column. The biological significance of studying nucleotide concentration makes this an important application of using a silica hydride based undecynoic acid column. Another objective of this project was to analyze the effect of a change in column temperature on the retention time of some polar compounds.

Additional objectives were directed at analyzing urine samples from farmers to check them for the presence of certain pesticides as well as their quantitative determination and examining pomegranate peel samples for the presence of certain phenolic and other compounds. Pomegranate peels contain a large variety of compounds such as phenols, flavonoids, tannins and besides their nutritive values have also been 
found to have many features such as antibacterial, antiamoebic, analgesic, and anthelminthic properties. ${ }^{25}$ The UDA column and an MS detector have been used to estimate the various compounds present in the pomegranate peel samples. 


\section{EXPERIMENTAL}

\section{A. Column}

The analytical columns used in this investigation were synthesized and characterized previously by another research student. The dimensions of the columns used for HPLC- UV detection and LC-MS detection are $7.5 \mathrm{~cm}$ x $4.6 \mathrm{~mm}$ id and $50 \times 2.1$ $\mathrm{mm}$ id column, respectively. The particle size of both columns is $4 \mu \mathrm{m}$ (micrometers) with a pore size of $100 \mathrm{~A}^{\circ}$ (Angstrom).

The silica hydride based UDA column exhibits weak cationic exchange properties in addition to the RP/ANP retention mechanism. The terminal carboxylic acid group contributes to the additional selectivity of the column. The (-COOH) group is between $90 \%$ and $99 \%$ negatively charged when using a mobile phase at pHs of 5.9 and 6.9 , respectively. The cationic nature of the column is exhibited only at a $\mathrm{pH}$ range of 6 or higher and is completely absent below pH 4.9. Table 2 gives details on some of the column specifications of the Cogent UDA columns manufactured by MicroSolv technologies (Eatontown, NJ). The maximum pressure that the columns can bear is 4500 psi and 8000 psi for the $4 \mu \mathrm{m}$ and $2 \mu \mathrm{m}$ particle sizes, respectively. ${ }^{26}$ 
Table 2. Column specifications of Cogent UDA column ${ }^{26}$ (Reprinted with permission from MicroSolv Technology

\begin{tabular}{|c|c|c|c|c|c|c|c|c|}
\hline Bonded Phase & $\begin{array}{c}\text { Pore } \\
\text { Size }\end{array}$ & $\begin{array}{c}\text { Surface } \\
\text { Area }\end{array}$ & Pore Volume & $\begin{array}{c}\text { Particle } \\
\text { Size }\end{array}$ & $\begin{array}{c}\text { End- } \\
\text { Capping }\end{array}$ & $\begin{array}{c}\text { Carbon } \\
\text { Load }\end{array}$ & $\begin{array}{c}\mathrm{pH} \\
\text { Range }\end{array}$ & $\begin{array}{c}\text { Max } \\
\text { Temp }\end{array}$ \\
\hline UDA $^{\mathrm{TM}}$ & $100 \AA$ & $\begin{array}{l}390+/ \cdot \\
30 \mathrm{~m} 2 / \mathrm{gm}\end{array}$ & $\begin{array}{l}1.00+/ \cdot \\
0.10 \mathrm{~mL} / \mathrm{g}\end{array}$ & $4 \mu \mathrm{m}$ & $\mathrm{N} / \mathrm{A}$ & $14-15 \%$ & $\begin{array}{l}2.0- \\
8.0\end{array}$ & $80^{\circ} \mathrm{C}$ \\
\hline UDA $2.0^{\mathrm{T} M}$ & $120 \AA$ & $\begin{array}{l}340+/ \cdot \\
20 \mathrm{~m} 2 / \mathrm{gm}\end{array}$ & $\begin{array}{l}1.00+/ \cdot \\
0.10 \mathrm{~mL} / \mathrm{g}\end{array}$ & $2.2 \mu \mathrm{m}$ & $\mathrm{N} / \mathrm{A}$ & $14-15 \%$ & $\begin{array}{l}2.0- \\
8.0\end{array}$ & $80^{\circ} \mathrm{C}$ \\
\hline
\end{tabular}

\section{B. Compounds and mobile phase used for characterization studies}

All the compounds used for this research were stored in the refrigerator and sample stock solutions with a $1 \mathrm{mg} / \mathrm{mL}$ concentration were prepared for the HPLC-UV and HPLC-MS studies. The mobile phases and the chemical compounds used for column characterization are shown in Tables 3, 4.1, 4.2, 4.3, 4.4, and 4.5 below. The chemical structures of all the compounds are shown in Figure 13.

Table 3. Chemicals used as mobile phase

\begin{tabular}{|c|l|}
\hline \multicolumn{1}{|c|}{ Chemical name } & \multicolumn{1}{c|}{ Manufacturing company } \\
\hline $\begin{array}{c}\text { Acetonitrile (Lot no: 981414, CAS- } \\
75-05-8)\end{array}$ & Fisher Chemicals Fair Lawn, NJ \\
\hline $\begin{array}{c}\text { Formic acid (Lot \# 127 F-3436) } \\
\text { Ammonium acetate (GFS lot no: }\end{array}$ & $\begin{array}{l}\text { Sigma Chemical Company, P.O Box } \\
\text { P997392) }\end{array}$ \\
\hline Rutherford, NJ \\
\hline
\end{tabular}


Table 4.1. Nitrogenous bases, nucleosides, nucleotides and ergogenic acids

\begin{tabular}{|c|c|}
\hline Chemical name & Manufacturing Company \\
\hline NADP & $\begin{array}{l}\text { Sigma Chemical Company, P.O Box } 14508 \text {, } \\
\text { St. Louis, MO - } 63178\end{array}$ \\
\hline NAD & $\begin{array}{l}\text { Sigma Chemical Company, P.O Box } 14508 \text {, } \\
\text { St. Louis, MO - } 63178\end{array}$ \\
\hline Creatinine & $\begin{array}{l}\text { Sigma Chemical Company, P.O Box } 14508 \text {, } \\
\text { St. Louis, MO - } 63178\end{array}$ \\
\hline Cytosine & Nutritional Biochemical Corp. Cleveland, $\mathrm{OH}$ \\
\hline Uracil & $\begin{array}{l}\text { Sigma Chemical Company, P.O Box } 14508 \text {, } \\
\text { St. Louis, MO - } 63178\end{array}$ \\
\hline Adenine & $\begin{array}{l}\text { Sigma Chemical Company, P.O Box } 14508 \text {, } \\
\text { St. Louis, MO - } 63178\end{array}$ \\
\hline Thymine & $\begin{array}{l}\text { Sigma Chemical Company, P.O Box } 14508 \text {, } \\
\text { St. Louis, MO - } 63178\end{array}$ \\
\hline Adenosine & CALBIOCHEM Co. LA \\
\hline Thymidine & Nutritional Biochemical Corp. Cleveland, $\mathrm{OH}$ \\
\hline ATP & $\begin{array}{l}\text { Sigma Chemical Company, P.O Box } 14508 \text {, } \\
\text { St. Louis, MO - } 63178\end{array}$ \\
\hline AMP & $\begin{array}{l}\text { Sigma Chemical Company, P.O Box 14508, } \\
\text { St. Louis, MO - } 63178\end{array}$ \\
\hline
\end{tabular}


Table 4.2. Amino acids

\begin{tabular}{|c|c|}
\hline Chemical name & Manufacturing Company \\
\hline L-tryptophan & $\begin{array}{l}\text { Sigma Chemical Company, P.O Box 14508, } \\
\text { St. Louis, MO - } 63178\end{array}$ \\
\hline L-phenylalanine & $\begin{array}{l}\text { J.T. Baker Chemical Co. Phillipsburg, NJ- } \\
08865\end{array}$ \\
\hline $\begin{array}{l}\text { PTH Asparagine [ Lot no: } \\
\text { 71F-7714] }\end{array}$ & $\begin{array}{l}\text { Sigma Chemical Company, P.O Box } 14508 \text {, } \\
\text { St. Louis, MO - } 63178\end{array}$ \\
\hline $\begin{array}{l}\text { PTH Isoleucine [ Lot no: } \\
\text { 90F-9018] }\end{array}$ & $\begin{array}{l}\text { Sigma Chemical Company, P.O Box } 14508 \text {, } \\
\text { St. Louis, MO - } 63178\end{array}$ \\
\hline $\begin{array}{l}\text { PTH Aspartic acid [ EEC no } \\
\quad: 227-055-5]\end{array}$ & $\begin{array}{l}\text { Sigma Chemical Company, P.O Box } 14508 \text {, } \\
\text { St. Louis, MO - } 63178\end{array}$ \\
\hline
\end{tabular}

Table 4.3. Organic acids and amines

\begin{tabular}{|c|l|}
\hline Chemical name & \multicolumn{1}{c|}{ Manufacturing Company } \\
\hline Benzoic acid & $\begin{array}{l}\text { Sigma Chemical Company, P.O Box 14508, } \\
\text { St. Louis, MO - 63178 }\end{array}$ \\
\hline p-amino benzoic acid & $\begin{array}{l}\text { Sigma Chemical Company, P.O Box 14508, } \\
\text { St. Louis, MO - 63178 }\end{array}$ \\
\hline p-nitro aniline & $\begin{array}{l}\text { Sigma Chemical Company, P.O Box 14508, } \\
\text { St. Louis, MO - 63178 }\end{array}$ \\
\hline $\begin{array}{c}\text { Ethyl p-amino } \\
\text { benzoate }\end{array}$ & $\begin{array}{l}\text { Sigma Chemical Company, P.O Box 14508, } \\
\text { St. Louis, MO - 63178 }\end{array}$ \\
\hline
\end{tabular}


Table 4.4 Polycyclic aromatic hydrocarbons

\begin{tabular}{|c|l|}
\hline Chemical name & \multicolumn{1}{|c|}{ Manufacturing Company } \\
\hline Naphthalene & $\begin{array}{l}\text { Sigma Chemical Company, P.O Box 14508,St. } \\
\text { Louis, MO - 63178 }\end{array}$ \\
\hline Fluorene & $\begin{array}{l}\text { Sigma Chemical Company, P.O Box 14508,St. } \\
\text { Louis, MO -63178 }\end{array}$ \\
\hline Acenapthene & $\begin{array}{l}\text { Sigma Chemical Company, P.O Box 14508,St. } \\
\text { Louis, MO -63178 }\end{array}$ \\
\hline
\end{tabular}

Table 4.5. Xanthine-related and other miscellaneous compounds

\begin{tabular}{|c|l|}
\hline Chemical name & \multicolumn{1}{|c|}{ Manufacturing Company } \\
\hline Caffeine & $\begin{array}{l}\text { Sigma Chemical Company, P.O Box 14508,St. } \\
\text { Louis, MO - 63178 }\end{array}$ \\
\hline Theophylline & $\begin{array}{l}\text { Sigma Chemical Company, P.O Box 14508,St. } \\
\text { Louis, MO -63178 }\end{array}$ \\
\hline $\begin{array}{c}\text { 7-(2,3-dihydroxypropyl) } \\
\text { theophylline }\end{array}$ & $\begin{array}{l}\text { Sigma Chemical Company, P.O Box 14508,St. } \\
\text { Louis, MO - 63178 }\end{array}$ \\
\hline Thiamine HCl & Matheson Coleman \& Bell, Cincinnati, Ohio \\
\hline
\end{tabular}




\section{Chemical structures of the chemical compounds analyzed}

Figure 11.1-11.8 shows the chemical structures of all different classes of compounds tested on the column.

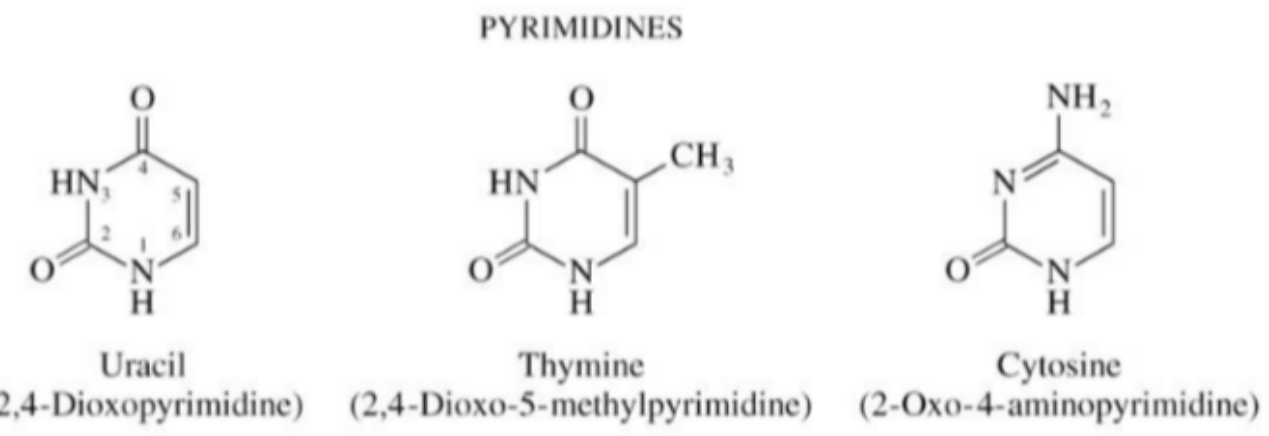

PURINES

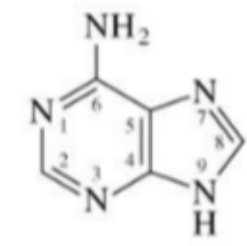

Adenine (6-Aminopurine)<smiles>Nc1nc2[nH]cnc2c(=O)[nH]1</smiles>

Guanine (2-Amino-6-oxopurine)

Figure 11.1. Chemical structures of nitrogenous bases 


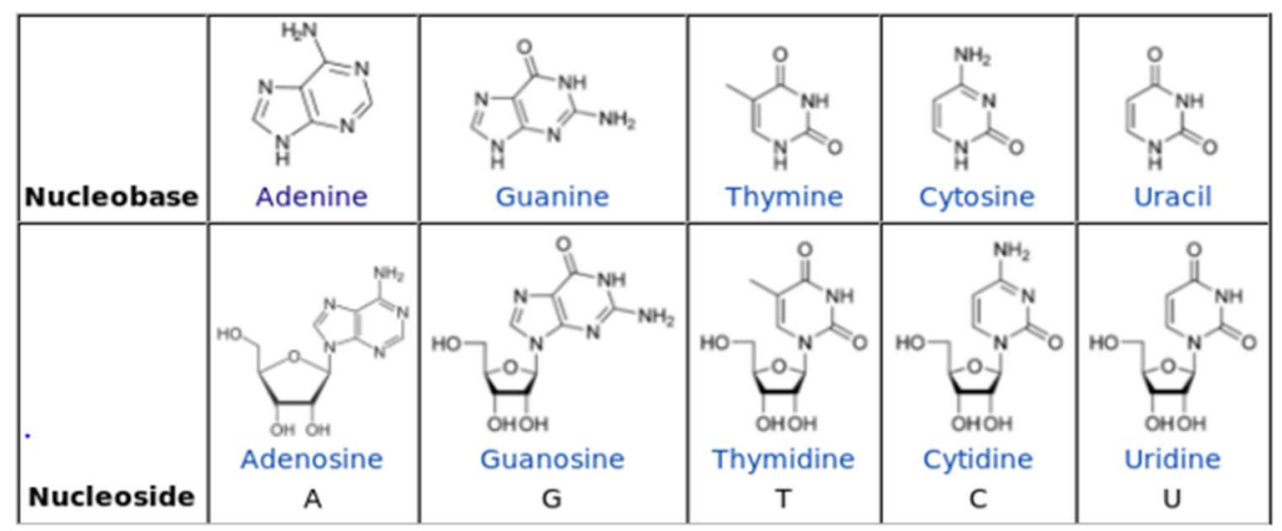

Figure 11.2. Chemical structures of nucleosides 

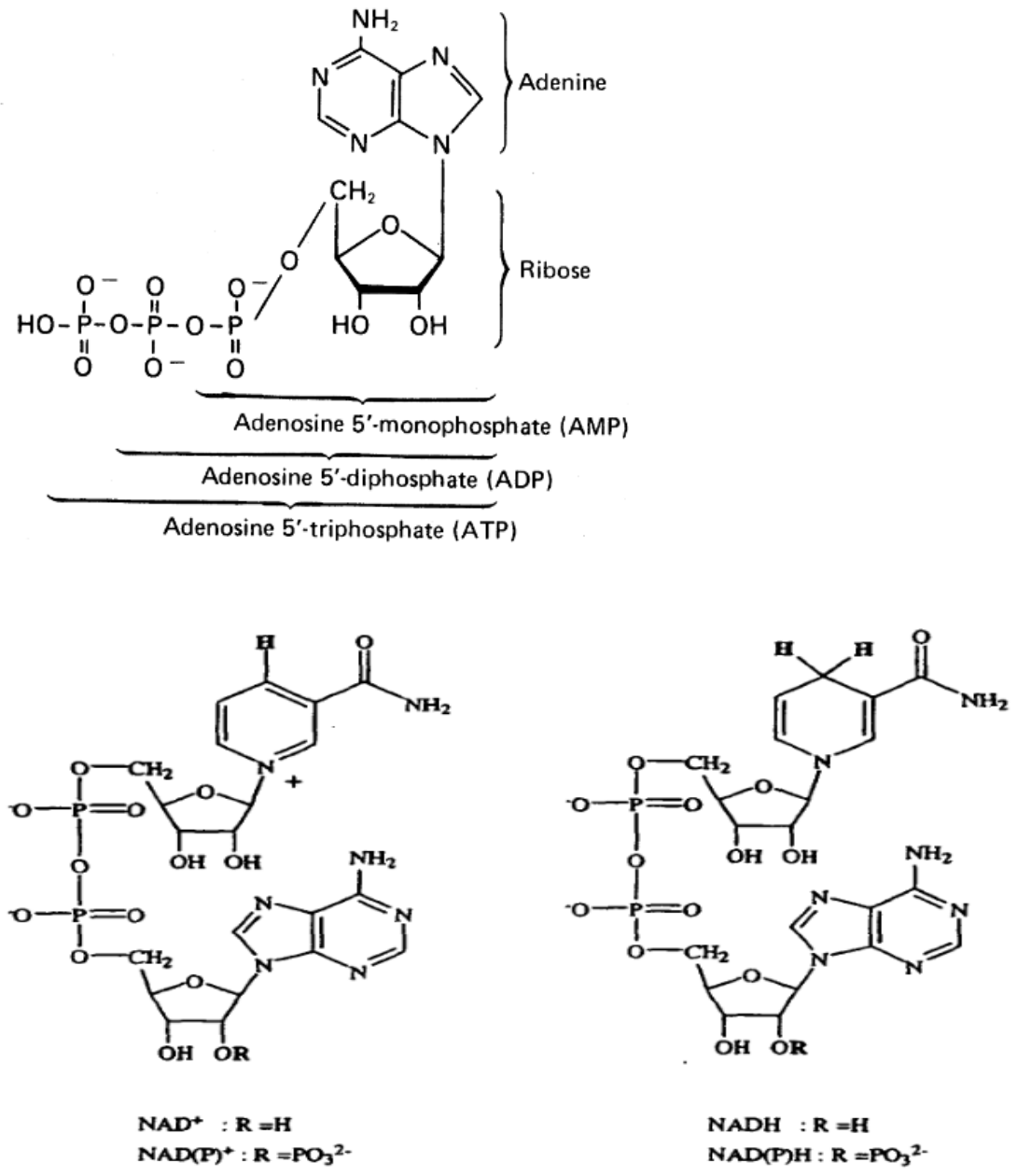

Figure 11.3. Chemical structures of nucleotides and coenzyme 


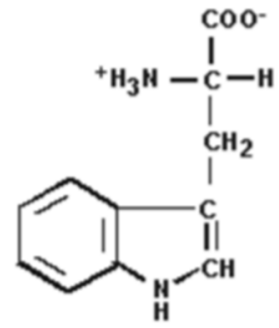

Tryptophan

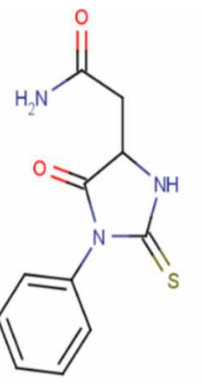

PTH Asparagine

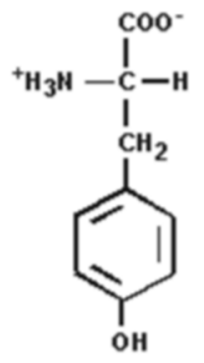

Tyrosine

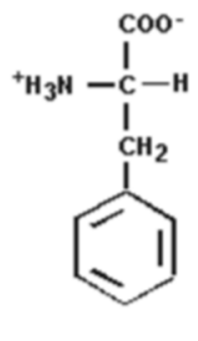

Phenylalanine

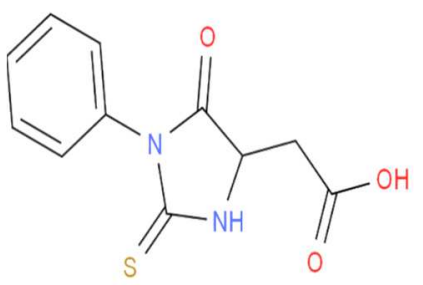

PTH Aspartic acid

Figure 11.4. Chemical structures of amino acids 
<smiles>Cn1c(=O)c2[nH]cnc2n(C)c1=O</smiles>

Theophylline<smiles>Cn1c(=O)c2c(ncn2CC(O)CO)n(C)c1=O</smiles>

7-(2,3-dihydroxypropyl) theophylline)<smiles>Cn1c(=O)c2c(ncn2C)n(C)c1=O</smiles>

Caffeine

Figure 11.5. Chemical structures of xanthine-related compounds<smiles>O=C(O)c1ccccc1</smiles><smiles>Nc1ccc(C(=O)O)cc1</smiles>

Benzoic acid

$$
\text { p-Aminobenzoic acid }
$$<smiles>CCOC(=O)c1ccc(N)cc1</smiles>

Ethyl p-Aminobenzoate<smiles>Nc1ccc([N+](=O)[O-])cc1</smiles>

Figure 11.6. Chemical structures of small organic molecules 


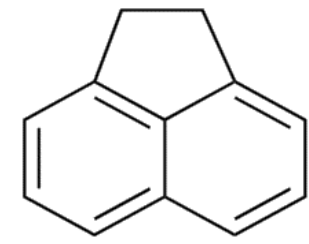

Acenapthene

Napthalene
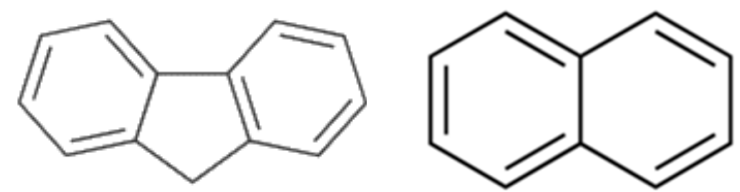

Figure 11.7. Chemical structures of Polycyclic aromatic hydrocarbons

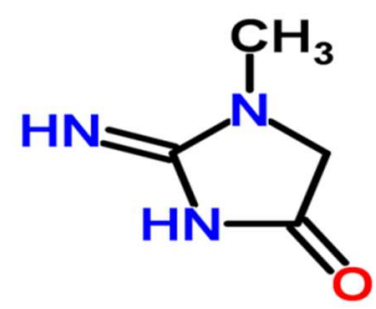

Creatinine<smiles>Cc1ncc2c(n1)NC1=[N+]([ClH+])C2C(CC=O)S1</smiles>

Thiamine hydrochloride (Vitamin B1)

Figure 11.8. Chemical structures of miscellaneous compounds 


\section{HPLC and MS Instrumentation}

Three types of instruments attached to three different kinds of detectors were employed to complete the current research. The first kind of HPLC instrument used for UV detection was a Hewlett Packard 1090 series which was used for column characterization and analyte retention studies. This instrument was introduced in the early 1980s. The 1090 series has a high performance solvent delivery system (DR5) with 1, 2 or 3 active solvent channels. ${ }^{27}$ Each solvent channel contains a reservoir and a dual syringe metering pump with a rotary valve. Helium $(\mathrm{He})$ degassing is essential and there are provisions for either manual injection or auto sampler injection. While it is only possible to do one injection at a time for the former, the latter permits up to 99 injections in a sequence. The oven temperature can be set to any range from $0-100{ }^{\circ} \mathrm{C}$. Nitrogen gas connected to the instrument provided the pressure for the injector needle to move up and down and it was set at a pressure of 70 psi. For the purpose of instrument control and data collection, Chem Station software was used. For all UV detection studies, the wavelength of the detector was set to $214 \mathrm{~nm}$ and $254 \mathrm{~nm}$, the injection volume to $2 \mu \mathrm{L}$ and flow rate at $0.5 \mathrm{~mL} / \mathrm{min}$. The oven temperature for all retention studies was $40{ }^{\circ} \mathrm{C}$. However, for the retention study with varying column temperature, the temperature was increased from $30-55{ }^{0} \mathrm{C}$ with a $5{ }^{0} \mathrm{C}$ increment at each step. The DI water used as a solvent was prepared on a Milli-QTM purification system (Millipore Corp., Bedford, MA). Figure 12 below illustrates a typical HP 1090 series instrument. 


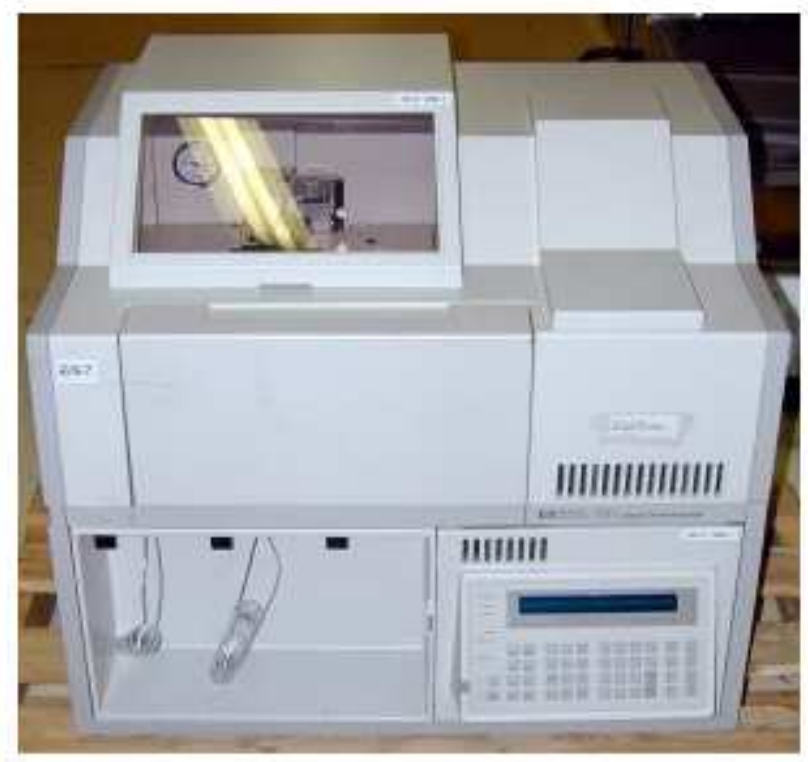

Figure 12. A view of the HP 1090 series HPLC-UV Instrument (Reprinted with permission from Labequip.com)

The second type of instrument used for pesticide analysis was an Agilent 1100 series LC system (Santa Clara, CA, USA), including a degasser, binary pump, and temperature controlled column compartment. The mass spectrometer was an Agilent 6220 MSD (time-of-flight) with a dual sprayer electrospray ionization source (ESI). The final mobile phase obtained after method development used a gradient. Solvent A was $10 \mathrm{mM}$ ammonium acetate in DI water and solvent B was acetonitrile with $0.1 \%$ formic acid (v/v). The gradient program started with $100 \% \mathrm{~B}$ and was gradually decreased to $95 \% \mathrm{~B}$ over the next two minutes and held at $95 \% \mathrm{~B}$ for another six minutes, and then linearly increased to $100 \% \mathrm{~B}$ over the next one minute. The flow rate was maintained at $0.4 \mathrm{~mL} / \mathrm{min}$ and the injection volume at $1 \mu \mathrm{L}$. The analysis was done using $\mathrm{m} / \mathrm{z}$ for $[\mathrm{M}+\mathrm{H}]^{+}$in the positive ion mode. Data acquisition and instrument control was done 
using Mass Hunter software. Figure 13 below illustrates the arrangement of a 1100 series LC system coupled with a 6220 series TOF detector.

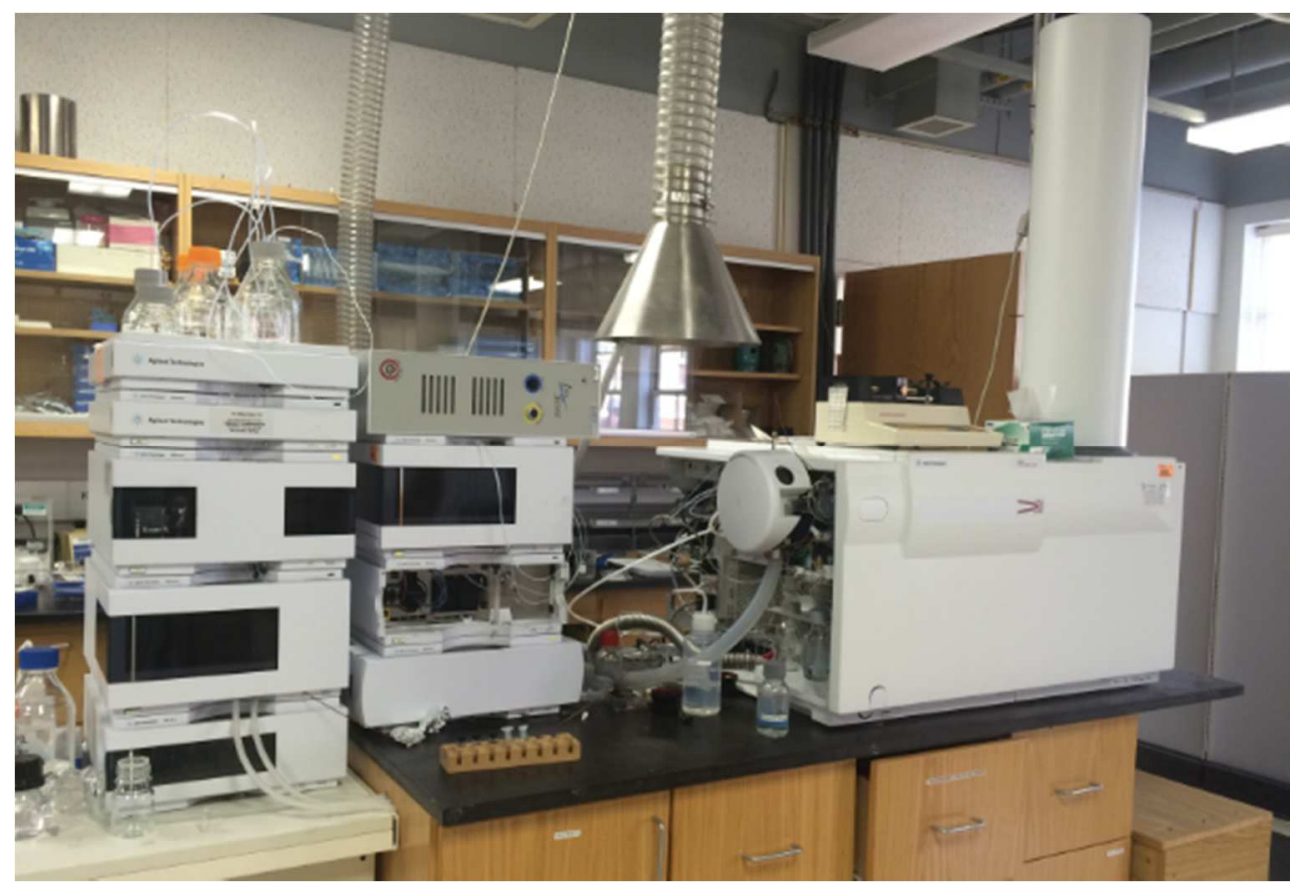

Figure 13. 1100 series LC system-6220 series TOF detector (Reprinted with permission from University of Florida)

The third instrument employed for the study on the pomegranate peel samples was an Agilent 1200 SL series LC system (Santa Clara, CA, USA), including a degasser, binary pump, temperature controlled, and temperature controlled column compartment . The mass spectrometer was an Agilent 6520 MSD TOF with a dual sprayer electrospray ionization source (ESI). The drying gas temperature was set at $250^{\circ} \mathrm{C}$, flow rate set at $0.4 \mathrm{~mL} / \mathrm{min}$ and the injection volume at $1 \mu \mathrm{L}$. Solvent A was DI water with $0.1 \%$ formic acid $(\mathrm{v} / \mathrm{v})$ and solvent B was acetonitrile with $0.1 \%$ formic acid $(\mathrm{v} / \mathrm{v})$. Two different columns were employed for this analysis. The UDA column used had the same dimensions as stated earlier. The gradient program started at 15\% B and was gradually 
increased to $80 \% \mathrm{~B}$ over the next four minutes and held at $80 \% \mathrm{~B}$ for another two determination was done using $\mathrm{m} / \mathrm{z}$ for $[\mathrm{M}+\mathrm{H}]^{+}$in the positive ion mode. Data acquisition and instrument control was done using Mass Hunter software. Figure 14 shows the layout of a 1200 SL series LC system coupled with a 6520 Q-TOF detector (Quadrupole- time of flight).

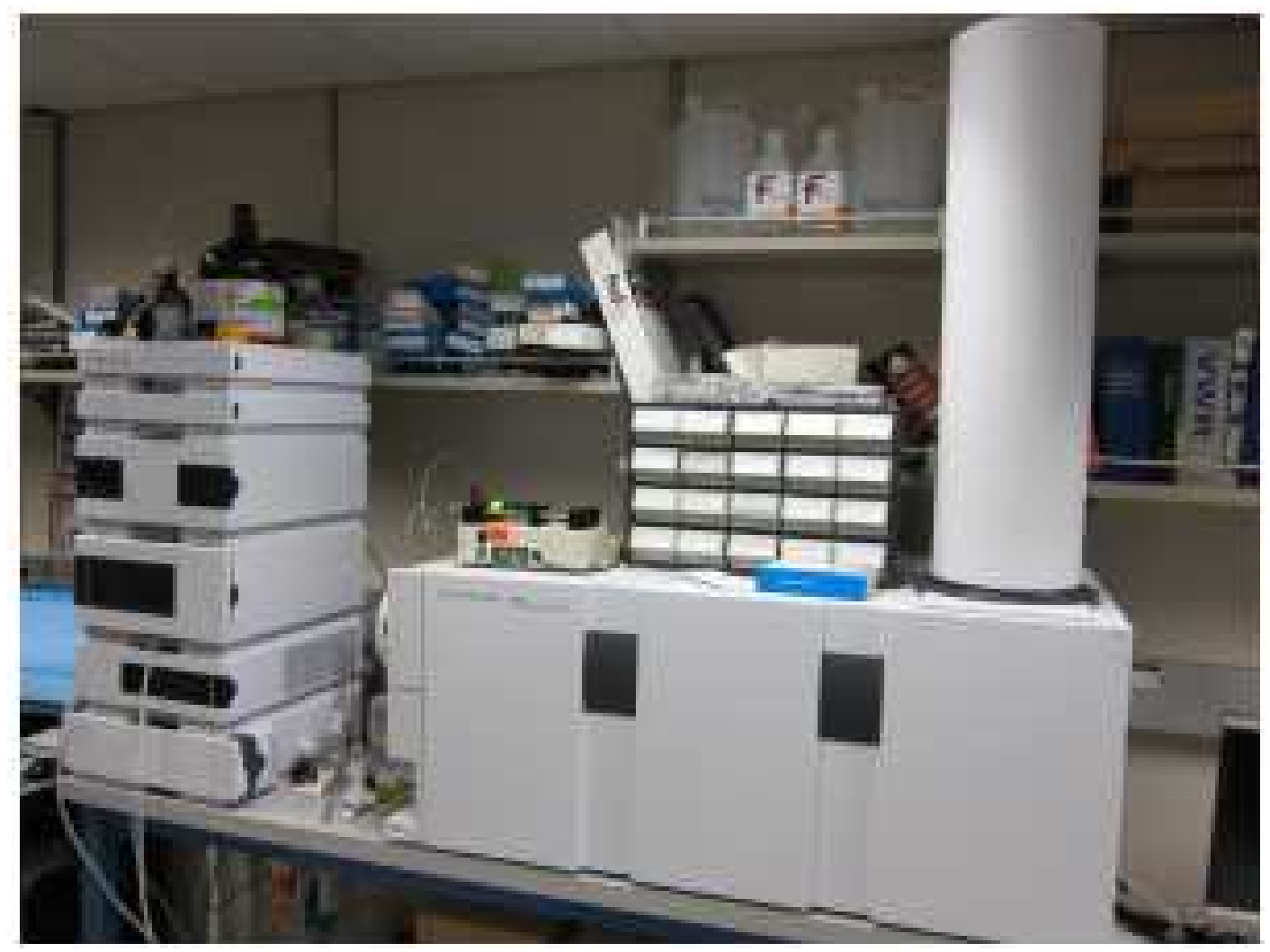

Figure 14. 1200 series LC system-6520 series Q-TOF detector (Reprinted with permission from University of Washington) 


\section{EXPERIMENTS AND DISCUSSION}

\section{Column characterization studies}

The main purpose of the research was to characterize the silica hydride-based undecynoic acid column. The dimension of the column used for this purpose was $7.5 \mathrm{~cm}$ $\mathrm{x} 4.6 \mathrm{~mm}$ id. Two different types of detectors were used for this purpose, an HPLC-UV detector (HP 1090 series) and an MS detector. Each HPLC run was repeated three times for the purpose of reproducibility and recorded. Graphs were plotted with retention time in minutes along the $y$-axis and \% composition of organic component in the mobile phase on the $\mathrm{x}$-axis. In studies where retention pattern was determined using a different concentration of the buffer/additive, the concentration was plotted on the $\mathrm{x}$-axis and retention time in minutes along the y-axis. Further, in the characterization studies done at different oven temperatures, the column temperature was plotted on the $\mathrm{x}$-axis and the retention time in minutes along the y-axis.

\section{A. Chromatographic evaluation of HPLC column using UV detection}

Amino acids, nitrogenous bases, nucleosides, nucleotides, ergogenic acids, xanthine-related compounds, and other small organic molecules were used to characterize

the column. A series of runs were conducted by varying the mobile phase composition of the organic solvent from $30-90 \%$, and each run was repeated three times. The injection volume for each sample was $2 \mu \mathrm{L}$ and the instrument flow rate and temperature were set at $0.5 \mathrm{~mL} / \mathrm{min}$ and $40{ }^{\circ} \mathrm{C}$, respectively. Stock solutions of the samples were prepared by dissolving $1 \mathrm{mg}$ in $1 \mathrm{~mL}$ of the solvent. Further, the solutions were sonicated to dissolve the solute completely and obtain a clear solution. A fixed amount $(100 \mu \mathrm{L})$ of the stock 
solution was micro-pipetted into a vial and diluted with $900 \mu \mathrm{L}$ of the solvent to be injected into the HPLC instrument. In all of the characterization studies, the polar solvent (A) was DI water and the organic solvent (B) was ACN. The buffer used for all the characterization studies was formic acid $(0.1 \% \mathrm{v} / \mathrm{v})$ premixed with solvents $\mathrm{A}$ and $\mathrm{B}$.

\subsection{Evaluation of nitrogenous bases}

All three pyrimidine bases (uracil, thymine, and cytosine) and a purine base (adenine) were run on the column with ACN compositions ranging from 30-90\%. A mixture of 50:50 DI water:ACN premixed with $0.1 \% \mathrm{v} / \mathrm{v}$ of formic acid was used to dissolve all samples and prepare the stock solution. The retention data and retention plots for these compounds are provided in Table 5 and Figure 15. The order of retention time observed for these nitrogenous compound is as expected on a cationic exchange column with maximum retention observed for adenine and minimum for uracil. The retention times of thymine and uracil were found to be very close to each other. The presence of the amino group on adenine could probably account for the strong interaction and hence longer retention on the column. The retention time is relatively long for cytosine also; however, it is also slightly lower than adenine and this could be due to the presence of an electron withdrawing moiety (keto group). Thymine and uracil have similar retention times, which can be explained by the similarity in their chemical structures. Thymine with an additional methyl group in the ring structure, is slightly less polar and thus displays a lower retention time than uracil. 
Table 5. Retention time data for nitrogenous bases

\begin{tabular}{|c|c|c|c|c|c|}
\hline \multicolumn{2}{|c|}{} & \multicolumn{4}{c|}{ Retention time (Minutes) } \\
\hline $\begin{array}{c}\text { DI Water } \\
+ \\
0.1 \% \text { Formic } \\
\text { acid }\end{array}$ & $\begin{array}{c}\text { ACN } \\
+ \\
0.1 \% \text { Formic } \\
\text { acid }\end{array}$ & Thymine & Cytosine & Uracil & Adenine \\
\hline 70 & 30 & 1.888 & 1.852 & 1.769 & 2.049 \\
\hline 60 & 40 & 1.834 & 1.877 & 1.744 & 2.076 \\
\hline 50 & 50 & 1.800 & 1.951 & 1.729 & 2.207 \\
\hline 40 & 60 & 1.811 & 2.143 & 1.742 & 2.506 \\
\hline 30 & 80 & 1.844 & 2.582 & 1.790 & 3.086 \\
\hline 20 & 90 & 2.150 & 4.971 & 2.865 & 11.823 \\
\hline 10 & 70 & 1.933 & 3.710 & 1.879 & 4.804 \\
\hline
\end{tabular}




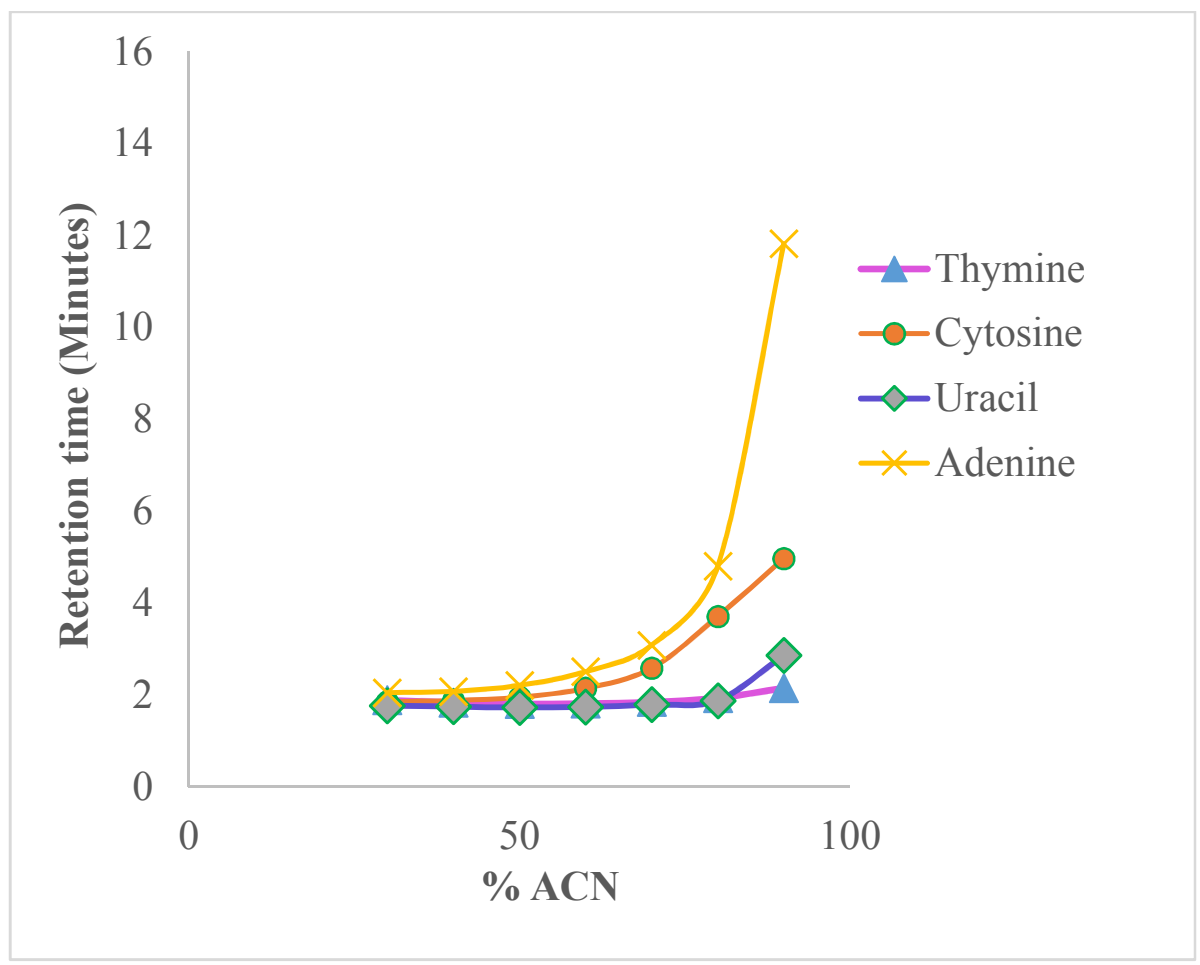

Figure 15. Retention time plot for nitrogenous bases

\subsection{Nucleosides and nucleotides}

Nucleosides consist of a nitrogenous base such as adenine, cytosine, guanine, and thymine along with a deoxyribose sugar, in the case of DNA. In RNA, uracil is found instead of thymine and each of the nitrogenous bases is attached to a ribose sugar for RNA. ${ }^{28}$ Nucleotides are monophosphate, diphosphate, or triphosphate nucleosides wherein either one, two, or three sugars are phosphorylated, respectively. The atoms and groups on the nucleobases are responsible for the interaction. The nucleosides used for this project were adenosine and thymidine. Adenosine and thymidine were dissolved in 50:50 DI water/ACN premixed with $0.1 \% \mathrm{v} / \mathrm{v}$ formic acid and this was used to dissolve the samples and prepare the stock solution. The retention time data and plots for nucleosides are given in Table 6 and Figure 16. The higher polarity of adenosine as 
compared to the thymidine results in the stronger retention on the UDA column and thus the retention time of adenosine is larger than thymidine.

\section{Table 6. Retention time data for nucleosides}

\begin{tabular}{|c|c|c|c|}
\hline \multicolumn{2}{|c|}{ Concentration (\%) } & \multicolumn{2}{c|}{ Retention time (Minutes) } \\
\hline $\begin{array}{c}\text { DI Water } \\
+ \\
0.1 \% \text { Formic acid }\end{array}$ & $\begin{array}{c}\text { ACN } \\
+.1 \% \text { Formic acid }\end{array}$ & Adenosine & Thymidine \\
\hline 70 & 30 & 2.078 & 1.852 \\
\hline 60 & 40 & 1.847 & 1.753 \\
\hline 50 & 50 & 1.835 & 1.676 \\
\hline 40 & 60 & 1.871 & 1.686 \\
\hline 30 & 70 & 1.952 & 1.720 \\
\hline 20 & 80 & 2.166 & 1.781 \\
\hline 10 & 90 & 2.670 & \\
\hline
\end{tabular}




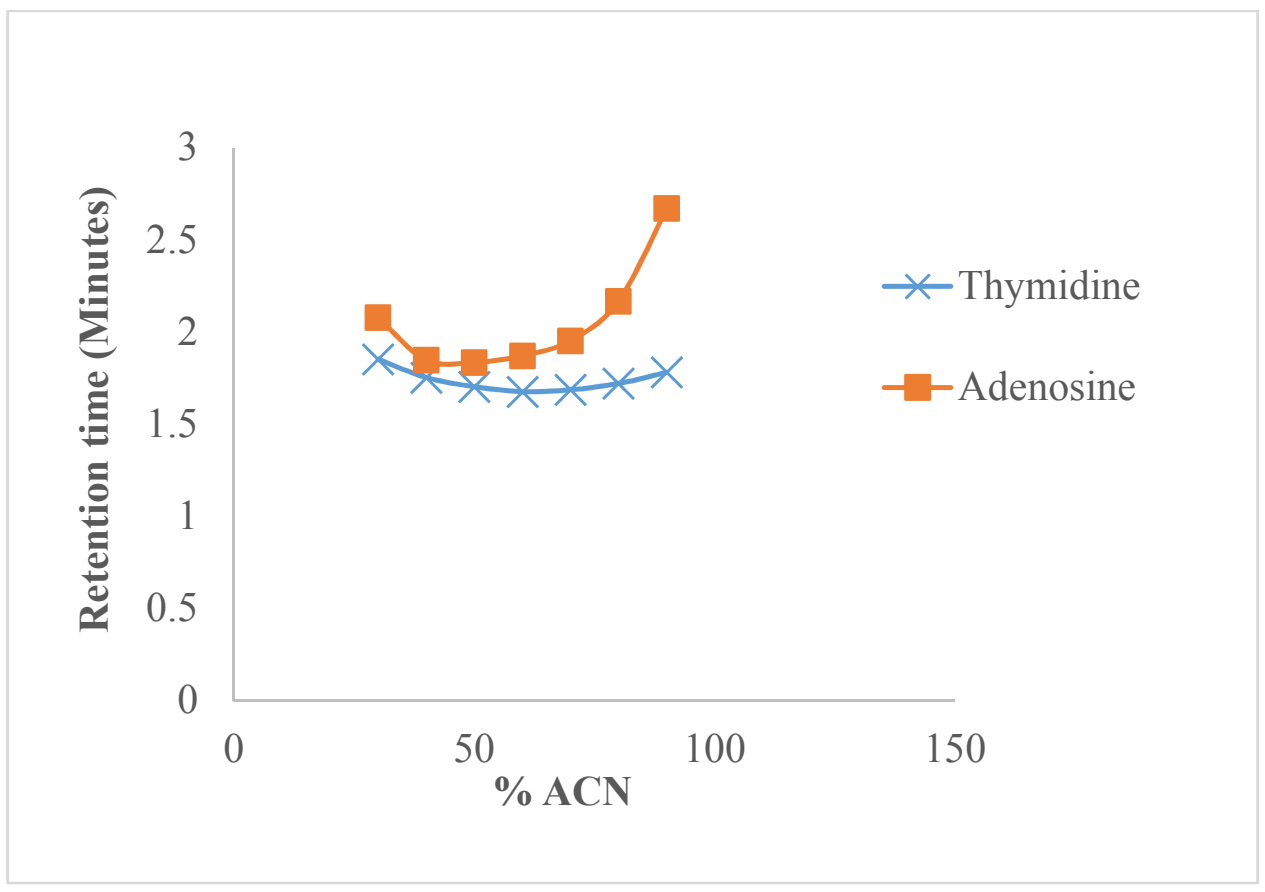

Figure 16. Retention time plot of nucleosides

\subsection{Underivatized and PTH derivatized amino acids}

L-phenylalanine, L-tryptophan, PTH asparagine, PTH aspartic acid, and PTH isoleucine were dissolved in 50:50 DI water/ACN premixed with $0.1 \%$ formic acid (v/v). Isocratic runs were conducted between $30 \%$ and $80 \%$ concentrations of ACN. The general order of elution of PTH derived amino acids was found to be PTH isoleucine $<\mathrm{PTH}$ asparagine $<\mathrm{PTH}$ aspartic acid and this follows the general pattern: acidic $<$ neutral $<$ basic.

For underivatized amino acids such as L-phenylalanine and L-tryptophan, L-tryptophan was retained slightly longer than phenylalanine at each of the mobile phase compositions. Among the 22 amino acids, only the 3 aromatic amino acids, tyrosine, tryptophan and phenylalanine, absorb light in the UV range and the maximum absorbance is observed for tryptophan. ${ }^{29}$ Phenylalanine is the most hydrophobic while 
the phenolic and indole rings of tyrosine and tryptophan make them somewhat polar. ${ }^{29}$ The retention time data is provided in Table 7 and the retention plot is shown in Figure 17. The hydrophobicity of L-phenylalanine is explained by the possibility of ring stacking (lack of substituents on the ring and equal sharing of electrons between the carbon atoms in the ring). In tyrosine, a hydroxyl group $(-\mathrm{OH})$ on the phenolic ring permits hydrogen bond thus making it more polar and hydrophilic. L-tryptophan has a more complex structure with a "nitrogen" containing indole ring that can additionally engage in hydrogen bonds accounting for its maximum polarity. ${ }^{30}$ 
Table 7. Retention time data for amino acids

\begin{tabular}{|c|c|c|c|c|c|c|}
\hline \multicolumn{2}{|c|}{ Concentration $(\%)$} & \multicolumn{5}{|c|}{ Retention time (Minutes) } \\
\hline $\begin{array}{c}\text { DI Water } \\
+ \\
0.1 \% \\
\text { Formic } \\
\text { acid } \\
\end{array}$ & $\begin{array}{c}\mathrm{ACN} \\
+ \\
0.1 \% \\
\text { Formi } \\
\text { c } \\
\text { acid } \\
\end{array}$ & $\begin{array}{l}\text { L- } \\
\text { phenylala } \\
\text { nine }\end{array}$ & $\begin{array}{c}\text { L- } \\
\text { tryptophan }\end{array}$ & $\begin{array}{c}\text { PTH } \\
\text { Isoleucine }\end{array}$ & $\begin{array}{c}\text { PTH } \\
\text { Aspartic } \\
\text { acid }\end{array}$ & $\begin{array}{c}\text { PTH } \\
\text { Asparagine }\end{array}$ \\
\hline 70 & 30 & 1.954 & 2.079 & 6.949 & 2.492 & 2.442 \\
\hline 60 & 40 & 1.897 & 1.977 & 3.747 & 2.082 & 2.100 \\
\hline 50 & 50 & 1.845 & 1.889 & 2.610 & 1.869 & 1.914 \\
\hline 40 & 60 & 1.919 & 1.981 & 2.113 & 1.754 & 1.815 \\
\hline 30 & 70 & 2.129 & 2.203 & 1.879 & 1.694 & 1.770 \\
\hline 20 & 80 & 2.238 & 2.796 & 1.775 & 1.644 & 1.762 \\
\hline 10 & 90 & 2.764 & 5.147 & 1.704 & 1.652 & 1.750 \\
\hline
\end{tabular}




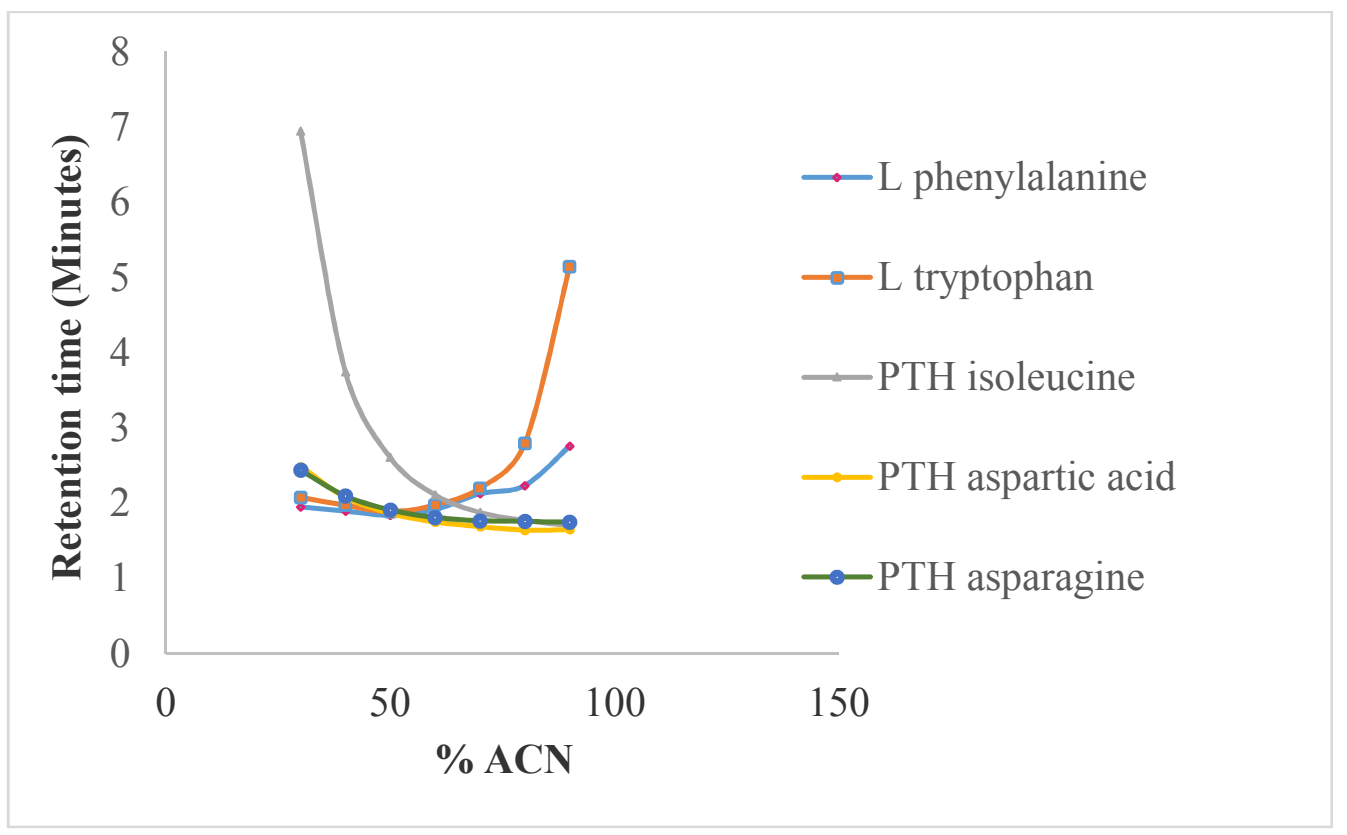

Figure 17. Retention time plots for amino acids

\subsection{Xanthine-related compounds}

All the analytes were dissolved in DI water to make the stock solution. The stock and sample concentrations were the same as used for the other studies. Theophylline has bronchodilation properties and is used to manage obstructive asthma while caffeine is the most active xanthine in stimulating the central nervous system. Lufyllin /diprophylline /7-(2,3-dihydroxpropyl) Theophylline is used to treat asthma, cardiac dyspnea, and bronchitis. It also serves as an adenosine receptor antagonist and phosphodiesterase inhibitor. ${ }^{31}$ The retention time data for these compounds is shown in Table 8 . The retention data has also been plotted in Figure 18. Isocratic runs between 20 and $90 \%$ ACN were conducted and in each of the runs 7-(2,3-dihydroxypropyl) Theophylline eluted first followed by theophylline and caffeine. The longer retention of caffeine can be substantiated due to the hydrophobic interaction of the molecule with the large non 
polar region of the stationary phase. Theophylline is slightly acidic and thus elutes faster from the UDA column.

Table 8. Retention time data for xanthine-related compounds

\begin{tabular}{|c|c|c|c|c|}
\hline \multicolumn{2}{|c|}{ Concentration (\%) } & \multicolumn{3}{|c|}{ Retention time (Minutes) } \\
\hline $\begin{array}{c}\text { DI Water } \\
+ \\
0.1 \% \\
\text { Formic acid }\end{array}$ & $\begin{array}{c}\text { ACN } \\
+ \\
0.1 \% \text { Formic } \\
\text { acid }\end{array}$ & Theophylline & Caffeine & $\begin{array}{c}\text { 7-(2,3-dihydroxyprop- } \\
\text { yl)Theophylline }\end{array}$ \\
\hline 80 & 20 & 2.538 & 3.468 & 1.926 \\
\hline 70 & 30 & 2.168 & 2.635 & 1.844 \\
\hline 60 & 40 & 2.014 & 2.315 & 1.785 \\
\hline 50 & 50 & 1.935 & 2.168 & 1.747 \\
\hline 40 & 60 & 1.919 & 2.104 & 1.757 \\
\hline 30 & 70 & 1.950 & 2.096 & 1.804 \\
\hline 20 & 80 & 2.043 & 2.154 & 1.900 \\
\hline 10 & 90 & 2.309 & 2.348 & 2.128 \\
\hline
\end{tabular}




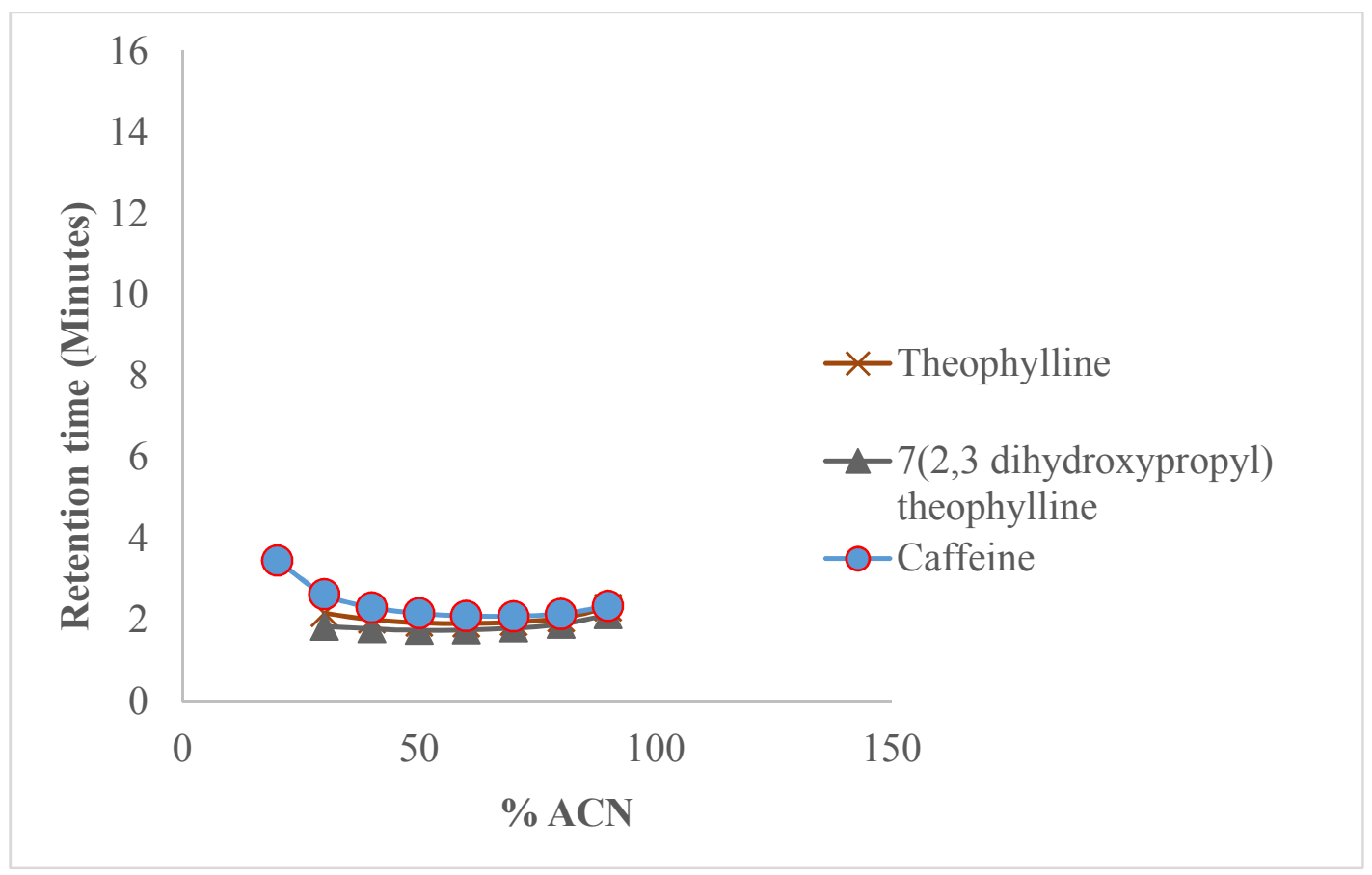

Figure 18. Retention time plots of xanthine-related compounds

\subsection{Small organic molecules}

Small organic molecules such as benzoic acid, p-amino benzoic acid, p-nitro aniline, and ethyl p-amino benzoate were also used for column characterization. All stock and sample solutions were prepared in 50:50 DI water/ ACN premixed with 0.1\% $\mathrm{v} / \mathrm{v}$ formic acid. For each of the four molecules the retention time was found to decrease with an increase in non-polar component of the mobile phase. The retention table and the corresponding plots are given in Table 9 and Figure 19 respectively. 
Table 9. Retention time data for small organic molecules

\begin{tabular}{|c|c|c|c|c|c|}
\hline \multicolumn{2}{|c|}{} & \multicolumn{4}{|c|}{ Retention time (Minutes) } \\
\hline $\begin{array}{c}\text { DI Water } \\
+ \\
0.1 \% \\
\text { Formic acid }\end{array}$ & $\begin{array}{c}\text { ACN } \\
+ \\
0.1 \% \\
\text { Formic } \\
\text { acid }\end{array}$ & $\begin{array}{c}\text { Benzoic } \\
\text { acid }\end{array}$ & $\begin{array}{c}\text { p-amino } \\
\text { Benzoic acid } \\
\text { Concentration } \%\end{array}$ & $\begin{array}{l}\text { p- } \\
\text { nitroaniline }\end{array}$ & $\begin{array}{l}\text { Ethyl } \\
\text {-amino } \\
\text { benzoate }\end{array}$ \\
\hline 70 & 30 & 3.582 & 2.489 & 4.256 & 5.073 \\
\hline 60 & 40 & 3.100 & 2.250 & 3.560 & 3.790 \\
\hline 50 & 50 & 2.393 & 1.982 & 2.392 & 2.565 \\
\hline 40 & 60 & 2.008 & 1.868 & 2.080 & 2.181 \\
\hline 30 & 70 & 1.887 & 1.818 & 1.911 & 1.977 \\
\hline 20 & 80 & 1.841 & 1.815 & 1.837 & 1.881 \\
\hline 10 & 90 & 1.728 & 1.815 & 1.715 & 1.730 \\
\hline
\end{tabular}




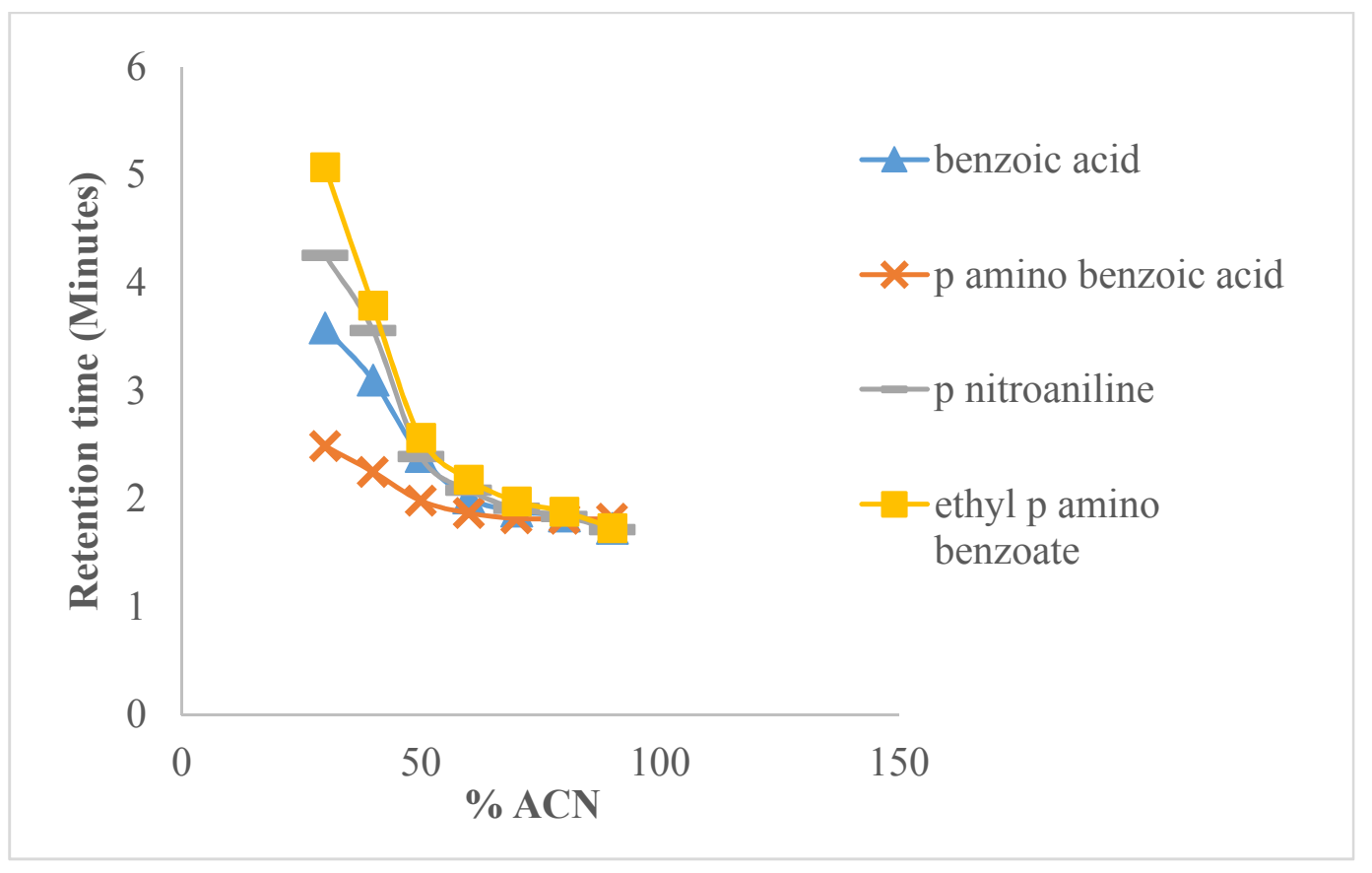

Figure 19. Retention time plot of small organic molecules

\subsection{Polycyclic aromatic hydrocarbons (PAHs)}

Stock solutions of PAH's such as naphthalene, fluorene, and acenapthene were prepared by dissolving $1 \mathrm{mg} / \mathrm{mL}$ of the samples in solvent. Sample solutions to be used on the HPLC were made from this stock solution. The solvent used for dissolving acenapthene and fluorene was 100\% ACN while naphthalene was dissolved in 50:50 (DI water/ACN premixed with $0.1 \%$ formic acid. Isocratic runs were conducted on all three molecules between $40 \%$ and $90 \%$ concentration of ACN. The least retention time was observed for naphthalene followed by fluorene and acenapthene. The retention time data and plots for the PAH's are shown in Table 10 and Figure 20. As can be seen from the plots, the retention times of all three molecules decreases with an increase in concentration of $\mathrm{ACN}$ in the mobile phase, thus confirming the reverse-phase retention mechanism for these non-polar compounds. 
Table 10. Retention time data for polycyclic aromatic hydrocarbons

\begin{tabular}{|c|c|c|c|c|}
\hline \multicolumn{2}{|c|}{ Concentration (\%) } & \multicolumn{3}{c|}{ Retention time (Minutes) } \\
\hline $\begin{array}{c}\text { DI Water } \\
+ \\
0.1 \% \text { Formic acid }\end{array}$ & $\begin{array}{c}\text { ACN } \\
+ \\
0.1 \% \text { Formic acid }\end{array}$ & Naphthalene & Fluorene & Acenapthene \\
\hline 60 & 40 & 8.747 & 13.746 & $*$ \\
\hline 50 & 50 & 4.772 & 6.334 & 13.457 \\
\hline 40 & 60 & 3.220 & 3.751 & 6.381 \\
\hline 30 & 70 & 2.507 & 2.703 & 3.833 \\
\hline 20 & 80 & 2.146 & 2.156 & 2.770 \\
\hline 10 & 90 & 1.972 & 1.864 & 2.256 \\
\hline
\end{tabular}




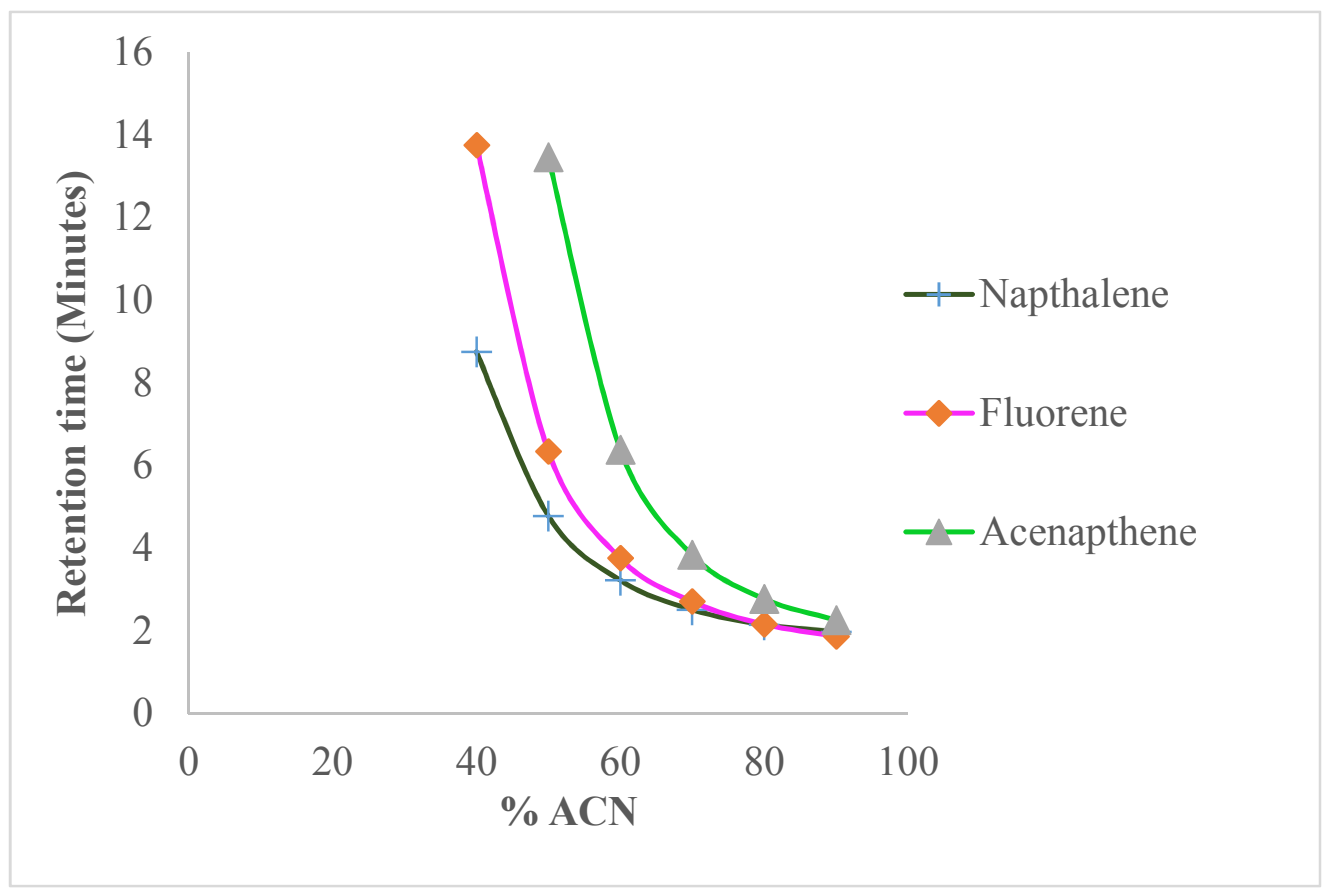

Figure 20. Retention time plot for polycyclic aromatic hydrocarbons

\subsection{Miscellaneous}

The last set of compounds tested on the columns were thiamine hydrochloride and creatinine. Creatinine is the breakdown product of creatine and belongs to the class of ergogenic acids. Creatinine is chiefly filtered out of the blood by the kidneys and their levels in physiological samples such as urine and blood is indicative of the kidney health of an individual.

Thiamine (vitamin B1) is an essential vitamin for aerobic metabolism, cell growth, transmission of nerve impulses, and acetylcholine synthesis. Vitamin B1 is also essential to maintain a healthy heart and nerves and lack of it may lead to heart failure/ nervous problems. Both the samples were dissolved in 50:50 DI water/ACN premixed with $0.1 \%$ formic acid (v/v) and isocratic runs were conducted between $30-80 \%$ 
compositions of ACN. Both the samples clearly showed a normal phase retention mechanism, with an increase in retention observed as the concentration of $\mathrm{ACN}$ was increased in the mobile phase as shown in Figure 21. The retention time data is given in Table 11.

Table 11. Retention time data for miscellaneous compounds

\begin{tabular}{|c|c|c|c|}
\hline \multicolumn{2}{|c|}{} & \multicolumn{2}{c|}{ Retention time (Minutes) } \\
\hline $\begin{array}{c}\text { DI Water } \\
+ \\
0.1 \% \text { Formic acid }\end{array}$ & $\begin{array}{c}\text { ACN } \\
+ \\
0.1 \% \text { Formic acid }\end{array}$ & Creatinine & Thiamine HCl \\
\hline 70 & 30 & 1.754 & 1.821 \\
\hline 60 & 40 & 1.915 & 1.856 \\
\hline 50 & 50 & 1.925 & 1.972 \\
\hline 40 & 60 & 1.884 & 2.438 \\
\hline 30 & 70 & 2.245 & 3.753 \\
\hline 20 & 80 & 2.742 & 8.494 \\
\hline 10 & 90 & 4.031 & 9.876 \\
\hline
\end{tabular}




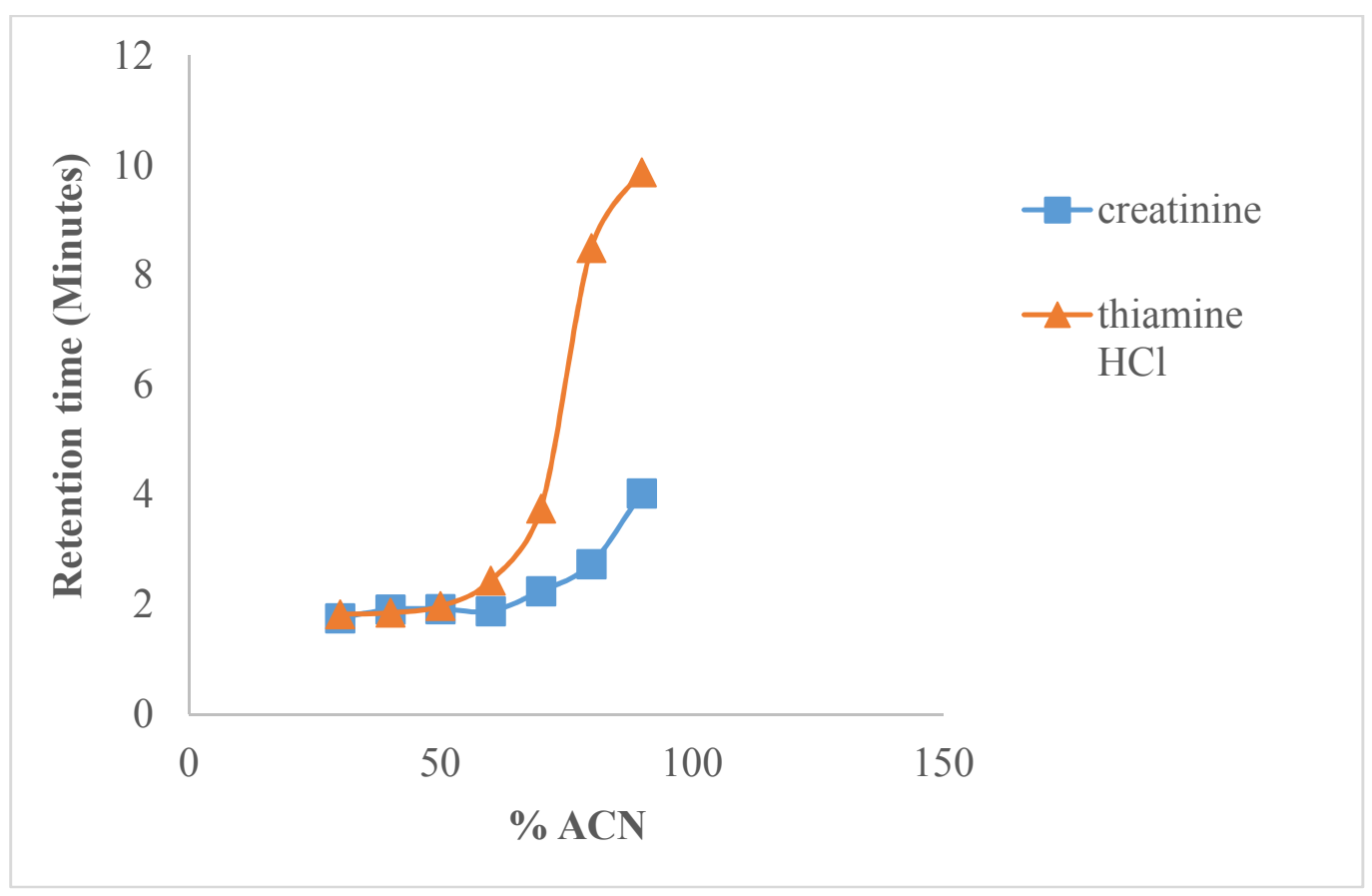

Figure 21. Retention time plots for miscellaneous compounds

\section{B. Retention study with a change in the additive concentration}

Polar compounds such as L-tryptophan, adenine, cytosine, and thiamine and nonpolar compounds such as naphthalene and fluorene were used to study the effect of varying buffer/additive concentrations on the retention time. Stock solutions of all solutes were prepared by dissolving $1 \mathrm{mg}$ of the compound in $1 \mathrm{~mL}$ of the solvent. The solvents used were the same as for the characterization studies. Sample solutions used for the retention time determinations were prepared by pipetting $100 \mu \mathrm{L}$ of the stock and mixing with $900 \mu \mathrm{L}$ of the solvent. The instrument parameters used were the same as earlier.

DI water (solvent A) and ACN (solvent B) were prepared with different concentrations of formic acid. The amounts of the formic acid used were $0.05 \%$, 
$0.075 \%, 0.1 \%, 0.2 \%$, and $0.3 \% \mathrm{v} / \mathrm{v}$. L-tryptophan, adenine, and cytosine were studied at a 20:80 (A: B) composition while a 30:70 (A: B) was used for thiamine for each new additive concentration. The non-polar compounds were tested at a 60:40 (A: B). The retention time data and plots for the polar compounds are given in Table12 and Figure 22. Table 13 provides the retention time data and Figure 23 shows the retention map for the non-polar compounds. While no significant trend can be inferred for the non-polar compounds, there was a slight decrease in retention time observed with an increase in the additive concentration for the tested polar compounds. This trend observed was opposite to that of hydrophilic interaction liquid chromatography (HILIC), that is based on type B silica based columns and separates only polar compounds. ${ }^{32}$ In the case of HILIC, when the formic acid concentration in the mobile phase increases, it readily partitions into the water layer on the polar silanol surface thereby causing an increase in the polarity of the surface and resulting in an increase in retention time for the polar compounds. For nonpolar compounds, the interaction happens with the silica hydride surface that has very low or negligible polar silanol group, and thus the retention is unaffected by the change in concentration of the formic acid. This experiment thus proves that the ANP retention is based on an adsorption mechanism as opposed to a partition mechanism suggested for HILIC. 
Table 12. Retention time data for polar compounds at varying formic acid concentrations

\begin{tabular}{|c|c|c|c|c|}
\hline \multirow{2}{*}{ \% Formic acid } & \multicolumn{4}{|c|}{ Retention time (Minutes) } \\
\cline { 2 - 5 } & $\begin{array}{c}\text { L-tryptophan } \\
80 \mathrm{~B}\end{array}$ & $\begin{array}{c}\text { Adenine } \\
80 \mathrm{~B}\end{array}$ & $\begin{array}{c}\text { Cytosine } \\
80 \mathrm{~B}\end{array}$ & Thiamine HCl 70B \\
\hline 0.050 & 2.936 & 4.983 & 3.435 & 4.481 \\
\hline 0.075 & 2.700 & 4.381 & 2.862 & 3.277 \\
\hline 0.100 & 2.796 & 4.804 & 3.710 & 3.753 \\
\hline 0.200 & 2.481 & 3.893 & 2.529 & 2.568 \\
\hline 0.300 & 2.293 & 3.361 & 1.966 & 1.918 \\
\hline
\end{tabular}




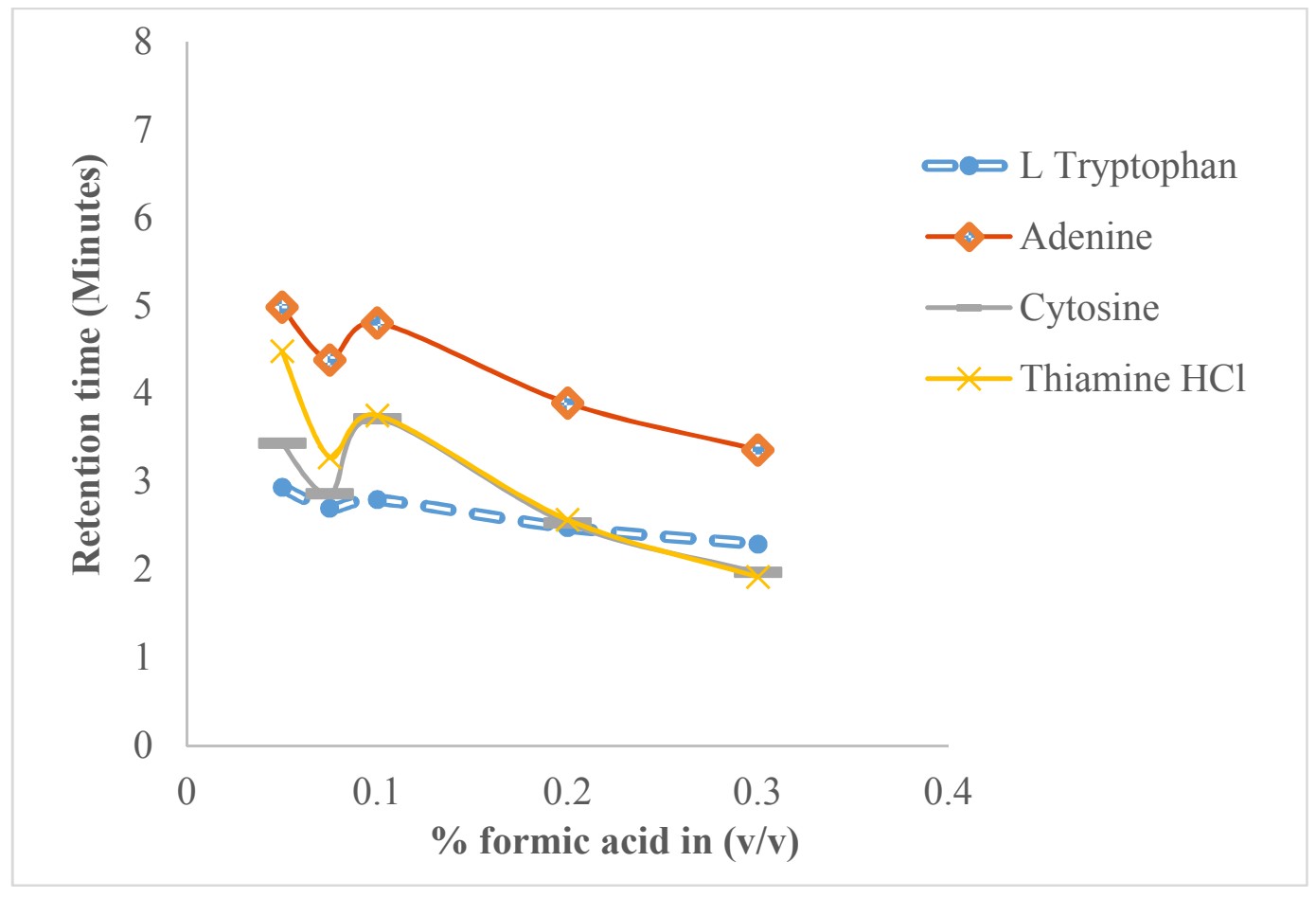

Figure 22. Retention time plots for polar compounds at various concentrations of formic acid

Table 13. Retention time data for non-polar compounds at varying formic acid concentrations

\begin{tabular}{|c|c|c|}
\hline \multirow{2}{*}{ \% Formic acid } & \multicolumn{2}{|c|}{ Retention time (Minutes) } \\
\cline { 2 - 3 } & $\begin{array}{c}\text { Naphthalene } \\
40 \mathrm{~B}\end{array}$ & Fluorene 40B \\
\hline 0.050 & 8.760 & 13.753 \\
\hline 0.075 & 8.811 & 13.868 \\
\hline 0.100 & 8.747 & 13.746 \\
\hline 0.200 & 8.833 & 13.887 \\
\hline 0.300 & 8.780 & 13.740 \\
\hline
\end{tabular}




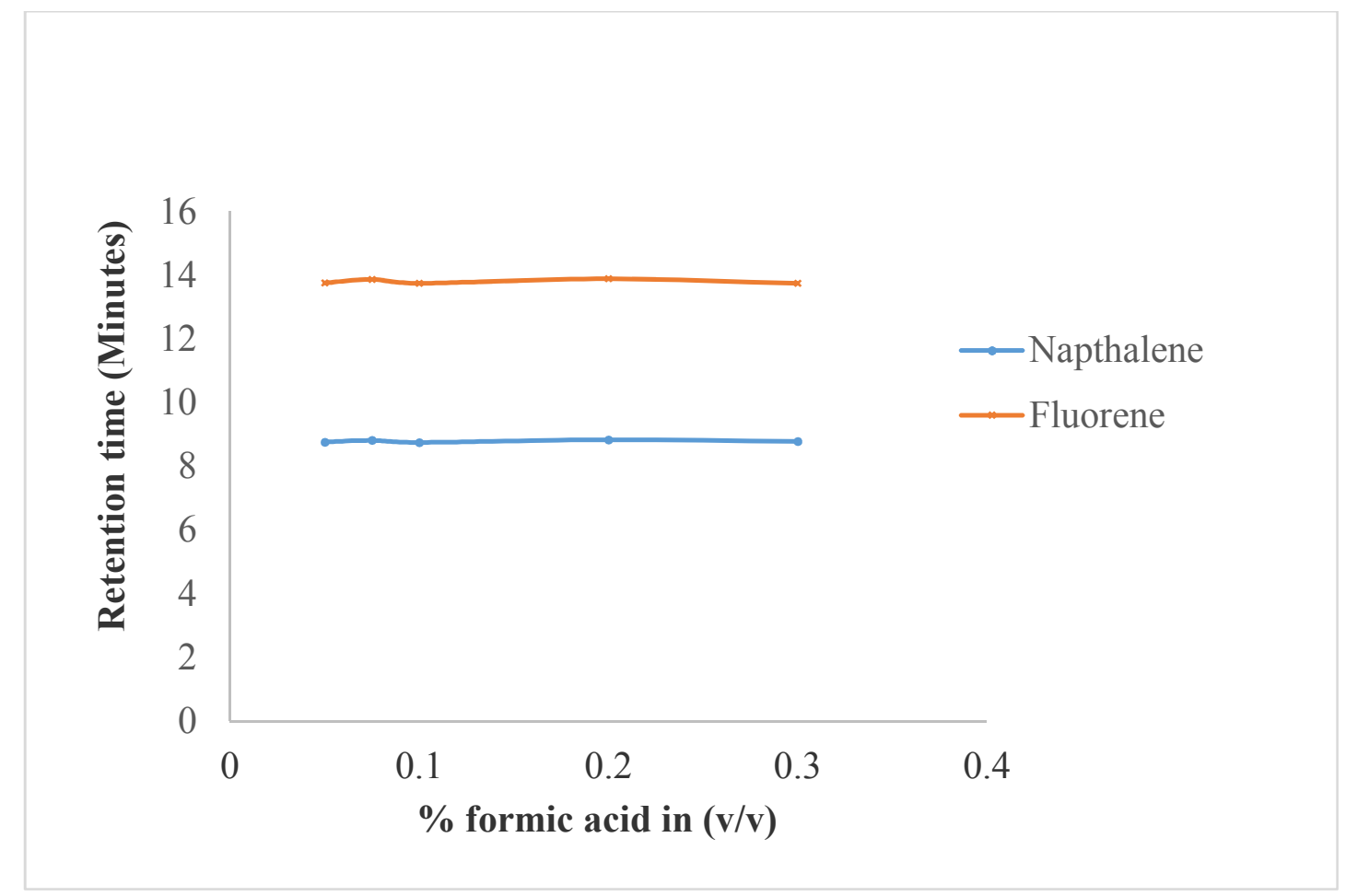

Figure 23. Retention time plots for non-polar compounds at various concentrations of formic acid

\section{Repeat study with various formic acid concentrations}

In order to reconfirm the observed decrease in retention time with an increase in concentration of the formic acid, the runs were repeated for some selected polar compounds such as L-tryptophan, adenine, and cytosine. The results obtained were found to be similar to those obtained earlier, thus demonstrating the reproducibility of the silica hydride based UDA column and the previously observed trend. The retention data and plots for the repeat study are shown in Table 14 and Figure 24. 
Table 14. Retention time data for selected polar compounds at varying formic acid concentrations-repeat study

\begin{tabular}{|c|c|c|c|}
\hline \multirow{2}{*}{ \% Formic acid } & \multicolumn{3}{|c|}{ Retention time (Minutes) } \\
\cline { 2 - 4 } & $\begin{array}{c}\text { L-Tryptophan } \\
80 \mathrm{~B}\end{array}$ & Adenine 80B & Cytosine 80B \\
\hline 0.050 & 2.733 & 5.206 & 3.305 \\
\hline 0.075 & 2.534 & 4.710 & 2.842 \\
\hline 0.100 & 2.806 & 5.372 & 3.380 \\
\hline 0.200 & 2.279 & 4.137 & 2.491 \\
\hline 0.300 & 2.071 & 3.640 & 2.207 \\
\hline
\end{tabular}




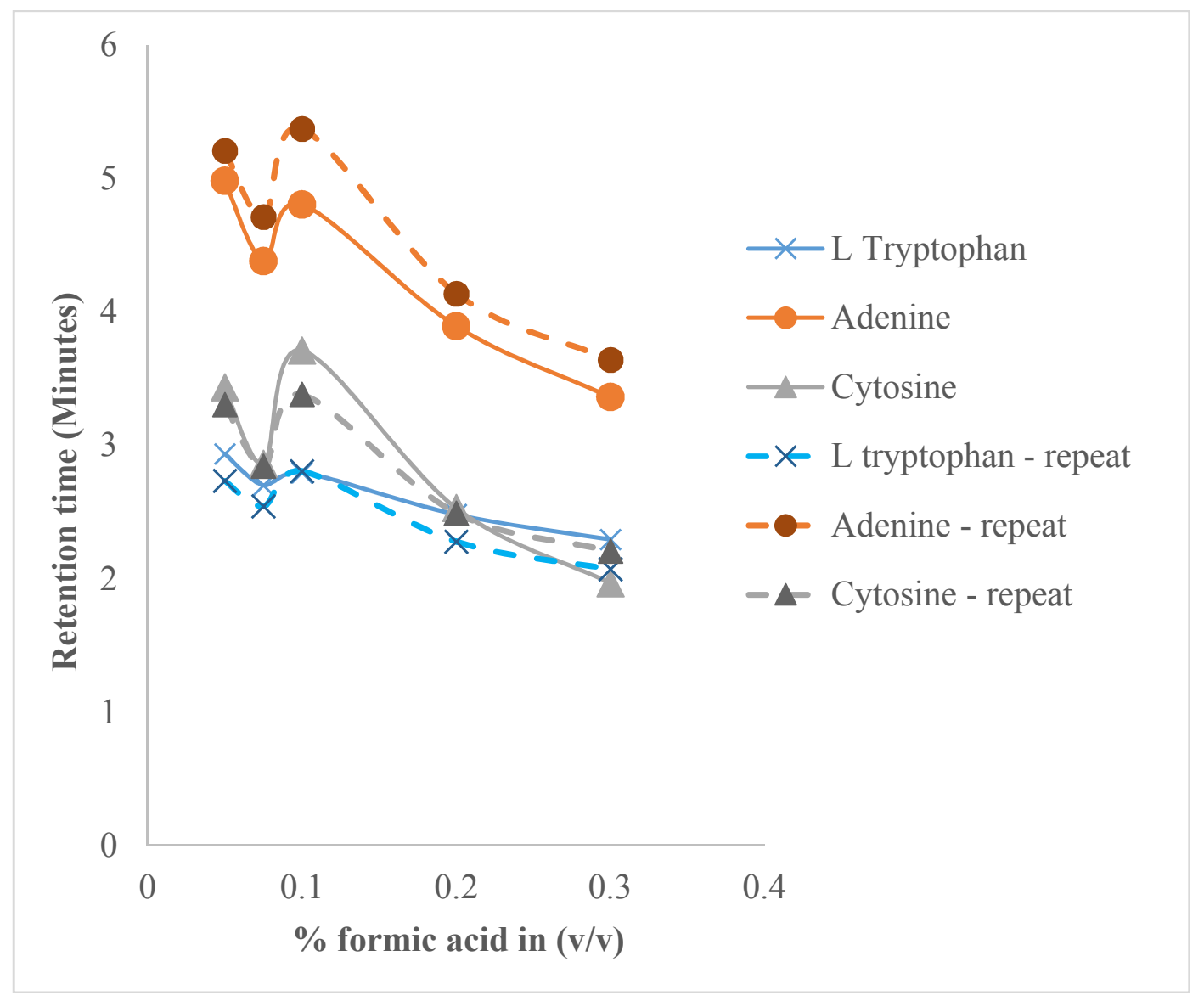

Figure 24. Retention time plots for selected polar compounds at various concentrations of formic acid - repeat study

\section{Compatibility of ammonium acetate as an additive}

A stock solution of ammonium acetate with a concentration of $128.72 \mathrm{mM}$ was made by diluting ammonium acetate in water and stored in the refrigerator. Sample solutions of polar compounds such as L-tryptophan, adenine, cytosine and uracil were prepared from a stock solution having a concentration of $1 \mathrm{mg} / \mathrm{mL}$. A non-polar compound, acenapthene was also tested. Solvent A was DI water and solvent B acetonitrile and each of the solvents was diluted with the required volume of stock ammonium acetate solution to get the desired concentration of $10 \mathrm{mM}$ ammonium 
acetate. Isocratic runs were conducted at mobile phase compositions ranging from 50\% and $85 \%$ acetonitrile and each run was repeated three times and the retention time measured. The data is tabulated in Table 15 and the retention time plots are shown in Figure 25.

For each of the polar compounds, an increase in retention time was observed with an increase in concentration of acetonitrile displaying a typical normal phase retention mechanism, while for acenapthene there was a decrease in retention time with an increase in the ACN concentration in mobile phase and this was typical of reverse-phase retention. For both polar and non-polar compounds the trend observed with ammonium acetate additive was similar as seen in the case of formic acid additive. These studies indicate the compatibility of ammonium acetate as an additive with the silica hydride-based UDA column. 
Table 15. Retention time data for compounds at $10 \mathrm{mM}$ ammonium acetate concentration

\begin{tabular}{|c|c|c|c|c|c|}
\hline \multirow{2}{*}{ ACN (\%) } & \multicolumn{5}{|c|}{ Retention time (Minutes) } \\
\cline { 2 - 6 } & L-tryptophan & Adenine & Cytosine & Uracil & Acenapthene \\
\hline 50 & 2.237 & 2.867 & 2.258 & 1.756 & 6.906 \\
\hline 60 & 2.339 & 2.955 & 2.402 & 1.798 & 3.985 \\
\hline 65 & 2.313 & 3.320 & 2.605 & 1.817 & 3.353 \\
\hline 70 & 2.806 & 3.219 & 2.733 & 1.868 & 2.837 \\
\hline 75 & 3.040 & 3.251 & 2.952 & 1.871 & 2.554 \\
\hline 85 & 3.634 & 3.693 & 3.304 & 2.022 & 2.096 \\
\hline
\end{tabular}




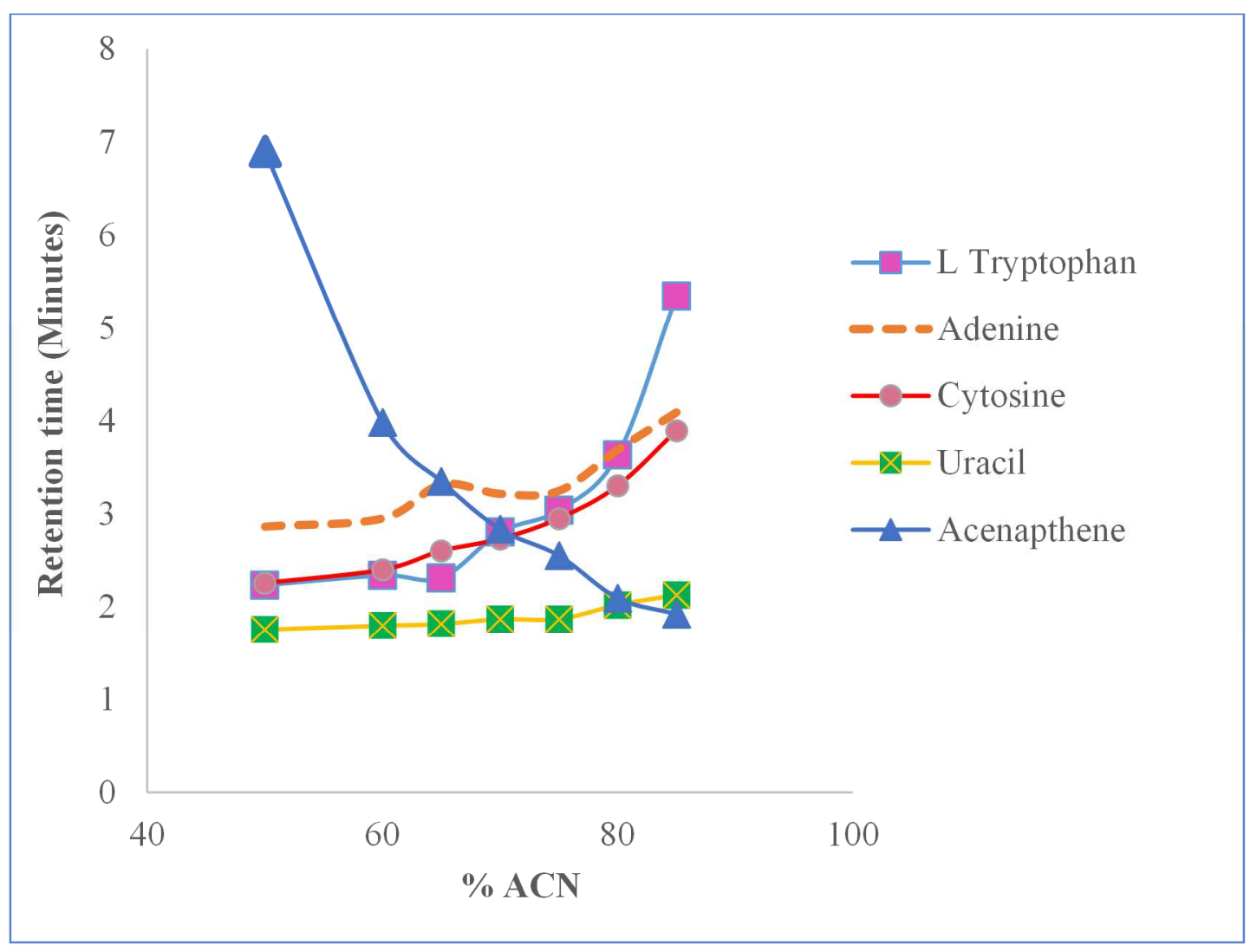

Figure 25. Retention time plots for compounds at $10 \mathrm{mM}$ ammonium acetate concentration

\section{E. Retention study with varying concentrations of ammonium acetate additive}

Various concentrations of the buffer were pipetted from the stock solution and added to each of the solvents (DI water and $\mathrm{ACN}$ ) to get strengths of $1 \mathrm{mM}, 2 \mathrm{mM}, 5$ $\mathrm{mM}$, and 15mM. Four different polar compounds, adenine, cytosine, uracil, and L-tryptophan were studied at a 30:70 (A: B) solvent ratio for each different concentration of ammonium acetate. No pronounced trend could be inferred from such a retention study as can be seen from Table 16 and Figure 26 shows the retention time and plot for such data respectively. All the compounds showed a reduction in retention time for $2 \mathrm{mM}$ concentration and this increased at $5 \mathrm{mM}$ and thereafter not much of a significant 
change could be seen. A possible explanation for the above trend could be the buffer out powering the analyte for adsorption on the stationary phase surface with an increase in $\mathrm{pH}$ as the strength of the buffer is increased.

At each of the above concentrations, the $\mathrm{pH}$ of the solvent was found to be in the 6.5-7 range. Above a $\mathrm{pH}$ of 6 , the ion-exchange property of the column is also expected to play a major role in the retention. With a change in $\mathrm{pH}$, the surface properties of the stationary phase is thus expected to change depending on the extent of ionization of the carboxylic acid group of the undecynoic acid and this could also be another factor for the observed trend for polar and non-polar compounds. At an acidic $\mathrm{pH}$, the carboxylic acid group on the undecynoic acid is protonated (unionized) and polar compounds are retained by interacting with the lone pair electrons on the $(-\mathrm{COOH})$ group of the undecynoic acid. At a basic $\mathrm{pH}$, the carboxylic acid group on the UDA column is ionized and in such a case, retention of polar compounds takes place by the interaction of the opposite charges on the stationary phase and the analyte molecules. In each of the above case, retention of non-polar compounds takes place by interacting with the alkyl group on the stationary phase.

A large retention is observed for adenine and the smallest for uracil. The order of retention time in decreasing order is adenine $>$ cytosine $>$ uracil $>$ L-tryptophan. For non-polar compounds such as acenapthene the retention time decreases initially and then increases at about $15 \mathrm{mM}$. 
Table 16. Retention time data for compounds at varying ammonium acetate concentration

\begin{tabular}{|c|c|c|c|c|}
\hline \multirow{2}{*}{$\begin{array}{c}\text { Concn of } \\
\text { ammonium } \\
\text { acetate }(\mathrm{mM})\end{array}$} & \multicolumn{4}{|c|}{ Retention time (Minutes) } \\
\cline { 2 - 5 } & L-tryptophan & Adenine & Cytosine & Uracil \\
\hline 1 & 2.487 & 4.555 & 3.956 & 1.853 \\
\hline 2 & 2.091 & 3.611 & 2.786 & 1.785 \\
\hline 5 & 3.351 & 3.269 & 2.930 & 1.956 \\
\hline 10 & 2.806 & 3.219 & 2.733 & 1.868 \\
\hline 15 & 2.422 & 3.063 & 2.610 & 1.894 \\
\hline
\end{tabular}




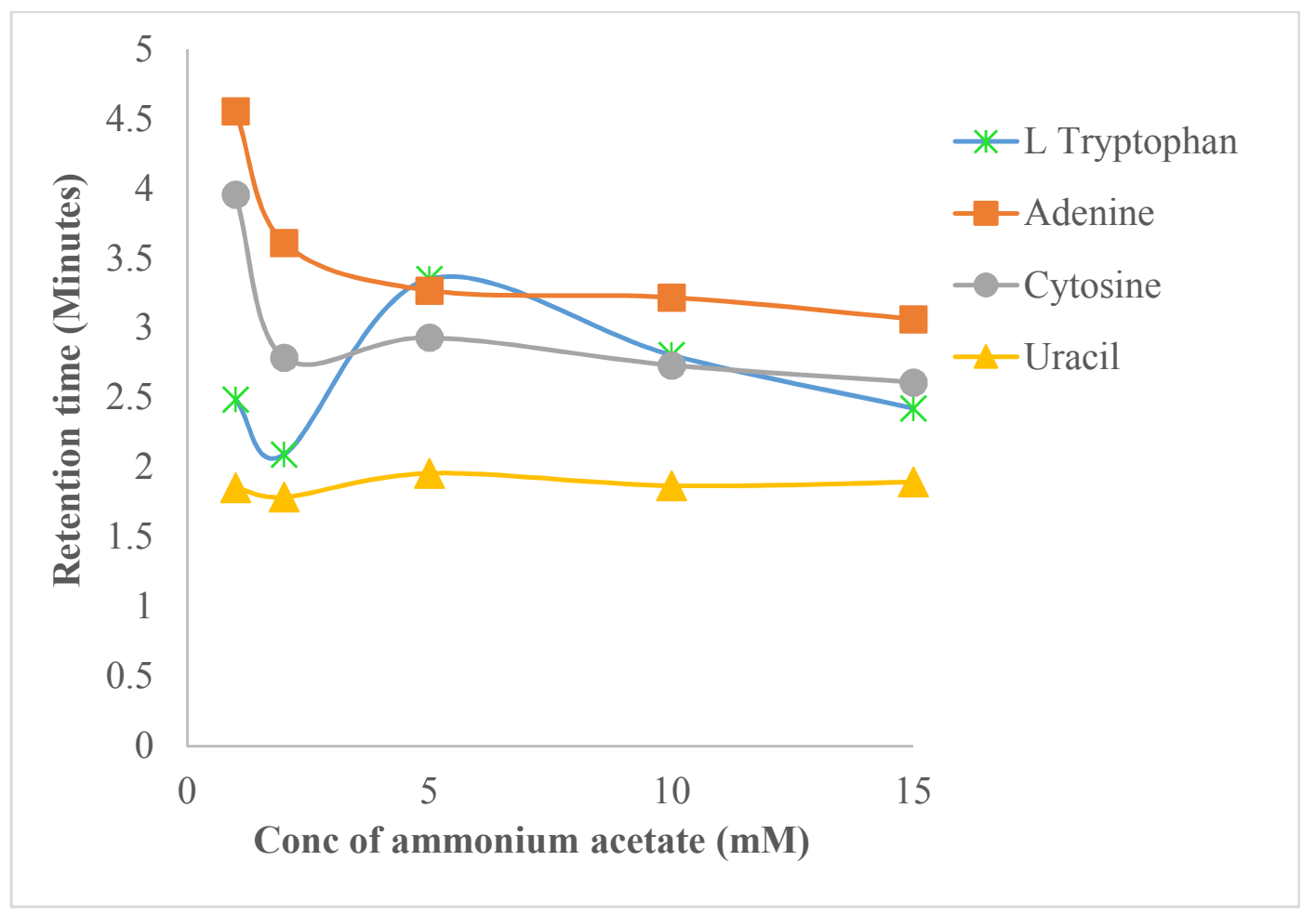

Figure 26. Retention time plots for compounds at varying concentrations of ammonium acetate

\section{F. Effect of temperature on retention}

In order to study the effect of retention with varying temperature, the column oven was varied from $30-55^{\circ} \mathrm{C}$ and the variation in retention time was studied. The retention data is tabulated in Table 17 and the retention plots are shown in Figure 27. The column temperature is plotted on the $\mathrm{x}$-axis and the retention time along the $\mathrm{y}$-axis in each case. It can be inferred from the table and the graph that as the temperature is increased, there is a slight decrease in retention time for one compound. This can be explained as a result of a decrease in viscosity or retention mechanism with an increase in temperature. 
Table 17. Retention time data for compounds at different oven temperature

\begin{tabular}{|c|c|c|c|}
\hline \multirow{2}{*}{$\begin{array}{c}\text { Oven } \\
\text { temperature }\left({ }^{\circ} \mathrm{C}\right)\end{array}$} & \multicolumn{3}{|c|}{ Retention time (Minutes) } \\
\cline { 2 - 4 } & L-tryptophan & Adenine & Cytosine \\
\hline 35 & 2.350 & 4.068 & 2.562 \\
\hline 40 & 2.306 & 3.892 & 2.515 \\
\hline 45 & 2.278 & 3.704 & 2.506 \\
\hline 50 & 2.278 & 3.586 & 2.497 \\
\hline 55 & 2.257 & 3.515 & 2.510 \\
\hline
\end{tabular}




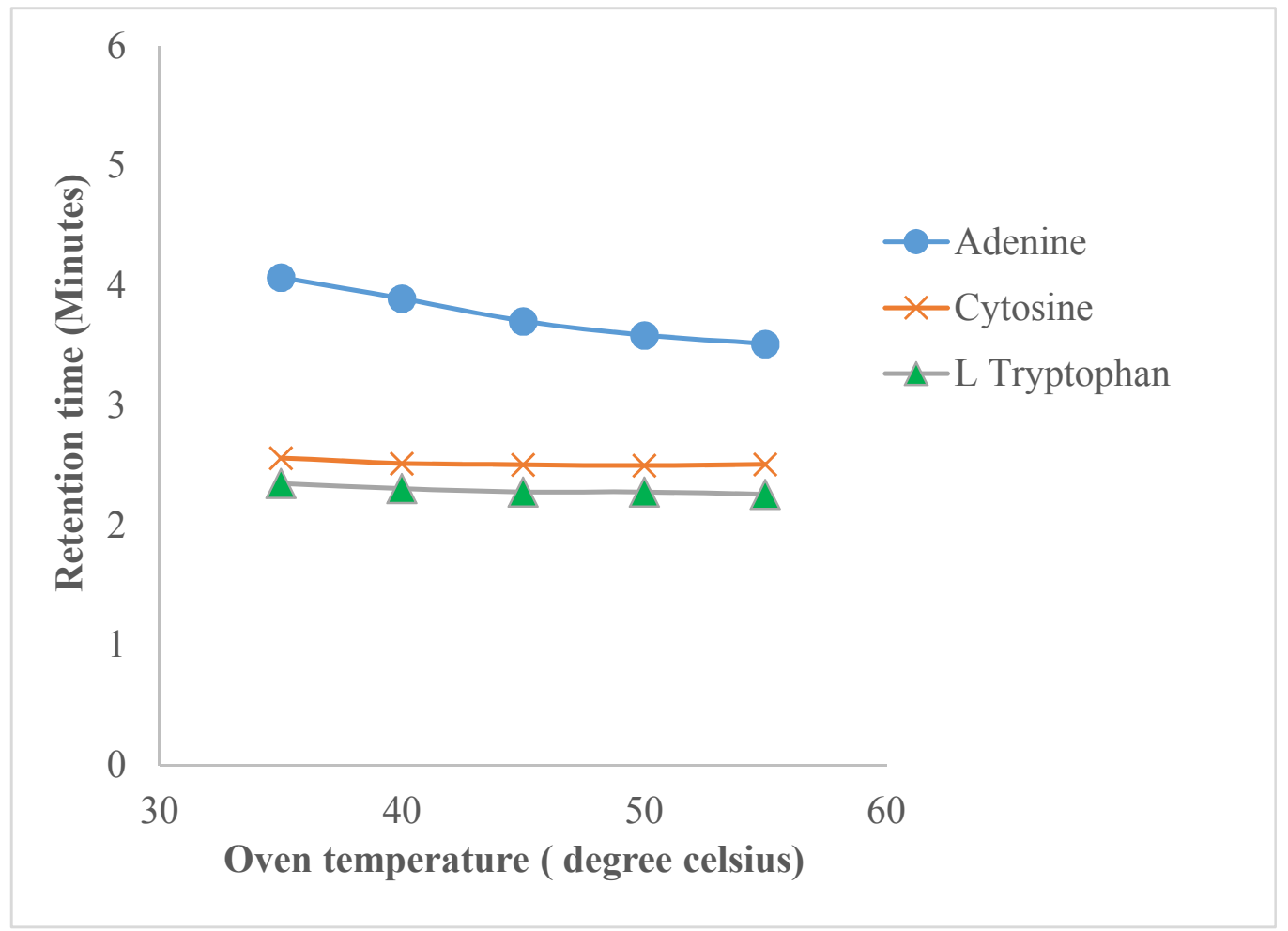

Figure 27. Retention time plots for varying temperature 


\section{APPLICATIONS}

\subsection{Nucleotide characterization}

The nucleotides used for characterization studies of the current column were adenosine monophosphate (AMP) and adenosine triphosphate (ATP) that are the mono and tri phosphorylated forms of adenine, respectively. The retention mechanisms of NAD and NADP that are important coenzymes found in cells were also studied. NAD participates in many cellular redox reactions such as glycolysis and the citric acid cycle of cellular respiration, while NADP is NAD with a third phosphate group is a reducing agent produced in the light reaction of photosynthesis and plays a role in many anabolic reactions of plants and animals. The retention time data and plots for the nucleotides and coenzymes are given in Table 18 and Figure 28.

The stock and sample solutions of all the nucleotides were prepared by their dissolution in DI water. Isocratic runs were conducted at ACN concentrations of $30-85 \%$. For each of the nucleotides, the retention time was found to be higher at the beginning (30\% ACN) and gradually decreased at 50\% ACN for ATP and $60 \% \mathrm{ACN}$ for NAD and NADP, respectively and again increased at $80 \%$ ACN. From the above set of runs, it is clear that these class of compounds are well retained on the UDA column and it is also suitable even to separate their complex mixtures. 
Table 18. Retention time data for nucleotides and coenzymes

\begin{tabular}{|c|c|c|c|c|c|}
\hline \multicolumn{2}{|c|}{ Concentration (\%) } & \multicolumn{4}{c|}{ Retention time (Minutes) } \\
\hline $\begin{array}{c}\text { DI Water } \\
+\end{array}$ & $\begin{array}{c}\text { ACN } \\
+ \\
0.1 \% \text { Formic acid }\end{array}$ & AMP & ATP & NAD & NADP \\
\hline 70 & 30 & 1.900 & 1.471 & 1.513 & 1.521 \\
\hline 60 & 40 & 1.813 & 1.461 & 1.510 & 1.518 \\
\hline 50 & 50 & 1.549 & 1.455 & 1.487 & 1.502 \\
\hline 40 & 60 & 1.567 & 1.484 & 1.478 & 1.478 \\
\hline 30 & 70 & 1.554 & 1.524 & 1.487 & 1.487 \\
\hline 20 & 80 & 1.538 & 1.579 & 1.533 & 1.547 \\
\hline 10 & 90 & 1.582 & 1.598 & 1.601 & 1.605 \\
\hline
\end{tabular}




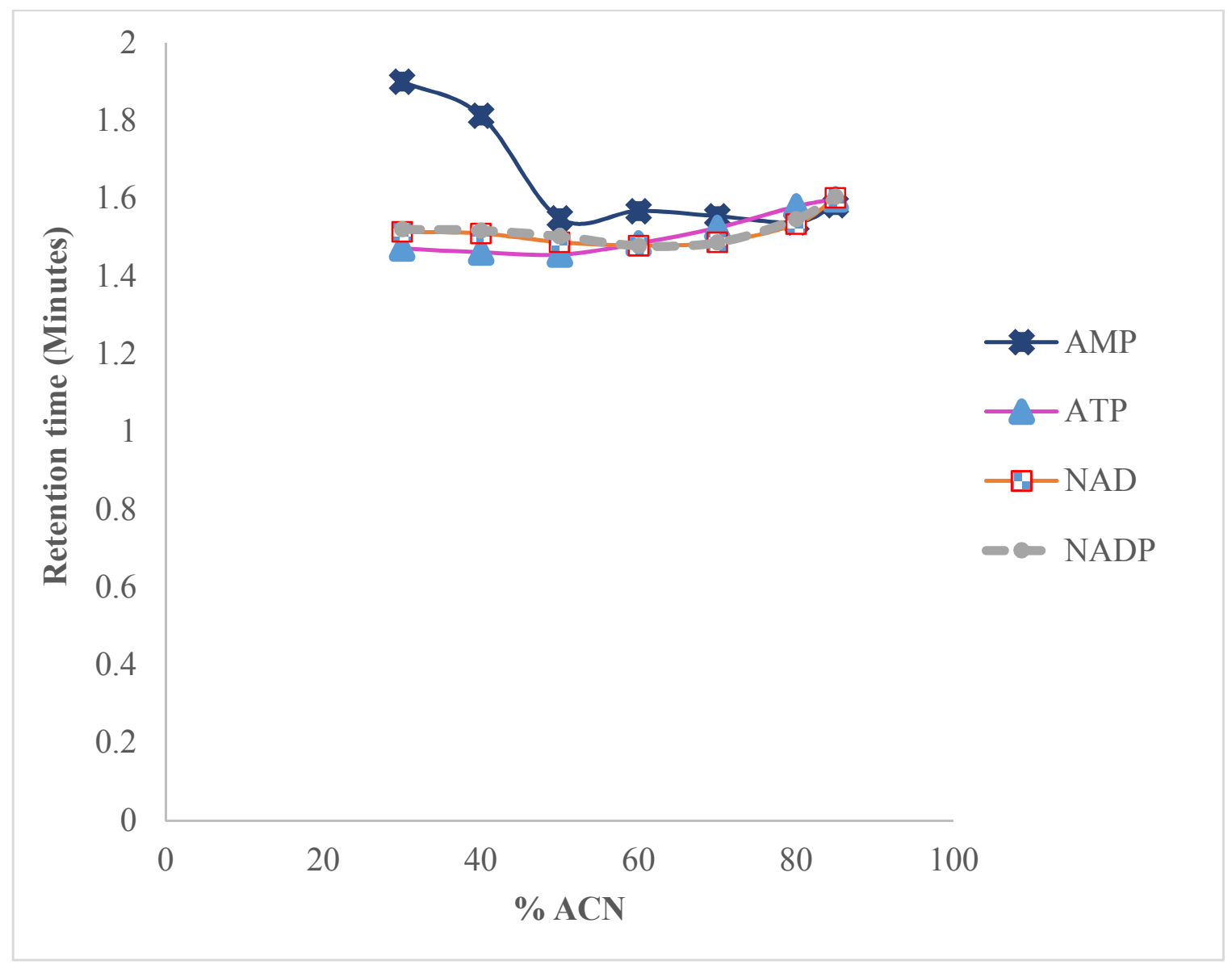

Figure 28. Retention time plot of nucleotides and coenzymes

\subsection{Retention of ATP and NADP at varying formic acid concentrations}

ATP and NADP were used to study the effects of varying additive concentrations on the retention time. Stock solutions of all solutes were prepared by dissolving $1 \mathrm{mg}$ of the compound in $1 \mathrm{~mL}$ of the solvent. The solvents used were the same as for the characterization studies. Sample solutions used for the run were prepared by pipetting $100 \mu \mathrm{L}$ of the stock in $900 \mu \mathrm{L}$ of the same solvent. The instrument parameters used were the same as earlier. 
DI water (solvent A) and ACN (solvent B) were prepared with different concentrations of formic acid. The amounts of the formic acid used were $0.05 \%$, $0.075 \%, 0.1 \%, 0.2 \%$, and $0.3 \% \mathrm{v} / \mathrm{v}$. ATP and NADP were studied at a 20:80 (A:B) composition. The retention time data and plots for the selected compounds are given in Table 19 and Figure 29. While no significant trend can be inferred for ATP, there was a slight increase in retention time observed with an increase in the additive concentration for NADP. Based on the previous set of experiments conducted for the characterization studies, the retention time was found to decrease with an increase in concentration of formic acid, thus clearly distinguishing the ANP and HILIC retention mechanisms. The difference between these results and those obtained earlier is most likely the effect of the carboxylic acid group on the bonded moiety. Thus, ion-exchange effects may also contribute to the retention mechanism. 
Table 19: Retention time data for ATP and NADP

\begin{tabular}{|c|c|c|}
\hline \multirow{2}{*}{$\%$ Formic acid } & \multicolumn{2}{|c|}{ Retention time (Minutes) } \\
\cline { 2 - 3 } & ATP & NADP \\
\hline 0.050 & 1.509 & 1.481 \\
\hline 0.075 & 1.510 & 1.484 \\
\hline 0.100 & 1.504 & 1.482 \\
\hline 0.200 & 1.517 & 1.482 \\
\hline 0.300 & 1.492 & 1.677 \\
\hline
\end{tabular}




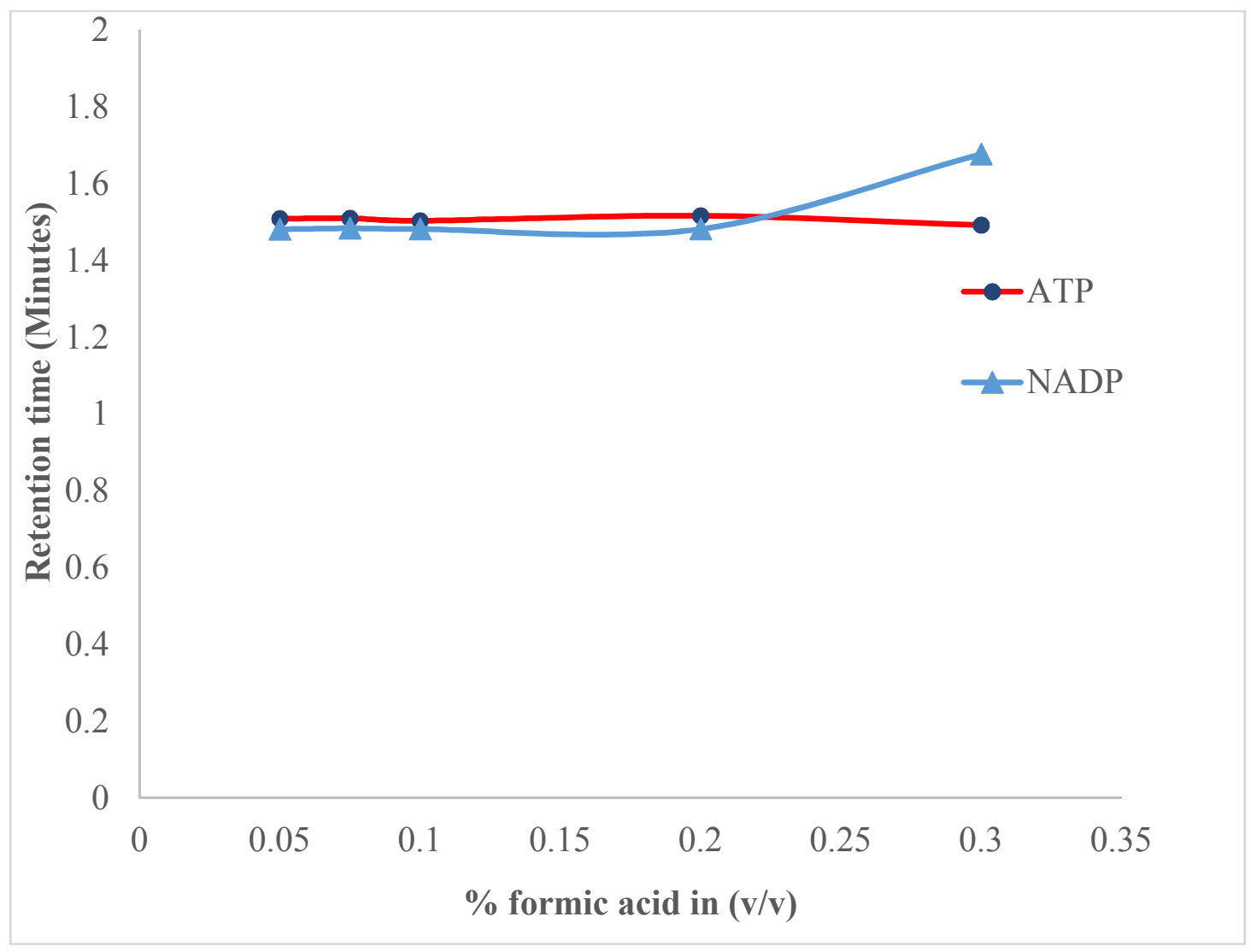

Figure 29. Retention time plot of ATP and NADP

\section{B. Pesticide analysis in urine sample}

Urine samples of farmers were collected for testing the presence of various types of chemicals found in pesticides, such as dimethyl phosphate (DMP), dimethyl thiophosphate (DMTP), dimethyldithiophosphate (DMDTP), diethyl phosphate (DEP), diethyl thiophosphate (DETP), diethyldithiophosphate (DEDTP), and the deuterated derivatives of all these compounds. The chemical structures of DMP, DMTP, DMDTP, DEP, DEDP, and DEDTP are shown in Figure 30.

The $(\mathrm{m} / \mathrm{z})$ and $[\mathrm{M}-\mathrm{H}]^{-}$of all the compounds and their deuterated derivatives are given in Table 20. A fixed volume $(1 \mu \mathrm{L})$ of each of the compound was injected into an 
Agilent 1100 series LC coupled with a Model 6220 TOF detector. The extracted ion chromatogram obtained is shown in Figure 31. As is clearly evident from the extracted ion chromatogram, only DMP-d6 and DEDTP-d10 was detected. These compounds are standards spiked in the samples and are not found in the real samples. This could either indicate the complete absence of the compounds in the urine sample or a lack of sensitivity of the TOF detector. A follow-up study on the MS-MS instrument is suggested to further confirm the results. 

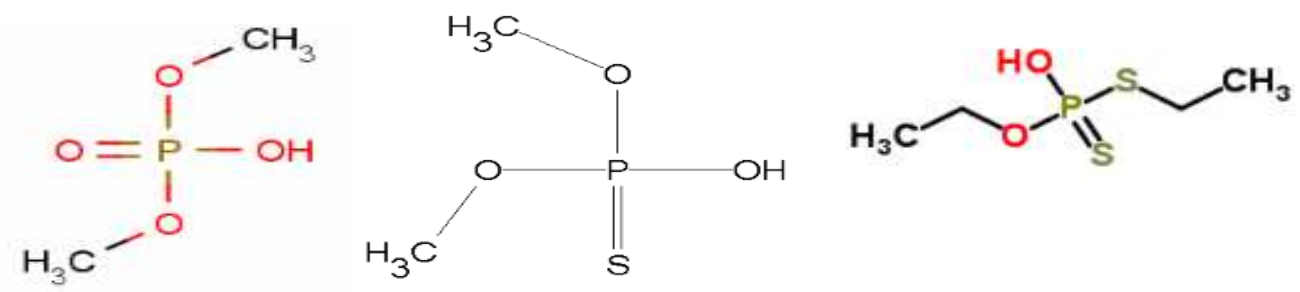

DMP

DMTP

DMDTP

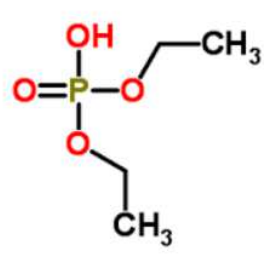

DEP

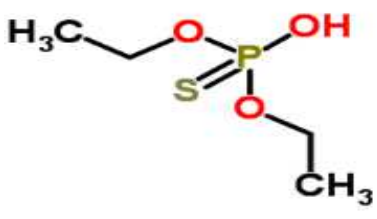

DETP

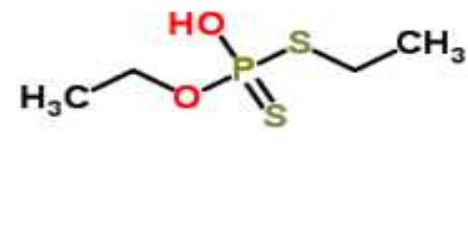

DEDTP

Figure 30. Chemical structures of non-deuterated forms of the compounds analyzed in the pesticide sample 
Table 20. $(\mathrm{m} / \mathrm{z})$ and $[\mathrm{M}-\mathrm{H}]^{-}$of deuterated and non-deuterated components analyzed

\begin{tabular}{|c|c|c|c|}
\hline $\begin{array}{l}\text { Name of } \\
\text { compound }\end{array}$ & Formula of anion & $\begin{array}{c}\text { Monoisotopic mass } \\
(\mathrm{m} / \mathrm{z})\end{array}$ & {$[\mathbf{M}-\mathbf{H}]^{-}$} \\
\hline DMP & $\mathrm{C}_{2} \mathrm{H}_{6} \mathrm{O}_{4} \mathrm{P}_{1}$ & 125.0003 & 123.9931 \\
\hline DMTP & $\mathrm{C}_{2} \mathrm{H}_{6} \mathrm{O}_{3} \mathrm{~S}_{1} \mathrm{P}_{1}$ & 140.9775 & 139.9702 \\
\hline DMDTP & $\mathrm{C}_{2} \mathrm{H}_{6} \mathrm{O}_{2} \mathrm{~S}_{2} \mathrm{P}_{1}$ & 156.9546 & 155.9474 \\
\hline DEP & $\mathrm{C}_{4} \mathrm{H}_{10} \mathrm{O}_{4} \mathrm{P}_{1}$ & 153.0316 & 152.0244 \\
\hline DETP & $\mathrm{C}_{4} \mathrm{H}_{10} \mathrm{O}_{3} \mathrm{~S}_{1} \mathrm{P}_{1}$ & 169.0088 & 168.0015 \\
\hline DEDTP & $\mathrm{C}_{4} \mathrm{H}_{10} \mathrm{O}_{2} \mathrm{~S}_{2} \mathrm{P}_{1}$ & 184.9859 & 183.9794 \\
\hline DMP-d6 & $\mathrm{C}_{2} \mathrm{D}_{6} \mathrm{O}_{4} \mathrm{P}_{1}$ & 131.0380 & 130.04 \\
\hline DMTP-d6 & $\mathrm{C}_{2} \mathrm{D}_{6} \mathrm{O}_{3} \mathrm{~S}_{1} \mathrm{P}_{1}$ & 147.0151 & 146.0172 \\
\hline DMDTP-d6 & $\mathrm{C}_{2} \mathrm{D}_{6} \mathrm{O}_{2} \mathrm{~S}_{2} \mathrm{P}_{1}$ & 162.9923 & 161.9944 \\
\hline DEP-d10 & $\mathrm{C}_{4} \mathrm{D}_{10} \mathrm{O}_{4} \mathrm{P}_{1}$ & 163.0944 & 162.1026 \\
\hline DETP-d10 & $\mathrm{C}_{4} \mathrm{D}_{10} \mathrm{O}_{3} \mathrm{~S}_{1} \mathrm{P}_{1}$ & 179.0715 & 178.0798 \\
\hline DEDTP-d10 & $\mathrm{C}_{4} \mathrm{D}_{10} \mathrm{O}_{2} \mathrm{~S}_{2} \mathrm{P}_{1}$ & 195.0487 & 194.057 \\
\hline
\end{tabular}


Scan Frag=140.0V UDA-2x50-Pesticides_A.W-10mMaac_BACNFA_Gr3_neg_284.d

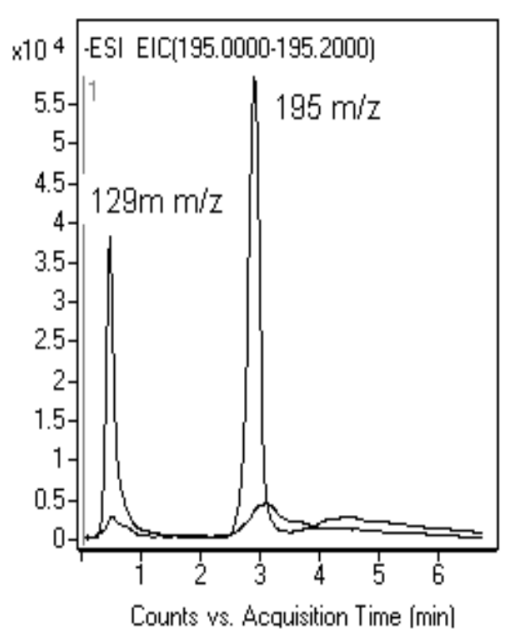

UDA column $2.1 \times 50 \mathrm{~mm}$

A: Dl water'10 mM ammonium acetate

B: acetonitrile $10.1 \%$ formic acid

Flow rate: $0.4 \mathrm{~mL} / \mathrm{min}$

Gr 3

Time (min) \%B Flow rate $\mathrm{mL} / \mathrm{min}$

$0.00 \quad 100.0 \quad 0.400$

$2.00 \quad 95.0 \quad 0.400$

$8.00 \quad 95.0 \quad 0.400$

$\begin{array}{lll}9.00 & 100.0 \quad 0.400\end{array}$

$129 \mathrm{~m} / \mathrm{z}[\mathrm{M}-\mathrm{H}]-=\mathrm{DMP}-\mathrm{d} 6$

$195 \mathrm{~m} / \mathrm{z}[\mathrm{M}]=$ DEDTPd10

Figure 31. Extracted ion chromatograms of standards spiked in urine sample 


\section{Quantification of phenolic acids in pomegranate peel samples on UDA column}

Five different varieties of lyophilized pomegranate peel samples that were grown around Davis, California (CA) were obtained from the UC Davis pomegranate germplasm and forwarded by the United States Department of Agriculture (USDA). The details (names, accession identification numbers (ID's), and place of origin) of these five samples are provided in Table 21. The samples were used to confirm the presence of eight phenolic acid compounds; gallic acid, caffeic acid, catechin, epicatechin, chlorogenic acid, ellagic acid, punicalagin, and rutin. Additionally the phenolic acids were also quantified in the peel samples where they were detected. All the standards were provided by Chromadex Inc, 10005 Muriands Blvd, Ste G, Irvine, California-92618, U.S.A.

Table 21. Accession ID's, names, and place of origin of the various pomegranate peel samples

\begin{tabular}{|c|c|c|}
\hline Accession ID & Pomegranate Cultivar & Country of Origin \\
\hline DPUN0014 & Molla Nepes & Turkmenistan \\
\hline DPUN0015 & Parfianka & Turkmenistan \\
\hline DPUN0117 & Vkusnyi & Turkmenistan \\
\hline DPUN0056 & Purple Heart & United States \\
\hline DPUN0081 & Wonderful & United States \\
\hline
\end{tabular}

Each of the lyophilized samples (1.0565 g of Molla Nepes, $1.0229 \mathrm{~g}$ of Wonderful one, $0.9881 \mathrm{~g}$ of Purple heart, $1.0959 \mathrm{~g}$ of Parfionka, and $1.0129 \mathrm{~g}$ of Vkunsyi) were milled using a coffee grinder and sieved through a $100 \mathrm{mesh} / \mathrm{standard}$ 
sieve. The powdered samples were extracted with $15 \mathrm{~mL}$ of $80 \%$ (v/v) aqueous methanol at room temperature and sonicated for 30 minutes. The solutions were then centrifuged at $2000 \mathrm{~g}$ (gravity) for 10 minutes and the supernatant was collected and extracted three times with $80 \%$ aqueous methanol. The combined supernatant was rotavapored to remove the methanol, and it was further reconstituted to $50 \mathrm{~mL}$ with $80 \%$ aqueous methanol, filtered, and transferred into vials. ${ }^{33}$

Stock solutions of all the standards (except ellagic acid) were prepared by dissolving $1 \mathrm{mg}$ of the solute in $1 \mathrm{~mL}$ of the solvent. The weights of the standards and the solvents used to dissolve each of the 7 standards are provided in Table 22. Table 23 lists the chemical formulae, $(\mathrm{m} / \mathrm{z})$ 's in the positive, and negative ionization modes, and the UV absorbance of each of the 7 phenolic acid standards. The chemical structures of these eight compounds are shown in Figure 32 below. 
Table 22. Weights and solvents used for the phenolic acid standards

\begin{tabular}{|c|c|c|}
\hline Solute & Weight & Solvent used \\
\hline Gallic acid & $10 \mathrm{~g}$ in $10 \mathrm{~mL}$ & $\begin{array}{c}50 \mathrm{ACN}+0 . \% \text { formic acid } \\
: 50 \mathrm{DI} \text { water }+0.1 \% \\
\text { formic acid }\end{array}$ \\
\hline Caffeic acid & $10.3 \mathrm{~g}$ in $10 \mathrm{~mL}$ & $\begin{array}{c}50 \mathrm{ACN}+0 . \% \text { formic acid } \\
: 50 \text { DI water }+0.1 \% \\
\text { formic acid }\end{array}$ \\
\hline Epicatechin & $13.1 \mathrm{~g}$ in $10 \mathrm{~mL}$ & $\begin{array}{c}50 \mathrm{ACN}+0 . \% \text { formic acid } \\
: 50 \mathrm{DI} \text { water }+0.1 \% \\
\text { formic acid }\end{array}$ \\
\hline Rutin & $1.4 \mathrm{mg} \mathrm{in} 1.4 \mathrm{~mL}$ & $\begin{array}{c}100 \% \text { methanol } \\
100 \% \text { ethanol }\end{array}$ \\
\hline Catechin & $1.3 \mathrm{mg}$ in $1.3 \mathrm{~mL}$ & $100 \%$ methanol \\
\hline Punicalagin & $1.7 \mathrm{mg}$ in $1.7 \mathrm{~mL}$ & $100 \%$ ethanol \\
\hline Chlorogenic acid & & \\
\hline
\end{tabular}


Table 23. Chemical formulae, $(\mathrm{m} / \mathrm{z})$ 's in positive, and negative ionization modes, and UV absorbance of the phenolic acid standards

\begin{tabular}{|c|c|c|c|c|}
\hline $\begin{array}{c}\text { Phenolic } \\
\text { compound }\end{array}$ & Formula & {$[\mathbf{M}+\mathbf{H}]^{+}$} & {$\left[\mathbf{M}+\mathbf{H}^{-}\right.$} & UV(nm) \\
\hline Gallic acid & $\mathrm{C}_{7} \mathrm{H}_{6} \mathrm{O}_{5}$ & 171.0288 & 169.0142 & 270 \\
\hline Punicalagin & $\mathrm{C}_{48} \mathrm{H}_{28} \mathrm{O}_{3}$ & 1085.0738 & 1083.0593 & $270(255)$ \\
\hline Catechin & $\mathrm{C}_{15} \mathrm{H}_{14} \mathrm{O}_{6}$ & 291.0863 & 289.0718 & 270 \\
\hline $\begin{array}{c}\text { Chlorogenic } \\
\text { acid }\end{array}$ & $\mathrm{C}_{16} \mathrm{H}_{18} \mathrm{O}_{9}$ & 355.1024 & 353.0878 & 320 \\
\hline Caffeic acid & $\mathrm{C}_{9} \mathrm{H}_{8} \mathrm{O}_{4}$ & 181.0495 & 179.0350 & 320 \\
\hline Epicatechin & $\mathrm{C}_{15} \mathrm{H}_{14} \mathrm{O}_{6}$ & 291.0863 & 289.0718 & 270 \\
\hline Rutin & $\mathrm{C}_{27} \mathrm{H}_{30} \mathrm{O}_{16}$ & 611.1607 & 609.1461 & 270 \\
\hline Ellagic acid & $\mathrm{C}_{14} \mathrm{H}_{6} \mathrm{O}_{8}$ & 303.0135 & 300.9990 & 255 \\
\hline
\end{tabular}



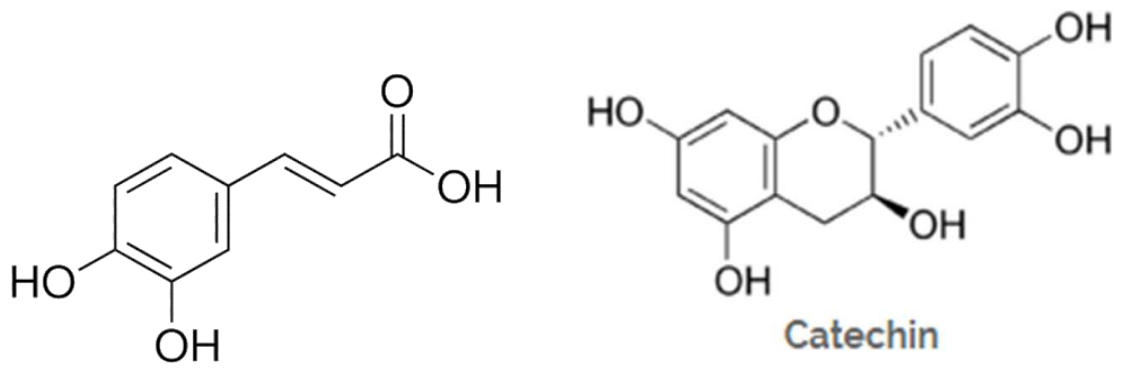

Caffeic acid<smiles>Oc1cc(O)c2c(c1)O[C@H](c1ccc(O)c(O)c1)[C@H](O)C2</smiles><smiles>O=c1oc2c(O)c(O)cc3c2c2c1oc(=O)c1cc(O)c(O)c-2c13</smiles>

Ellagic acid

Figure 32. Chemical structures of the phenolic acids being identified and quantified 


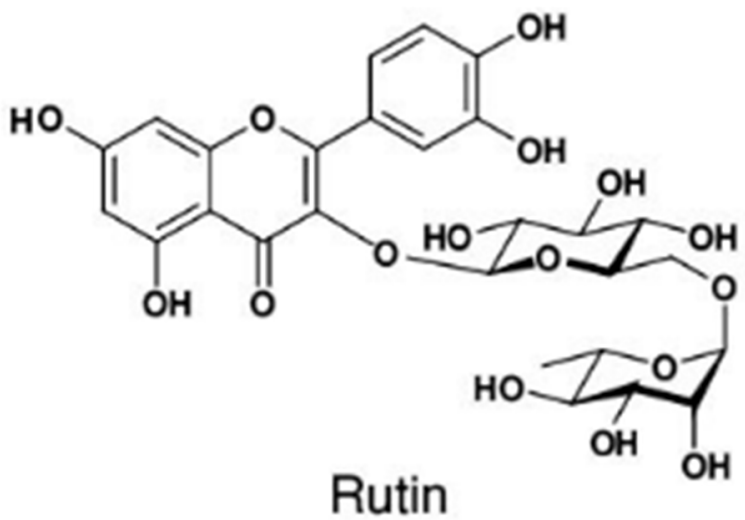<smiles>O=C(O)c1cc(O)c(O)c(O)c1</smiles>

Gallic acid<smiles>O=c1oc2c(O)c(O)cc3c2c2c1oc(=O)c1cc(O)c(O)c-2c13</smiles>

Chlorogenic acid

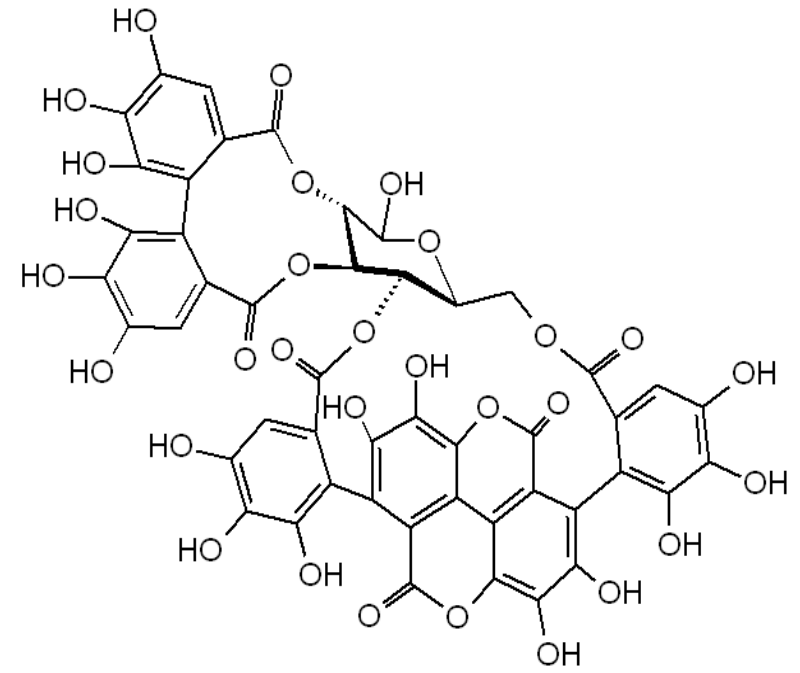

Punicalagin

Figure 32. Chemical structures of the phenolic acids being identified and quantified 
A definite amount $(100 \mu \mathrm{L})$ of each of the 7 standards were dissolved in $300 \mu \mathrm{L}$ of DI water and this standard mix was used to spike each of the pomegranate peel samples. The five pomegranate samples were transferred to vials and run on the 6520 series Q TOF. The retention time (RT) and peak area (PA) were noted for the phenolic acids in each analysis. Tables 24 (a-e) show the retention times and peak areas of the standards, unspiked, and spiked versions of Molla Nepes (MN), Wonderful, Purple heart (PH), Parfionka, and Vkunsyi samples respectively. The injection volume in each case was $5 \mu \mathrm{L}$ and the solvents used were DI water $+0.1 \%$ formic acid (solvent $\mathrm{A}$ ) and ACN $+0.1 \%$ formic acid (solvent B). The flow rate was kept at $0.4 \mathrm{~mL} / \mathrm{min}$. The method used for all solutions was a gradient that started at $15 \%$ B that was increased to $80 \% \mathrm{~B}$ over a period of 4 minutes and then held at $80 \% \mathrm{~B}$ for another two minutes, and later decreased to $15 \%$ B over the next three minutes. A fixed amount $(100 \mu \mathrm{L})$ of the standard stock solution was micro pipetted and diluted with $900 \mu \mathrm{L}$ of the respective solvent and the RT's and PA's were noted in this case too. The presence of a phenolic acid compound was confirmed by comparing the $(\mathrm{m} / \mathrm{z})$ of that particular phenolic acid compound in the pomegranate peel sample with the $(\mathrm{m} / \mathrm{z})$ of that phenolic acid standard. An illustrative example is shown in Figure 33, where the $(\mathrm{m} / \mathrm{z})$ observed for the caffeic acid standard is also seen in the Vkunsyi sample, clearly confirming the presence of this compound in the peel sample.

In order to further confirm that the observed peak for the peel samples was due to the phenolic acid compound, $450 \mu \mathrm{L}$ of each pomegranate peel sample was spiked with $50 \mu \mathrm{L}$ of the standard mix and recording the RT and PA. An increase in the peak area of 
the detected compound confirmed that the observed $(\mathrm{m} / \mathrm{z})$ in the peel sample was due to the presence of the compound being investigated. In some cases the phenolic acid compounds were not detected in the peel samples, but were observed after spiking the samples with the standards. Some surprising results were also seen in samples for certain phenolic acid compounds where there was either a decrease in peak areas or total disappearance of the previously observed peaks after spiking. There has been no reasonable explanation for this observation. Figures 34 and 35 are representative graphs illustrating the comparison of the observed $(\mathrm{m} / \mathrm{z})$ 's in two of the pomegranate peel samples (Parfionka and Vkunsyi) with the standards (rutin and chlorogenic acid). It is clearly evident from these figures that though rutin is detected in both the peel samples, chlorogenic acid is absent in the Parfionka sample as the characteristic peak of this compound (seen in the standard) is absent in this sample.

For the Molla Nepes sample, while there was an increase in the peak areas of gallic acid, rutin, and ellagic acid there was a decrease in the peak areas observed for catechin, epicatechin, punicalagin, and chlorogenic acid. The peak that was observed for caffeic acid was absent after spiking. For the Wonderful sample, while there was an increase in the peak areas of punicalagin, chlorogenic acid, and rutin, a decrease in the peak areas was observed for catechin, epicatechin, and ellagic acid. No chlorogenic acid was present in the peel, while the peak for gallic acid was seen after spiking. For the PH sample too, no gallic acid was present in the peel, while the peak for chlorogenic acid was seen after spiking and there was a decrease in the peak areas observed for all the other phenolic acid compounds. It was interesting to note that there was a drastic 
reduction in the peak areas of catechin and epicatechin after spiking the sample with the standards.

For the Parfianka sample, while there was an increase in the peak areas of rutin, catechin, and epicatechin; there was a decrease in the peak areas observed for gallic acid and punicalagin. The peak for ellagic was visible after spiking while gallic acid and punicalagin was completely absent. For the Vkunsyi sample, there was an increase in the peak areas of gallic acid, and there was a decrease in peak areas for all other compounds except caffeic acid. Two surprising observations for this sample was the disappearance of the caffeic acid after spiking and a great decrease in peak areas of chlorogenic acid after spiking. 
UDA_2x50_Vkusnyi_AFA_BFA_VeenaRPGr1_5uL_04.d

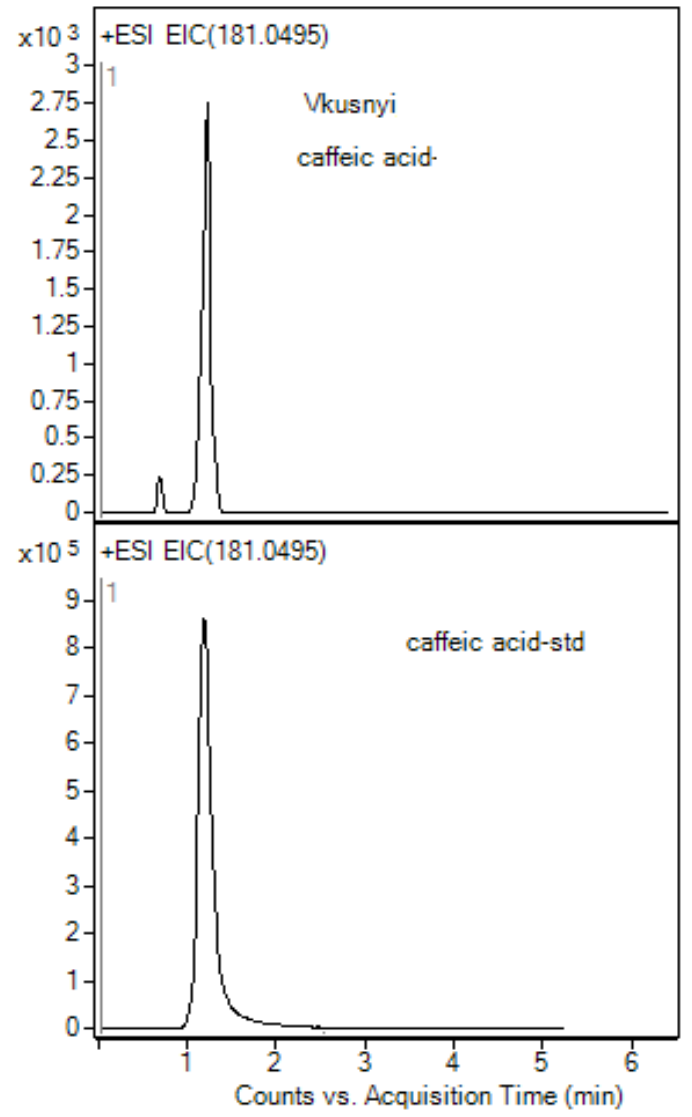

UDA $2.1 \times 50 \mathrm{~mm}$

Gr 1

A: DI water/0.1\%formic acid

B: acetonitrile $/ 0.1 \%$ formic acid

$0.4 \mathrm{~mL} / \mathrm{min}$

$0 \min 15 \% \mathrm{~B}$

$4 \min 80 \% B$

$6 \min 80 \% \mathrm{~B}$

$9 \min 15 \% \mathrm{~B}$

Figure 33. Comparison of caffeic acid standard with Vkunsyi sample 


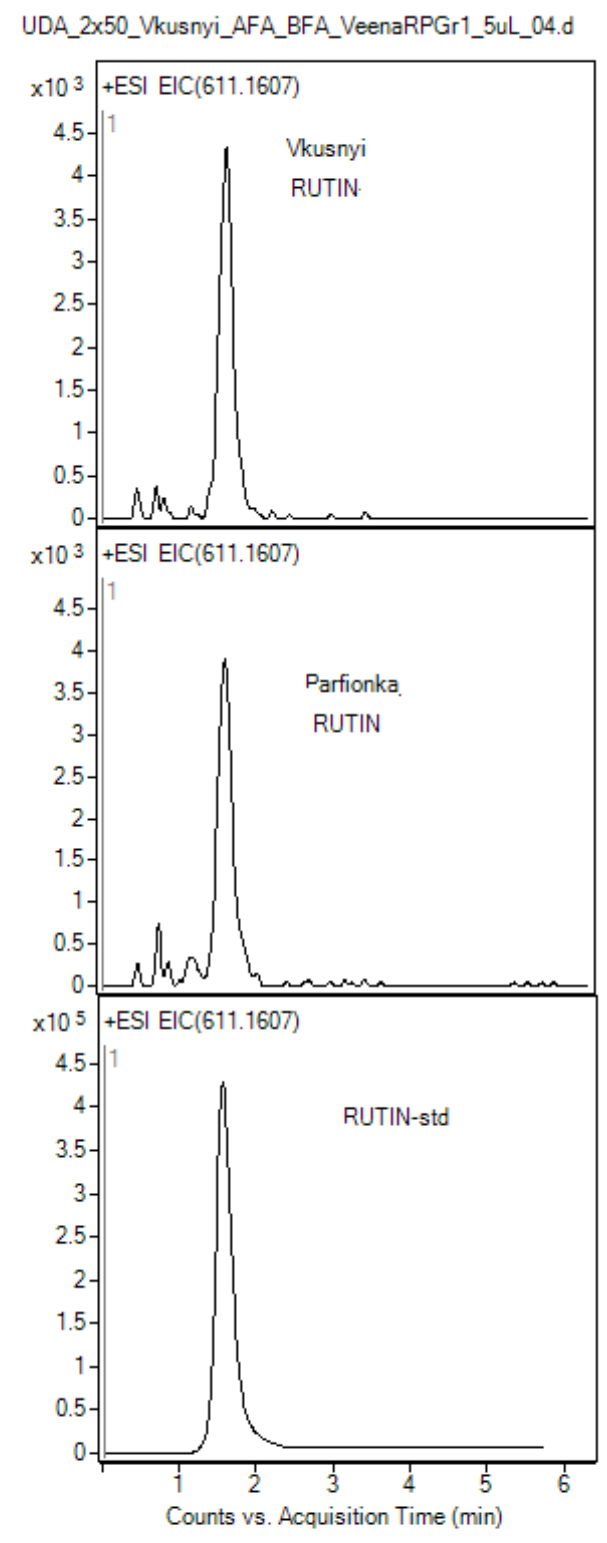

Figure 34. Comparison of Vkunsyi and Parfionka sample with rutin standard 

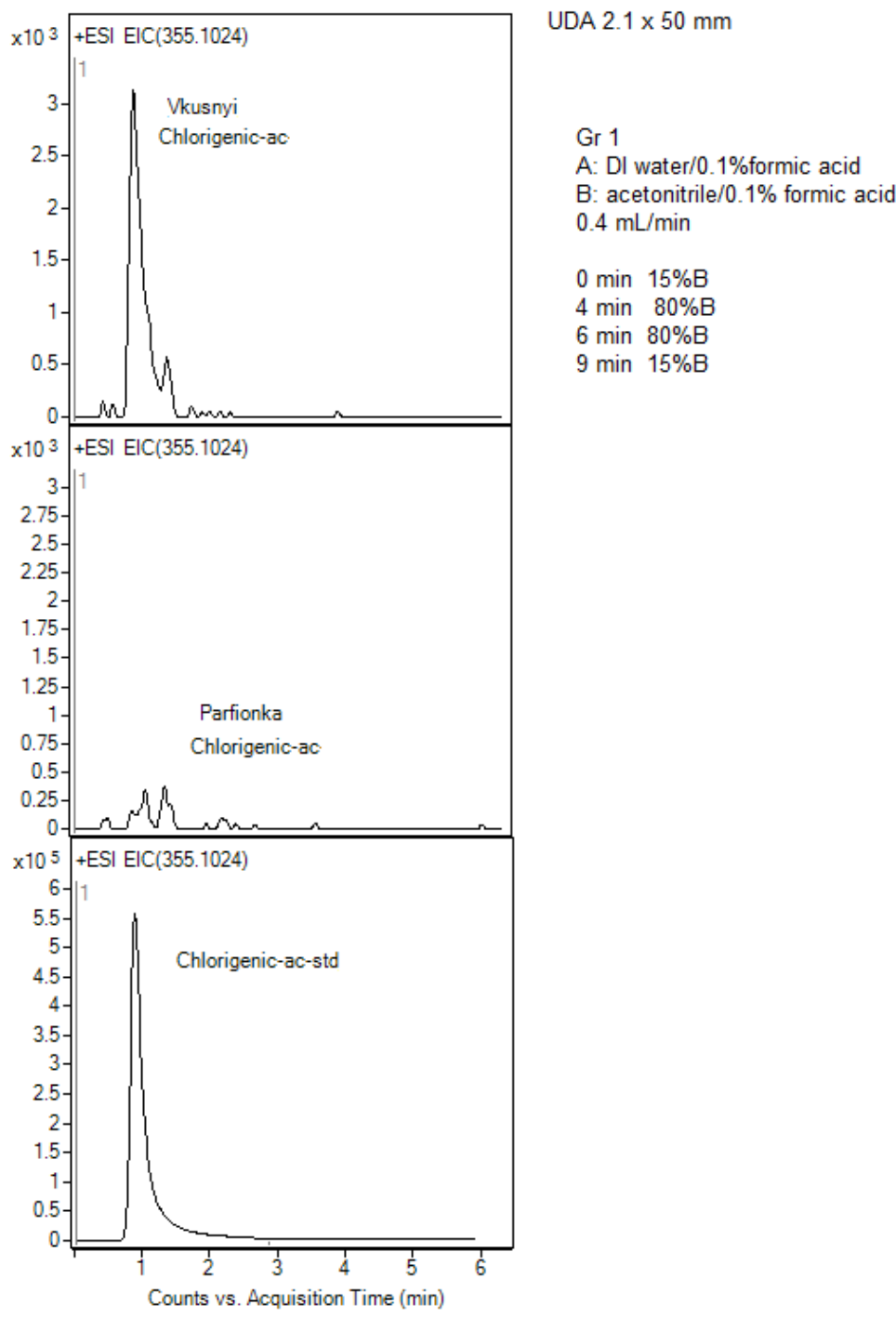

Figure 35. Comparison of Vkunsyi and Parfionka sample with chlorogenic acid standard 
Another interesting observation from the UDA column was that no separation of the isomers, catechin and epicatechin was achieved and this is shown in Figure 36. It is very clear from Figure 36 that the retention time of catechin and epicatechin are very close to each other. A correct quantification of all the eight phenolic acid compounds was thus not possible on the UDA column leading to the use of a phenyl hydride column for investigating if these isomers could be well resolved. 


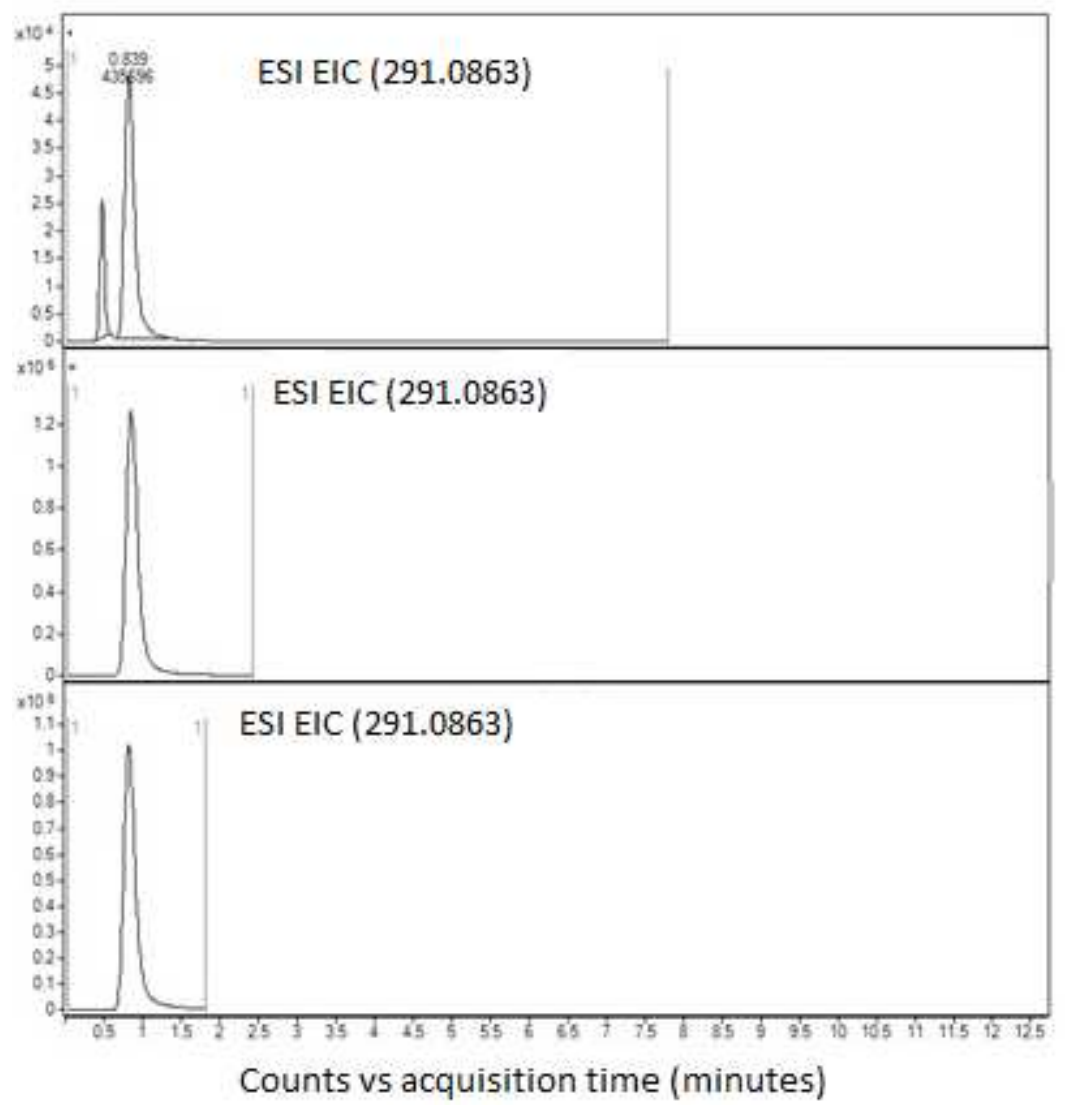

Figure 36. Comparison of retention times of catechin, epicatechin, and spiked Molla Nepes sample 
Table 24a. Retention time and peak areas of standards, unspiked, and spiked Molla Nepes (MN) sample on the UDA column

\begin{tabular}{|c|c|c|c|}
\hline $\begin{array}{c}\text { Phenolic acids } \\
\text { (RT,PA) }\end{array}$ & Standards & $\begin{array}{c}\text { Unspiked MN } \\
(5 \mu \mathrm{L})\end{array}$ & Spiked MN $(5 \mu \mathrm{L})$ \\
\hline Gallic (RT,PA) & $0.655,5819408$ & $0.648,8491$ & $0.651,8961$ \\
\hline Punicalagin (RT,PA) & $0.688,126608$ & $0.730,90319$ & $0.721,69518$ \\
\hline Catechin (RT,PA) & $0.811,10693244$ & $0.848,461640$ & $0.839,435696$ \\
\hline $\begin{array}{c}\text { Chlorogenic Acid } \\
\text { (RT,PA) }\end{array}$ & $0.895,6549993$ & $0.977,4567$ & $0.851,1924$ \\
\hline Caffeic Acid (RT,PA) & $1.191,8893976$ & $1.259,320$ & no peak \\
\hline Epicatechin (RT,PA) & $0.837,13309604$ & $0.848,461640$ & $0.839,435696$ \\
\hline Rutin (RT,PA) & $1.568,6309965$ & $1.635,3022$ & $1.638,4966$ \\
\hline Ellagic Acid (RT,PA) & $*$ & $1.165,119549$ & $1.144,138560$ \\
\hline
\end{tabular}

Table 24b. Retention time and peak areas of standards, unspiked, and spiked Wonderful sample on the UDA column

\begin{tabular}{|c|c|c|c|}
\hline $\begin{array}{c}\text { Phenolic acids } \\
\text { (RT,PA) }\end{array}$ & Standards & $\begin{array}{c}\text { Unspiked } \\
\text { Wonderful }(5 \mu \mathrm{L})\end{array}$ & $\begin{array}{c}\text { Spiked } \\
\text { Wonderful }(5 \mu \mathrm{L})\end{array}$ \\
\hline Gallic (RT,PA) & $0.655,5819408$ & no peak & 0.78113486 \\
\hline $\begin{array}{c}\text { Punicalagin } \\
\text { (RT,PA) }\end{array}$ & $0.688,126608$ & $0.718,91259$ & $0.722,93271$ \\
\hline Catechin (RT,PA) & $0.811,10693244$ & $0.848,773038$ & $0.849,706388$ \\
\hline $\begin{array}{c}\text { Chlorogenic Acid } \\
\text { (RT,PA) }\end{array}$ & $0.895,6549993$ & no peak & no peak \\
\hline $\begin{array}{c}\text { Caffeic Acid } \\
\text { (RT,PA) }\end{array}$ & $1.191,8893976$ & $1.177,591$ & $1.250,835$ \\
\hline $\begin{array}{c}\text { Epicatechin } \\
\text { (RT,PA) }\end{array}$ & $0.837,13309604$ & $0.848,773038$ & $0.849,706388$ \\
\hline \begin{tabular}{c} 
Rutin (RT,PA) \\
\hline $\begin{array}{c}\text { Ellagic Acid } \\
\text { (RT,PA) }\end{array}$
\end{tabular} & $1.568,6309965$ & $1.635,72890$ & $1.638,73305$ \\
\hline
\end{tabular}


Table 24c. Retention time and peak areas of standards, unspiked, and spiked Purple heart (PH) sample on the UDA column

\begin{tabular}{|c|c|c|c|}
\hline $\begin{array}{c}\text { Phenolic acids } \\
\text { (RT,PA) }\end{array}$ & Standards & Unspiked PH $(5 \mu \mathrm{L})$ & Spiked PH $(5 \mu \mathrm{L})$ \\
\hline Gallic (RT,PA) & $0.655,5819408$ & no peak & no peak \\
\hline Punicalagin (RT,PA) & $0.688,126608$ & $0.736,98424$ & $0.736,89184$ \\
\hline Catechin (RT,PA) & $0.811,10693244$ & $0.853,504190$ & $0.866,431504$ \\
\hline $\begin{array}{c}\text { Chlorogenic Acid } \\
\text { (RT,PA) }\end{array}$ & $0.895,6549993$ & no peak & $0.948,80044$ \\
\hline $\begin{array}{c}\text { Caffeic Acid } \\
\text { (RT,PA) }\end{array}$ & $1.191,8893976$ & $1.255,956$ & $1.253,235$ \\
\hline Epicatechin (RT,PA) & $0.837,13309604$ & $0.853,504190$ & $1.253,235$ \\
\hline Rutin (RT,PA) & $1.568,6309965$ & $1.664,20350$ & $1.653,17077$ \\
\hline Ellagic Acid (RT,PA) & $*$ & $1.147,196183$ & $1.148,183239$ \\
\hline
\end{tabular}

Table 24d. Retention time and peak areas of standards, unspiked, and spiked Parfionka sample on the UDA column

\begin{tabular}{|c|c|c|c|}
\hline $\begin{array}{l}\text { Phenolic acids } \\
\text { (RT,PA) }\end{array}$ & Standards & $\begin{array}{c}\text { Unspiked } \\
\text { Parfionka }(5 \mu \mathrm{L})\end{array}$ & $\begin{array}{c}\text { Spiked } \\
\text { Parfionka }(5 \mu \mathrm{L})\end{array}$ \\
\hline Gallic (RT,PA) & $0.655,5819408$ & $0.70,46628$ & $0.700,46208$ \\
\hline Punicalagin (RT,PA) & $0.688,126608$ & $0.724,101351$ & $0.723,72768$ \\
\hline Catechin (RT,PA) & $0.811,10693244$ & $0.841,482477$ & $0.841,484938$ \\
\hline $\begin{array}{c}\text { Chlorogenic Acid } \\
\text { (RT,PA) }\end{array}$ & $0.895,6549993$ & no peak & no peak \\
\hline $\begin{array}{l}\text { Caffeic Acid } \\
\text { (RT,PA) }\end{array}$ & $1.191,8893976$ & no peak & no peak \\
\hline Epicatechin (RT,PA) & $0.837,13309604$ & $0.841,482477$ & $0.841,484938$ \\
\hline Rutin (RT,PA) & $1.568,6309965$ & $1.629,51360$ & $1.628,58388$ \\
\hline $\begin{array}{c}\text { Ellagic Acid } \\
\text { (RT,PA) }\end{array}$ & $*$ & no peak & $1.135,113979$ \\
\hline
\end{tabular}


Table 24e. Retention time and peak areas of standards, unspiked, and spiked Vkunsyi sample on the UDA column

\begin{tabular}{|c|c|c|c|}
\hline $\begin{array}{c}\text { Phenolic acids } \\
\text { (RT,PA) }\end{array}$ & Standards & $\begin{array}{c}\text { Unspiked } \\
\text { Vkunsyi }(5 \mu \mathrm{L})\end{array}$ & $\begin{array}{c}\text { Spiked } \\
\text { Vkunsyi }(5 \mu \mathrm{L})\end{array}$ \\
\hline Gallic (RT,PA) & $0.655,5819408$ & $0.736,15188$ & $0.727,23222$ \\
\hline Punicalagin (RT,PA) & $0.688,126608$ & $0.724,64471$ & $0.715,54791$ \\
\hline Catechin (RT,PA) & $0.811,10693244$ & $0.854,751274$ & $0.821,612191$ \\
\hline $\begin{array}{c}\text { Chlorogenic Acid } \\
\text { (RT,PA) }\end{array}$ & $0.895,6549993$ & $0.901,38984$ & $0.891,7572$ \\
\hline $\begin{array}{c}\text { Caffeic Acid } \\
\text { (RT,PA) }\end{array}$ & $1.191,8893976$ & $1.229,18570$ & no peak \\
\hline $\begin{array}{c}\text { Epicatechin (RT,PA) } \\
\text { Rutin (RT,PA) }\end{array}$ & $0.837,13309604$ & $0.854,751274$ & $0.821,612191$ \\
\hline Ellagic Acid (RT,PA) & $* 568,6309965$ & $1.655,54829$ & $1.573,36328$ \\
\hline
\end{tabular}

\section{Quantification of phenolic acids in pomegranate peel samples on phenyl hydride column}

The pomegranate peel samples prepared earlier were run on the phenyl hydride column. The instrumental parameters and the solvents were the same as for the UDA column. The gradient method that was used for the UDA column was not effective for this column, hence a different gradient (gradient 4) was used where the concentration of the organic solvent was kept at $5 \%$ for ten minutes and gradually changed to $80 \%$ over the next three minutes and finally decreased to the initial concentration over the course of the next one minute. The spiking in this case was carried out by mixing $825 \mu \mathrm{L}$ of each sample with $25 \mu \mathrm{L}$ of each of the seven standards (except ellagic acid) and noting the RT and PA. 
The RT and PA were tabulated for the unspiked and spiked samples and are shown in Tables 25 (a-e). It is very clear from Tables 25(a-e) that in each of the samples, catechin and epicatechin had different retention times thus proving that the phenyl hydride column was effective in carrying out the separation. Figure 37 shows the separation of catechin and epicatechin in the same standard mix as was used for the UDA column. Figure 38 shows the separation of catechin and epicatechin in the Molla Nepes and Parfianka sample.

Table 25a. Retention time and peak areas of unspiked and spiked Molla Nepes (MN) sample on the phenyl hydride column

\begin{tabular}{|c|c|c|}
\hline Phenolic acids (RT,PA) & Unspiked MN & Spiked MN \\
\hline Gallic(RT,PA) & $1.535,81611$ & $1.611,1065050$ \\
\hline Punicalagin(RT,PA) & $\begin{array}{c}(7.280,13.519), \\
(415712,268964)\end{array}$ & $\begin{array}{c}(7.097,13.488), \\
(507100,21159)\end{array}$ \\
\hline Catechin(RT,PA) & $6.235,575582$ & $6.204,3000083$ \\
\hline $\begin{array}{c}\text { Chlorogenic } \\
\text { Acid(RT,PA) }\end{array}$ & $8.749,465$ & $8.237,1947904$ \\
\hline Caffeic Acid(RT,PA) & no peak & $6.568,2135079$ \\
\hline Epicatechin(RT,PA) & $8.15,91694$ & $8.013,3909163$ \\
\hline Rutin(RT,PA) & $13.953,43897$ & $13.982,183613$ \\
\hline Ellagic Acid(RT,PA) & no peak & no peak \\
\hline
\end{tabular}


Table 25b. Retention time and peak areas of unspiked and spiked Wonderful sample on the phenyl hydride column

\begin{tabular}{|c|c|c|}
\hline Phenolic acids (RT,PA) & Unspiked Wonderful & Spiked Wonderful \\
\hline Gallic(RT,PA) & $1.448,219262$ & $1.624,1077140$ \\
\hline Punicalagin(RT,PA) & $\begin{array}{c}(7.134,13.443), \\
(1505561,907779)\end{array}$ & $\begin{array}{c}(7.028,13.454), \\
(981385,637275)\end{array}$ \\
\hline Catechin(RT,PA) & $6.123,20330$ & $6.17,3603784$ \\
\hline $\begin{array}{c}\text { Chlorogenic } \\
\text { Acid(RT,PA) }\end{array}$ & no peak & $6.262,1838922$ \\
\hline Caffeic Acid(RT,PA) & no peak & $6.593,16074077$ \\
\hline Epicatechin(RT,PA) & $8.003,76780$ & $7.98,3759658$ \\
\hline Rutin(RT,PA) & $13.971,44519$ & $3.983,1098566$ \\
\hline Ellagic Acid(RT,PA) & no peak & no peak \\
\hline
\end{tabular}

Table 25c. Retention time and peak areas of unspiked and spiked Purple heart sample on the phenyl hydride column

\begin{tabular}{|c|c|c|}
\hline Phenolic acids (RT,PA) & Unspiked PH & Spiked PH \\
\hline Gallic(RT,PA) & $1.46,150852$ & $1.596,975720$ \\
\hline Punicalagin(RT,PA) & $\begin{array}{c}(7.04,13.455), \\
(33337,845942)\end{array}$ & $\begin{array}{c}(7.073,13.476), \\
(945722,567538)\end{array}$ \\
\hline Catechin(RT,PA) & $6.23,721939$ & $6.216,3102462$ \\
\hline $\begin{array}{c}\text { Chlorogenic } \\
\text { Acid(RT,PA) }\end{array}$ & no peak & $8.283,1949716$ \\
\hline Caffeic Acid(RT,PA) & no peak & $6.592,2622042$ \\
\hline Epicatechin(RT,PA) & no peak & $8.025,3709687$ \\
\hline Rutin(RT,PA) & $15.64,50096$ & $13.981,1125633$ \\
\hline Ellagic Acid(RT,PA) & no peak & no peak \\
\hline
\end{tabular}


Table 25d. Retention time and peak areas of unspiked and spiked Parfionka sample on the phenyl hydride column

\begin{tabular}{|c|c|c|}
\hline Phenolic acids (RT,PA) & Unspiked Parfionka & Spiked Parfionka \\
\hline Gallic(RT,PA) & $1.615,149771$ & $1.603,956752$ \\
\hline Punicalagin(RT,PA) & $\begin{array}{c}(7.067,13.446), \\
(842323,777695)\end{array}$ & $\begin{array}{c}(7.242,13.481), \\
(650150,433272)\end{array}$ \\
\hline Catechin(RT,PA) & $6.162,854715$ & $6.22,3183409$ \\
\hline $\begin{array}{c}\text { Chlorogenic } \\
\text { Acid(RT,PA) }\end{array}$ & no peak & $83,232,048,343$ \\
\hline Caffeic Acid(RT,PA) & no peak & $6.596,2293162$ \\
\hline Epicatechin(RT,PA) & $7.912,207004$ & $8.018,3940811$ \\
\hline Rutin(RT,PA) & $13.975,45778$ & $13.986,1262438$ \\
\hline Ellagic Acid(RT,PA) & no peak & no peak \\
\hline
\end{tabular}

Table 25e. Retention time and peak areas of unspiked and spiked Vkunsyi sample on the phenyl hydride column

\begin{tabular}{|c|c|c|}
\hline Phenolic acids (RT,PA) & Unspiked Vkunsyi & Spiked Vkunsyi \\
\hline Gallic(RT,PA) & $1.626,1044853$ & $1.6,1070255$ \\
\hline Punicalagin(RT,PA) & $\begin{array}{c}(6.959,13.456), \\
(2712,37950)\end{array}$ & $\begin{array}{c}(7.228,13.478), \\
(338302,249900)\end{array}$ \\
\hline Catechin(RT,PA) & $6.149,908005$ & $6.194,3197456$ \\
\hline $\begin{array}{c}\text { Chlorogenic } \\
\text { Acid(RT,PA) }\end{array}$ & no peak & $8.262,2059708$ \\
\hline Caffeic Acid(RT,PA) & no peak & $6.582,2245427$ \\
\hline Epicatechin(RT,PA) & $7.958,70129$ & $8.015,3987484$ \\
\hline Rutin(RT,PA) & $13.973,52292$ & $13.983,1210974$ \\
\hline Ellagic Acid(RT,PA) & no peak & no peak \\
\hline
\end{tabular}


From Tables 25 (a-e) it can be inferred that for the Molla Nepes sample, there was an increase in the peak areas of all the seven phenolic compounds while caffeic acid and chlorogenic acid was absent initially, but appeared after spiking. For the Wonderful sample, while there was an increase in the peak areas of all compounds except punicalagin. Chlorogenic acid and caffeic acid were not present in the original sample, however they were seen after spiking. For the PH sample too, all the compounds except chlorogenic acid, caffeic acid, and epicatechin were present initially. After spiking, the initially absent compounds showed up and there was a substantial increase in the peak areas of the other compounds as well. In the Parfianka and Vkunsyi samples chlorogenic acid and caffeic acid were absent and the other compounds tested showed an increase in peak areas after spiking. Figures 39 and 40 illustrates the absence or presence of chlorogenic acid and rutin respectively in the unspiked and spiked Molla Nepes samples. Figure 42 shows the presence of the characteristic peaks for punicalagin in each of the five unspiked pomegranate peel samples.

The amount of each of the phenolic acid compound detected in the peel samples were calculated using Equation 7 given below.

$$
\mathrm{Cb}=\frac{A b \times C s \times \Delta V}{[(A c \times V \text { tot })-(A b \times V b)]} \quad \text { Equation } 7
$$

In the above equation the terms denote: $\mathrm{Cb}$ - concentration of the analyte in the sample in parts per million (ppm), Ab - peak area of the unspiked sample, Ac- peak area of the spiked sample, $\mathrm{Cs}$ - concentration of the standard used for spiking the sample in ppm, $\Delta \mathrm{V}$ - volume of the standard used for spiking the sample, Vtot- volume of sample+ volume of standard used for spiking the sample, and Vb-volume of sample. From the 
values of $\mathrm{Cb}$ obtained for each of the component, their amounts in 1gram of each of the pomegranate peel sample was determined and this is tabulated in Table 26. Figure 42 shows the bar graph showing the amount of each of the phenolic acid components in the five peel samples. From the bar graph we can infer that Vkunsyi sample is one variety that has most of the phenolic acid components being analyzed. Caffeic acid and chlorogenic acid were not detected in any of the five samples. Thus it can be concluded from this study that Vkunsyi is an ideal sample, although Wonderful is commercially available in the market. 
Phenyl-2x100_Mix_5 uL_Veena-95A_03.d

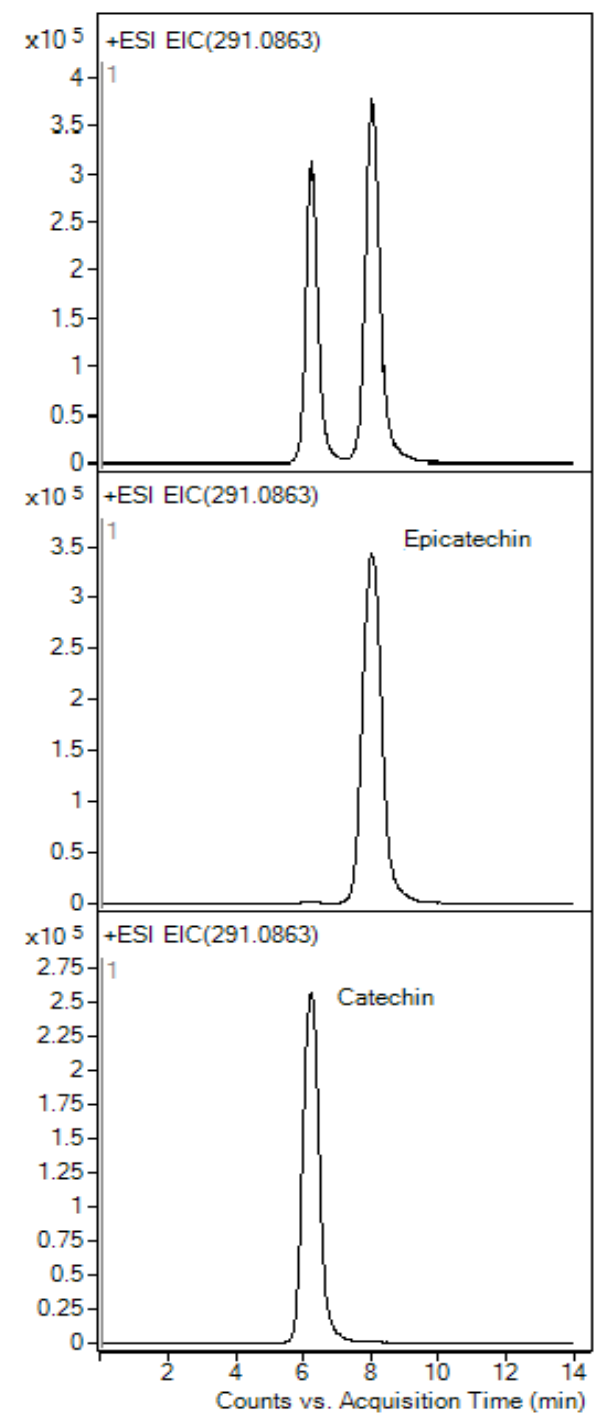

Figure 37. Separation of catechin and epicatechin in the standard mix on phenyl hydride column 
Phenyl-2x100_PARFIANKA_5 uL_Veena-RP-Gr4-5uL_01.d

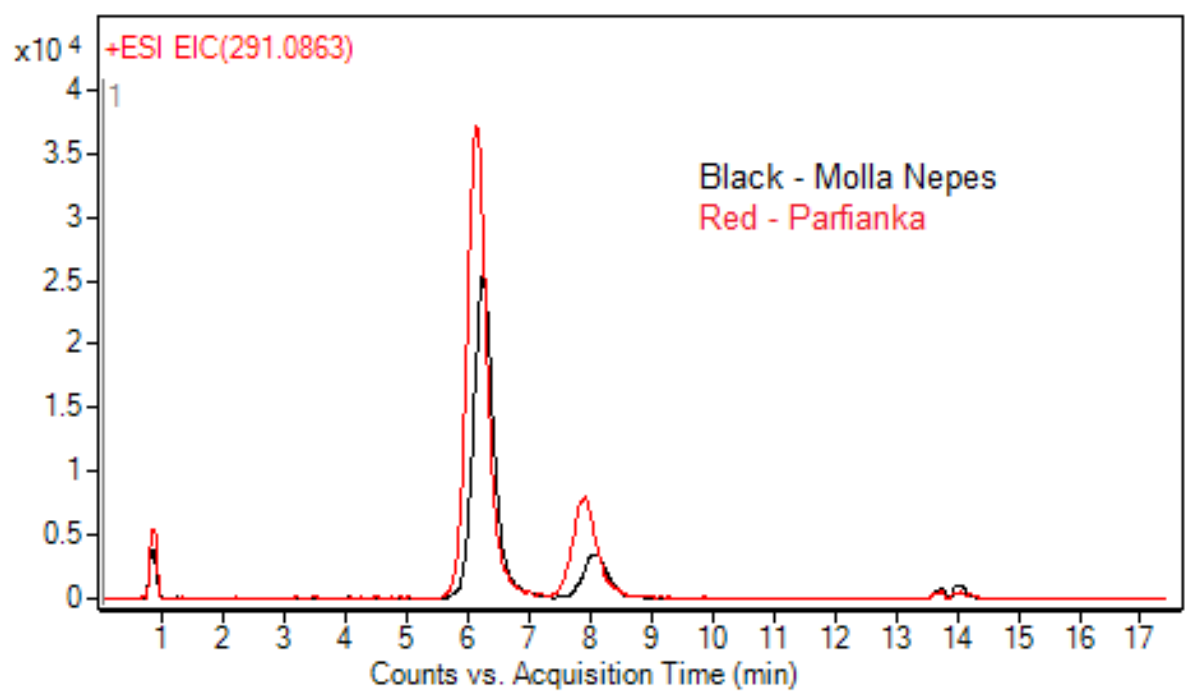

Black - Molla Nepes

Figure 38. Separation of catechin and epicatechin on phenyl hydride column in Molla Nepes and Parfianka sample 
Phenyl-2x100_Molla_Negre_5 uL_Veena-RP-Gr4-5uL_08.

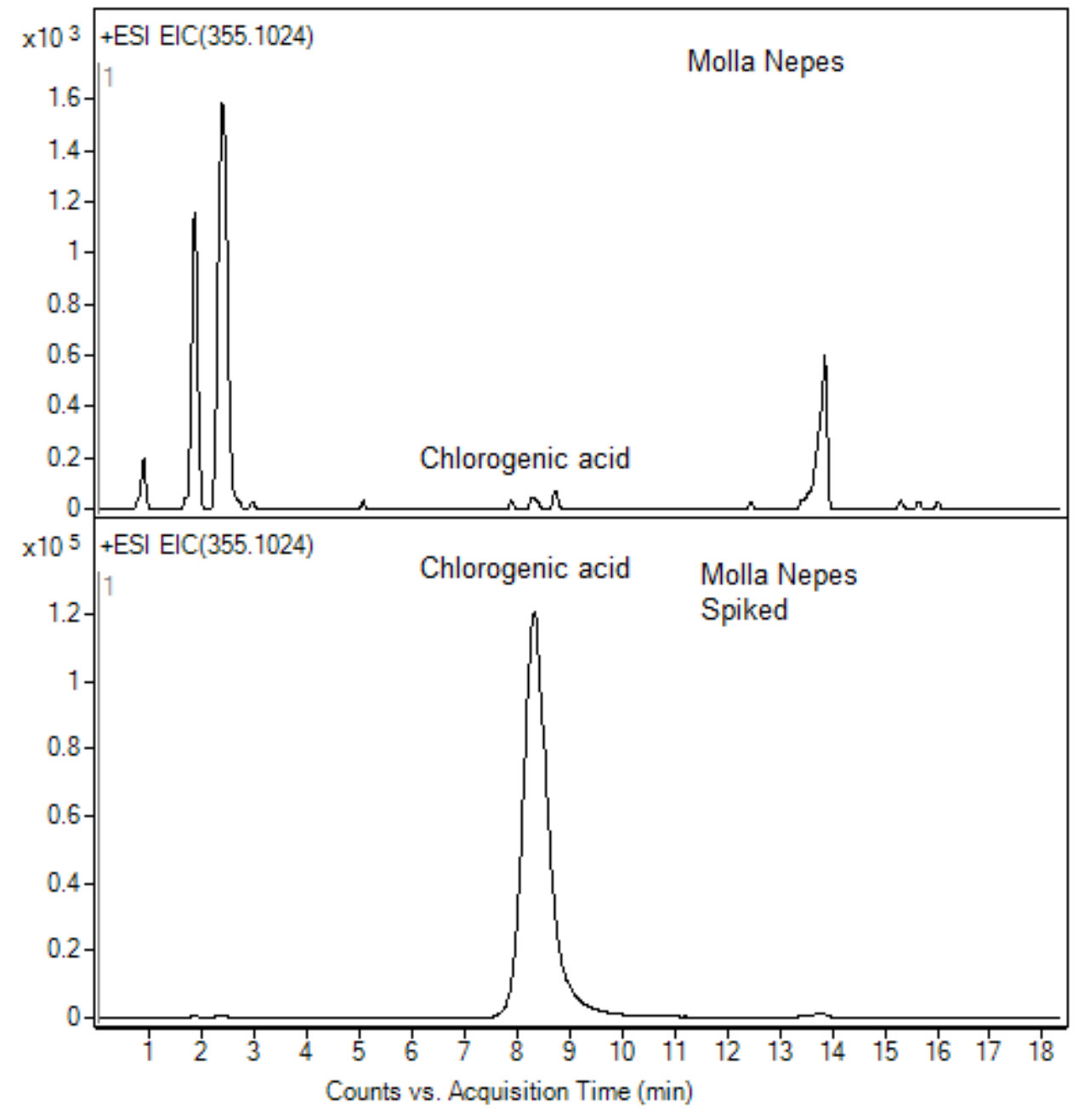

Figure 39. $(\mathrm{m} / \mathrm{z})$ of chlorogenic acid absent in the original sample and clearly seen in the spiked Molla Nepes sample 
Scan Frag=175.0V Phenyl-2x100_Molla_Negre_5 uL_Veena-RP-Gr4-5uL_08.d

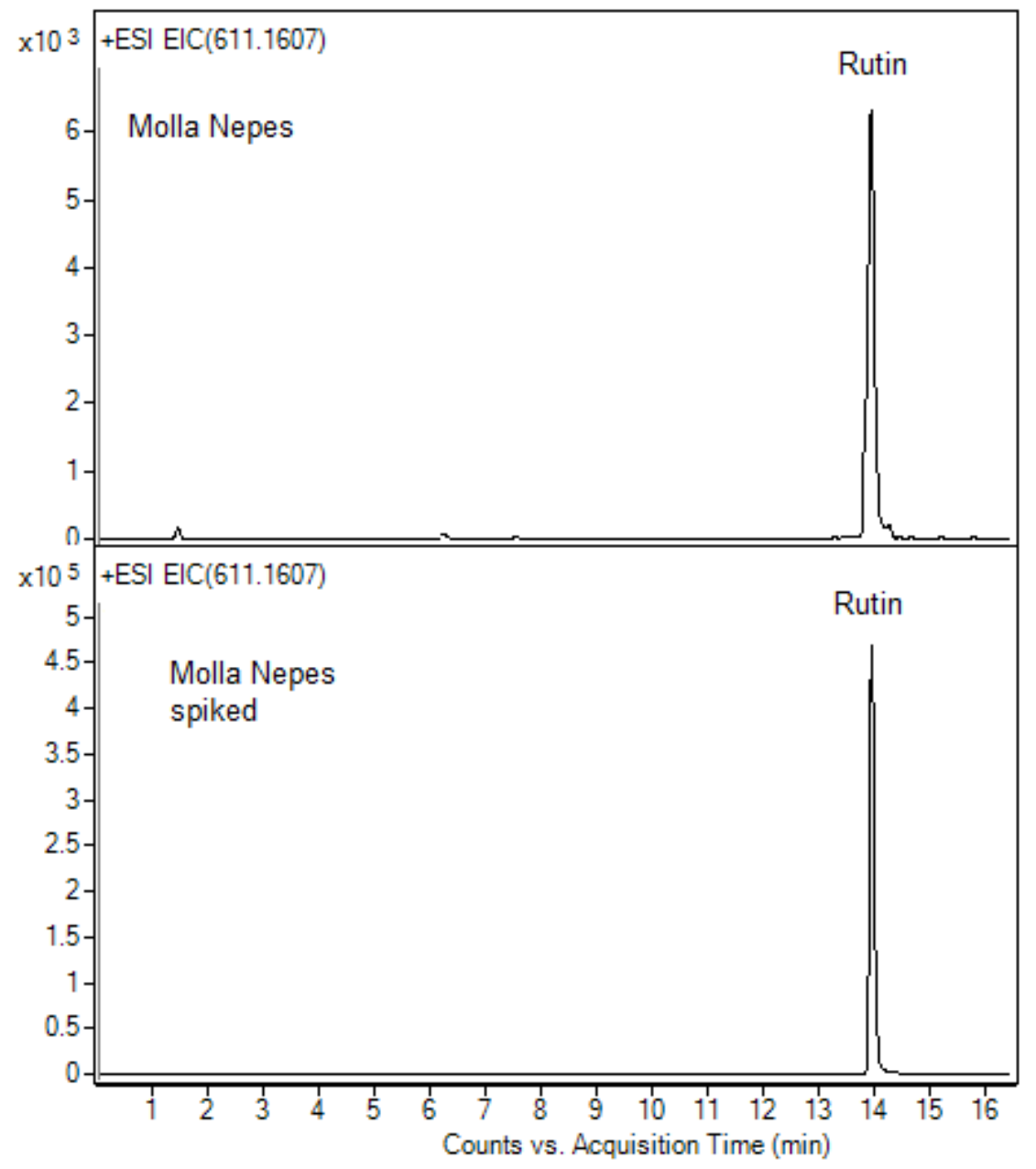

Figure 40. $(\mathrm{m} / \mathrm{z})$ of rutin in the unspiked and spiked Molla Nepes sample 


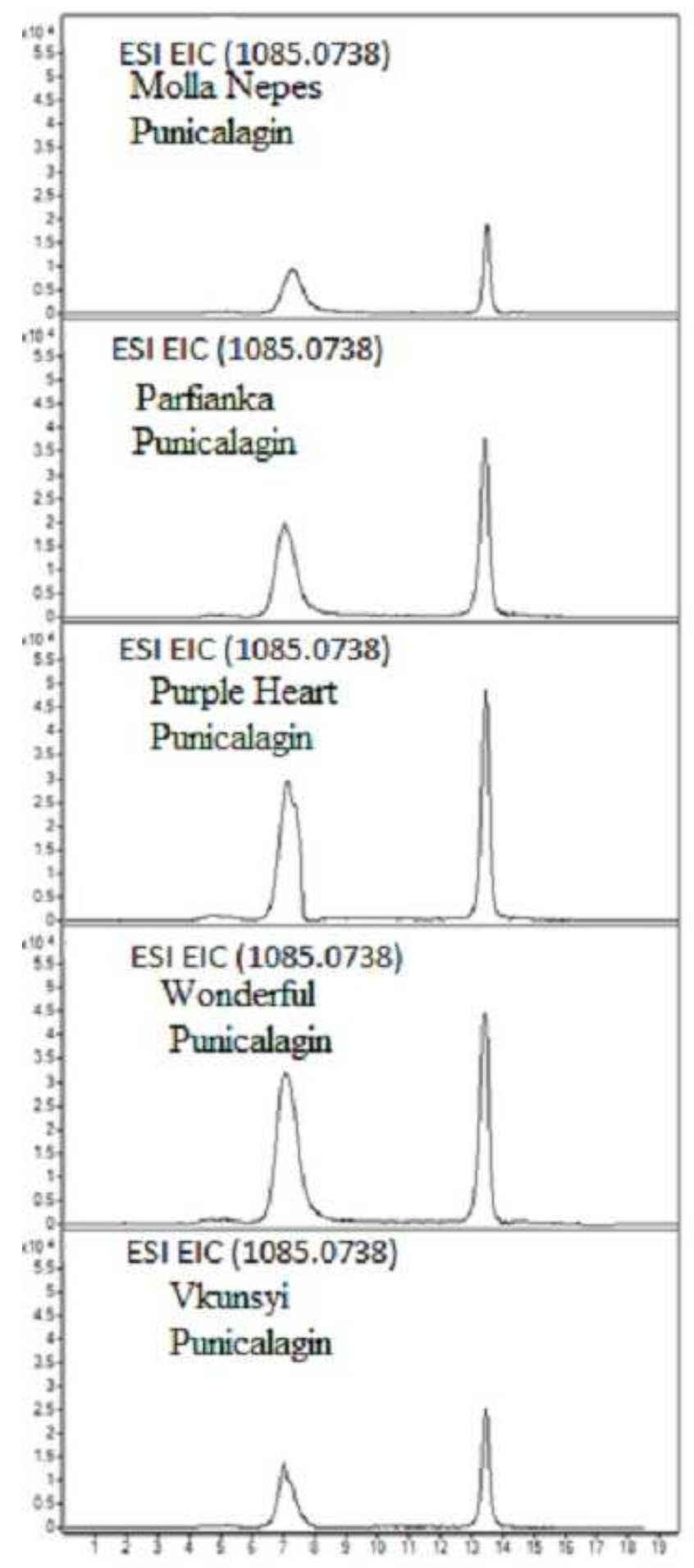

Counts vs Acquisition time ( $\min )$

Figure 41. $(\mathrm{m} / \mathrm{z})$ 's for punicalagin in each of the five unspiked pomegranate peel samples 
Table 26. Amount of each of the phenolic acid component in the pomegranate peel samples in $\mu \mathrm{g} / \mathrm{g}$

\begin{tabular}{|c|c|c|c|c|c|}
\hline \multirow{2}{*}{$\begin{array}{l}\text { Amount of } \\
\text { phenolic } \\
\text { acid } \\
\text { compounds } \\
(\mu \mathrm{g} / \mathrm{g})\end{array}$} & \multicolumn{5}{|c|}{ Names of the pomegranate samples } \\
\hline & $\mathrm{MN}$ & Parfianka & $\mathrm{PH}$ & Wonderful & Vkunsyi \\
\hline Gallic acid & 97.809 & 210.714 & 230.300 & 310.348 & 25026.19 \\
\hline Punicalagin & $*$ & $*$ & $*$ & $*$ & 11438.93 \\
\hline Catechin & 362.993 & 539.293 & 494.994 & 9.011 & 630.027 \\
\hline $\begin{array}{l}\text { Chlorogenic } \\
\text { acid }\end{array}$ & 0.480 & 0 & 0 & 0 & 0 \\
\hline Caffeic acid & 0 & 0 & 0 & 0 & 0 \\
\hline Epicatechin & 479.484 & 82.093 & 0 & 33.102 & 28.707 \\
\hline Rutin & 516.368 & 60.027 & 82.397 & 72.185 & 77.884 \\
\hline Ellagic acid & $*$ & $*$ & $*$ & $*$ & $*$ \\
\hline
\end{tabular}




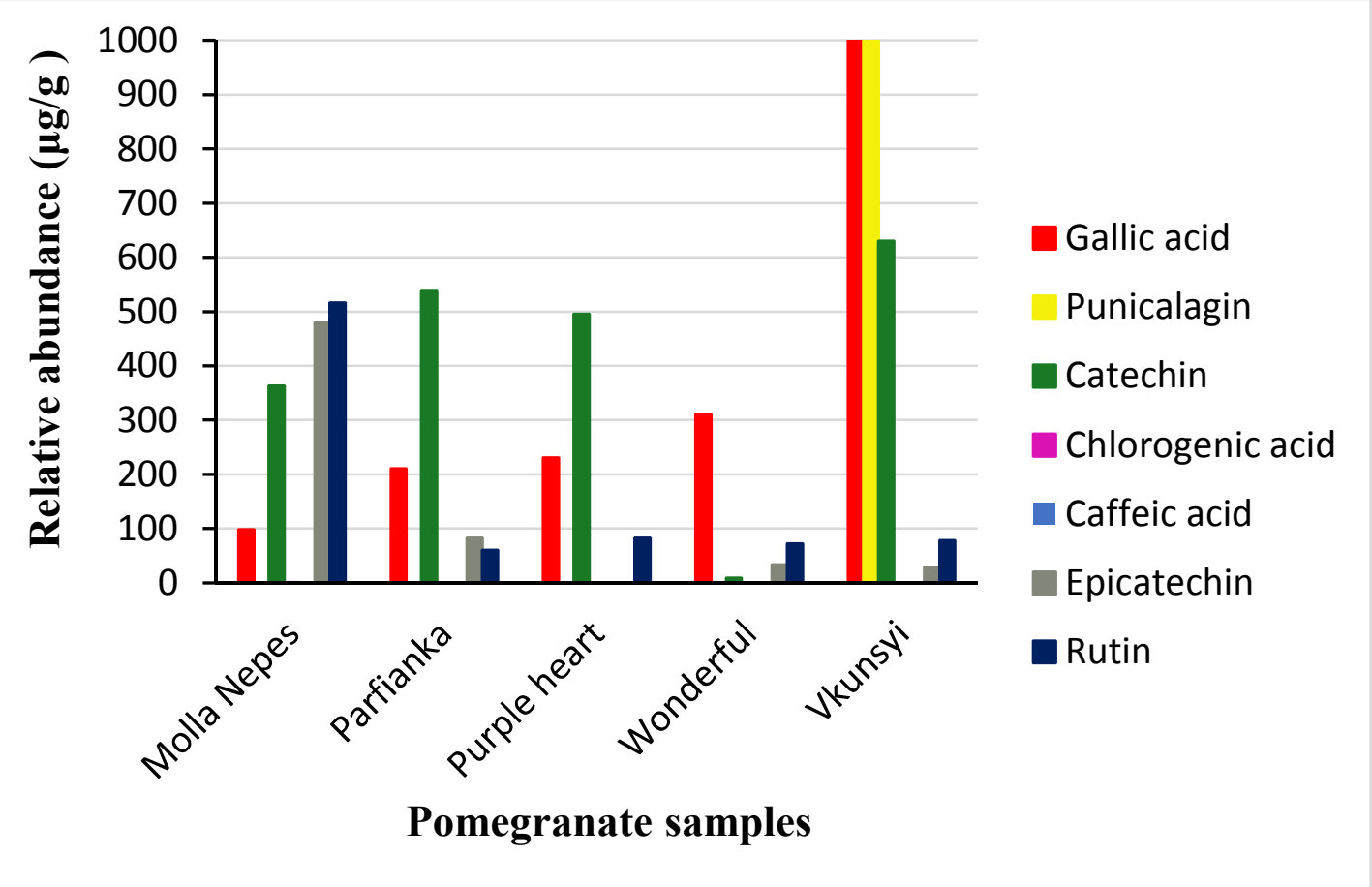

Figure 42. Bar graph showing the amount of each of the phenolic acid component in the pomegranate peel samples 


\section{CONCLUSION}

One of the primary goals of this project was to characterize the silica hydride UDA column and establish the dual retention profile. Polar compounds were retained by the ANP mechanism at higher concentrations of the organic component in the mobile phase, while non-polar compounds displayed the usual RP mechanism. The ANP and RP data for the polar and non-polar compounds displayed a typical $U$ shaped retention map when overlaid that is similar to other silica hydride based stationary phase.

Another aspect of the current project was to investigate the effect of varying concentrations of formic acid buffer. While polar compounds showed a decrease in retention as the concentration of the buffer was increased, no such trend was observed for non-polar compounds. The observed trend for polar compounds was clearly different from the HILIC retention mechanism [32], thus clearly distinguishing the ANP and HILIC retention mechanisms.

The compatibility of another buffer, ammonium acetate was also tested and established. The effect of varying the ammonium acetate buffer was also studied. No significant conclusion was made from the varying buffer study and this could be possibly due to the effect of ionization of the carboxylic acid group on the UDA above a $\mathrm{pH}$ of 6 .

Lastly, characterization of the silica hydride based UDA column was done by varying the column oven temperature to study its effect on the retention of some compounds. The retention time of all compounds tested was found to vary slightly with varying temperature, thus proving the temperature dependence on retention time. 
In addition to characterization studies, applications of the UDA column were also investigated. Several nucleotides and coenzymes, urine samples to check for the presence of pesticides, and the separation and quantification of the phenolic acid components in pomegranate peel samples were studied. The UDA column was found to be a suitable candidate to separate nucleotides and the pesticide samples. Complete separation of isomeric compounds in the pomegranate peel samples could not be achieved, and this led to the use of a phenyl hydride column that gave more promising results.

The data obtained from the current studies could be useful for future investigations of the silica hydride-based UDA column. However, at this point, a detailed account of the separation mechanism and weak cationic nature of the UDA column has not been established. Further goals include studying the retention of more non-polar compounds especially at a concentration greater than $50 \%$, organic solvent in the mobile phase, and checking for any change in retention time beyond this concentration. It would also be interesting to look into the retention of amino acids and how the presence of acidic/basic groups and hydrophobic portions influence retention by studying these molecules under a range of concentrations of the mobile phase, in both RP and ANP mechanisms. Yet another future goal would be to analyze the separation of the nucleotides in a more complex physiological matrix. The urine sample analysis could also be done using an MS-MS detector to check for the presence of additional compounds. Lastly, the use of different gradients to separate the isomeric compounds, catechin, and epicatechin could also be studied. 


\section{REFERENCES}

1. Skoog, A. D.; Holler, F. J.; Nieman, T. A. Principles of Instrumental Analysis, 5th ed; Saunders College Publishing: Orlando, Florida, 1998, Chapters 26, 28.

2. Ranganr.Types of Chromatography| Based on Different Techniques \& Methods http://www.rajaha.com/types-chromatography-experiments/ (accessed Dec 10, 2015).

3. Kupiec, T. Quality-control analytical methods: High-performance liquid chromatography. Int.J.Pharm.Compd. 2004, 8, 223-227.

4. Agilent Technologies. Overview on a chromatographical system. http://www.teamcag.com/support/theory/chroma/hplc_bas_at/chromatography/chromatographicalSys tem.html ( accessed 10 Dec , 2015).

5. Swartz, M. Seeing is Believing: Detectors for HPLC. LC GC North America. 2010, 28, 880-889.

6. Taylor, Tony. Important aspects of UV detection for HPLC. LC GC North America. 2015, 33,870 .

7. Resources. Getting Started in HPLC Section 2E. HPLC Detector http://www.lcresources.com/resources/getstart/2e01.htm (accessed Dec 10, 2015).

8. Lendia, B.E.; Meyer, V.R. The UV Detector for HPLC- An ongoing success story. LC GC Europe. 2005, 18, 156-163.

9. El-Aneed, A.; Cohen, A.; Banoub, J. Mass spectrometry, review of the basics: electrospray, MALDI, and commonly used mass analyzers. Appl. Spectrosc.Rev. 2009, 44, 210-230.

10. William Reusch . Mass spectrometry. http://www2.chemistry.msu.edu/faculty/reusch/virttxtjml/spectrpy/massspec/masspec 1.htm (accessed 24 February 2016).

11. Finehout, E. J.; Lee, K. H. An introduction to mass spectrometry applications in biological research. Biochem. Mol. Biol. Educ. 2004, 32, 93-100. 
12. Miller, P. E.;Denton, M. B. The quadrupole mass filter: basic operating concepts. $J$. Chem. Educ. 1986, 63(7), 617-622.

13. Bill Champion. Tips and tricks of HPLC separations. http://www.agilent.com/cs/library/eseminars/public/Tips\%20and\%20Tricks\%20of\% 20HPLC\%20Separation\%20(4-12-2011).pdf (accessed 29 Decemebr 2015).

14. Brown, L.; Ciccone, B.; Pesek, J. J.; Matyska, M. T. An evolution in separation media for HPLC. Am Lab. 2003, 35, 23-29.

15. Pesek, J. J.; Matyska, M. T.; Boysen, R. I.; Yang, Y.;Hearn, M. T. Aqueous normalphase chromatography using silica-hydride-based stationary phases. TrAC, Trends Anal. Chem. 2013, 42, 64-73.

16. Pesek, J. J.; Matyska, M. T.; Loo, J. A.; Fischer, S. M.; Sana, T. R. Analysis of hydrophilic metabolites in physiological fluids by HPLC $\square$ MS using a silica hydride $\square$ based stationary phase. J. Sep. Sci. 2009, 32, 2200-2208.

17. Pesek, J. J.; Boysen, R. I.; Hearn, M. T.; Matyska, M. T. Hydride-based HPLC stationary phases: a rapidly evolving technology for the development of new bioanalytical methods. Anal. Methods. 2014, 6, 4496-4503.

18. Boysen, R. I.; Yang, Y.; Chowdhury, J.; Matyska, M. T.; Pesek, J. J.; Hearn, M. T.; Simultaneous separation of hydrophobic and hydrophilic peptides with a silica hydride stationary phase using aqueous normal phase conditions. J. Chromatogr. A. 2011, 1218, 8021-8026.

19. Pesek, J. J, Matyska, M. T. Hydrophilic interaction liquid chromatography (HILIC) and advanced applications; Wang .J.Perry; He Weixuan, Taylor and Francis group: Florida,U.S.A, 2011, Chapter1, pp 1-26.

20.Yang, Y.; Boysen, R. I.; Kulsing, C.; Matyska, M. T.; Pesek, J. J.; Hearn, M. T. Analysis of polar peptides using a silica hydride column and high aqueous content mobile phases. J. Sep. Sci. 2013, 36, 3019-3025.

21. Pesek, J. J.; Matyska, M. T. Our favorite materials: Silica hydride stationary phases. J. Sep. Sci. 2009, 32, 3999-4011.

22. Bayer, E.; Grom, E.; Kaltenegger, B.; Uhmann, R. Separation of amino acids by high performance liquid chromatography. Anal. Chem. 1976, 48, 1106-1109.

23. Matyska, M. T.; Pesek, J. J.; Duley, J.; Zamzami, M.; Fischer, S. M. Aqueous normal phase retention of nucleotides on silica hydride $\square$ based 
columns: Method development strategies for analytes revelant in clinical analysis. J. Sep. Sci. 2010, 33, 930-938.

24. Microsolv technologies. Cogent UDA ${ }^{\mathrm{TM}}$ HPLC column use and application. http://kb.mtc-usa.com/article/AA-02490/99/(accessed on 10 December 2015).

25. Al-Rawahi, A. S.; Edwards, G.; Al-Sibani, M.; Al-Thani, G.; Al-Harrasi, A. S.; Rahman, M. S. Eur. J. Med.Plants. 2014, 4, 315-331.

26. Microsolv technologies. Cogent UDA ${ }^{\mathrm{TM}}$ HPLC columns: weak cationic exchange on silica. http://mtc-usa.com/cogent-uda.aspx(accessed 24 February, 2016).

27. GMI.HPLC systems. HP 1090 series HPLC systems. http://www.gmi-inc.com/hp1090-series-hplc-system.html(accessed on 10 December 2015).

28. Dewey, C. N., \& Pachter, L. Evolution at the nucleotide level: the problem of multiple whole-genome alignment. Hu. Mol. Gen. 2006, 15, 51-56.

29. Dougherty, D. A. Cation- $\pi$ interactions involving aromatic amino acids. $J$. Nutr. 2007, 137, 1504-1508.

30. Lieberman, M., Marks, A. D., Smith, C. M., \& Marks, D. B.Marks' essential medical biochemistry; Lippincott Williams \& Wilkins: Baltimore, Maryland USA,2007; Chapter 4, pp 53-62.

31. Ribeiro, J. A.; Sebastiao, A. M. Caffeine and adenosine. J. Alzheimers. Dis. 2010, 20 , 3-15.

32. Pesek, J. J.; Matyska, M. T.; Natekar, H. Evaluation of the dual retention properties of stationary phases based on silica hydride: Perfluorinated bonded material J. Sep. Sci. 2016, 39, 1050-1055

33. Wang, B. N.; Liu, H. F.; Zheng, J. B.; Fan, M. T.; Cao, W. J. Agric.

Food.Chem. 2011, 59, 1288-1292. 